\title{
Collusion and price wars: a dynamic approach to price competition
}

Citation for published version (APA):

Pot, E. A. (2010). Collusion and price wars: a dynamic approach to price competition. [Doctoral Thesis, Maastricht University]. Maastricht University. https://doi.org/10.26481/dis.20101008ep

Document status and date:

Published: 01/01/2010

DOI:

10.26481/dis.20101008ep

Document Version:

Publisher's PDF, also known as Version of record

\section{Please check the document version of this publication:}

- A submitted manuscript is the version of the article upon submission and before peer-review. There can be important differences between the submitted version and the official published version of record.

People interested in the research are advised to contact the author for the final version of the publication, or visit the DOI to the publisher's website.

- The final author version and the galley proof are versions of the publication after peer review.

- The final published version features the final layout of the paper including the volume, issue and page numbers.

Link to publication

\footnotetext{
General rights rights.

- You may freely distribute the URL identifying the publication in the public portal. please follow below link for the End User Agreement:

www.umlib.nl/taverne-license

Take down policy

If you believe that this document breaches copyright please contact us at:

repository@maastrichtuniversity.nl

providing details and we will investigate your claim.
}

Copyright and moral rights for the publications made accessible in the public portal are retained by the authors and/or other copyright owners and it is a condition of accessing publications that users recognise and abide by the legal requirements associated with these

- Users may download and print one copy of any publication from the public portal for the purpose of private study or research.

- You may not further distribute the material or use it for any profit-making activity or commercial gain

If the publication is distributed under the terms of Article $25 \mathrm{fa}$ of the Dutch Copyright Act, indicated by the "Taverne" license above, 


\section{Collusion and Price Wars \\ A Dynamic Approach to Price Competition}

Erik Alexander Pot 
This book was typeset by the author using LaTeX.

All rights reserved. No part of this publication may be reproduced, stored in a retrieval system, or transmitted, in any form, or by any means, electronic, mechanical, photocopying, recording or otherwise, without the prior permission in writing from the author.

Collusion and Price Wars: a Dynamic Approach to Price Competition (C) Erik Pot, 2010

Cover design by Ianthe Bato

Cover illustration: J.M.W. Turner - A Fish Market, Calais (ca. 1826)

ISBN: 9789461080837

Printed in the Netherlands by Gildeprint B.V. Enschede 


\title{
Collusion and Price Wars
}

A Dynamic Approach to Price Competition

\author{
Proefschrift
}

ter verkrijging van de graad van doctor aan de Universiteit Maastricht, op gezag van Rector Magnificus,

Prof. mr. G.P.M.F. Mols,

volgens het besluit van het College van Decanen,

in het openbaar te verdedigen

op vrijdag 8 oktober 2010 om 16.00 uur

door

Erik Alexander Pot 


\section{Promotor:}

Prof. dr. H.J.M. Peters

\section{Copromotores:}

Dr. J. Flesch

Dr. R. Peeters

Dr. A.J. Vermeulen

\section{Beoordelingscommissie:}

Prof. dr. P.J.J. Herings (voorzitter)

Prof. dr. M.A. Carree

Dr. M.A. Haan

Dit onderzoek werd financieel mogelijk gemaakt door Maastricht Research School of Economics of Technology and Organizations (METEOR). 


\section{Dankwoord}

Een project zo uitgebreid als iemands proefschrift is nauwelijks te voltooien zonder de hulp en steun van verschillende mensen binnen en buiten de universiteit. Dit is dan ook de aangewezen plek om mijn dank te betuigen aan al diegenen die in de loop der jaren een zichtbare of onzichtbare rol hebben gespeeld in de werkzaamheden die uiteindelijk hebben geleid tot afronding van deze dissertatie.

Allereerst wil ik graag mijn begeleiders bedanken: Hans Peters, Ronald Peeters, Dries Vermeulen en János Flesch. Hans, mijn promotor, ik wil je hartelijk danken voor de mogelijkheid die je me geboden hebt in 2006 om bij de vakgroep Kwantitatieve Economie in dienst te komen. Ook wil ik je graag bedanken voor de vrijheid die je me gegeven hebt om mijn interesses te ontdekken en na te streven, en voor je directe en indirecte betrokkenheid in het schrijfproces van mijn verschillende papers. Ronald, ik heb altijd ontzettend genoten van onze samenwerking. Jouw enthousiasme, positiviteit, expertise en energie hebben altijd als zeer motiverend gewerkt voor mij. Dries, wij kennen elkaar al sinds de periode dat ik nog bezig was met University College en jij mijn begeleider was tijdens mijn capstone project. Ik vind het erg leuk dat de inhoud van dit proefschrift deels herleid kan worden tot die samenwerking van jaren geleden. Ik heb veel van je geleerd en ben je zeer dankbaar dat je altijd beschikbaar was als ik ergens vragen over had. János, onze samenwerking heeft uiteindelijk maar één project geduurd, wat geleid heeft tot hoofdstuk 4 van dit proefschrift. Toch hebben we altijd contact gehouden en ben je steeds betrokken gebleven bij mijn project. Hartelijk dank voor je enthousiaste inzet en de interesse die je altijd hebt getoond. Een andere persoon die een belangrijke rol gespeeld heeft in het tot stand 
komen van de inhoud van dit proefschrift is Iwan Bos. Iwan, Om de één of andere reden had ik eigenlijk altijd al wel verwacht dat we ooit gezamenlijk een paper zouden schrijven; het zijn er uiteindelijk zelfs drie geworden! Verder wil ik ook graag Ianthe ontzettend bedanken voor haar hulp bij het ontwerpen van de kaft die om dit boekje zit.

Iemands collega's kunnen een belangrijke invloed hebben op het plezier dat diegene heeft in zijn werk. In mijn geval is die invloed altijd zeer positief geweest en ik wil dan ook graag alle collega's van de vakgroep bedanken voor de prettige werksfeer de afgelopen jaren. Karin en Haydeé, jullie hebben altijd klaargestaan om me te helpen bij wat dan ook en daar wil ik jullie heel hartelijk voor bedanken. Ook noem ik hier graag de verschillende collega's met wie ik in de loop der jaren met veel plezier een kantoor heb gedeeld: Bram, Bas, en de laatste maanden Cyriel en Hans.

In 2008 had ik de mogelijkheid om een aantal maanden te werken aan de University of Warwick in Engeland. Deze periode is me heel erg goed bevallen en heeft een belangrijke rol gespeeld in het besef welke richting ik graag heen wilde met dit proefschrift. In het bijzonder wil ik graag professor Margaret Slade bedanken, die mij met veel gastvrijheid deze mogelijkheid heeft geboden.

Ik heb het geluk gehad om naast mijn werk als $\mathrm{PhD}$ student ook andere initiatieven te kunnen ontplooien, zowel op de eigen faculteit als universiteitsbreed in het kader van $\mathrm{PhD}$ Academy. Ik wil graag iedereen bedanken met wie ik altijd zo prettig samen gewerkt heb in deze twee organisaties tijdens het organiseren van activiteiten als barbecues, workshops, feesten, conferenties enzovoort. Ik heb hier ontzettend veel plezier aan beleefd en dingen van kunnen leren die het onderzoekswerk zelf me niet had kunnen bieden. In het bijzonder wil ik graag mijn collega-bestuursleden van $\mathrm{PhD}$ Academy bedanken: Adrienne, Daniel, Marco, Siu Hing en Stephanie.

Ik realiseer me heel vaak hoe gelukkig ik ben met de mensen die in mijn leven dichtbij mij staan. Daarom wil ik op deze plaats nog heel graag mijn familie en vrienden enorm bedanken voor hun betrokkenheid en interesse in mijn onderzoek. Ik heb de belangrijkste reden waarom de afgelopen jaren zo prettig waren tot het laatst bewaard. Nikki, uiteraard wil ik jou niet alleen bedanken voor het helpen verbeteren van de tekst van dit proefschrift maar vooral voor je steun, vertrouwen en liefde. 


\section{Contents}

I The Role of Information and Stability 21

2 Collusion under Exogenous Demand Fluctuations 23

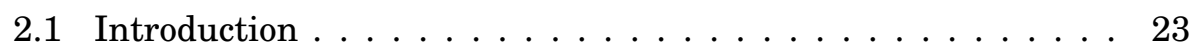

2.2 Basic model . . . . . . . . . . . . . . . . 27

2.2.1 The one-shot game . . . . . . . . . . . . . 27

2.2 .2 The repeated game $\ldots \ldots \ldots \ldots \ldots$

2.3 Collusive equilibria under private information . . . . . . . . 30

2.4 Collusive equilibria under public information . . . . . . . . 33

2.5 Collusive equilibria when market shares form a martingale . . 35

2.6 Conclusion . . . . . . . . . . . . . . . . . . . 37

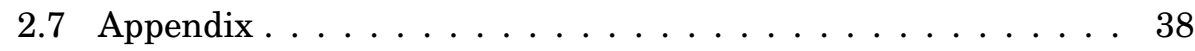

3 Intentional Price Wars on the Equilibrium Path 41

3.1 Introduction . . . . . . . . . . . . . . . 41

3.2 Model . . . . . . . . . . . . . . . . . . . . . . 44

3.2 .1 The one-shot game . . . . . . . . . . . . 45

3.2 .2 The repeated game . . . . . . . . . . . . 45

3.2 .3 Incentives and strategies . . . . . . . . . . . . 46

3.3 Results . . . . . . . . . . . . . . . . 47

3.3.1 Market shares are public information . . . . . . . . 47

3.3.2 Market shares are private information . . . . . . . . 49 
Contents

3.4 Concluding remarks $\ldots \ldots \ldots \ldots \ldots \ldots$

3.5 Proofs . . . . . . . . . . . . . . . . . . 52

II The Impact of Consumer Inertia 63

4 Dynamic Competition with Consumer Inertia 65

4.1 Introduction . . . . . . . . . . . . . . 65

4.2 General framework . . . . . . . . . . . . . . . . . 69

4.3 When there is just one competitive state . . . . . . . . 71

4.4 Illustrating examples . . . . . . . . . . . . . . . . 78

4.5 Market share dynamics . . . . . . . . . . . . . . . . . . . 81

4.6 Generalization of equilibrium properties . . . . . . . . . 87

4.7 Concluding remarks . . . . . . . . . . . . . . . . 90

4.8 Appendix: incentives, best responses and equilibria . . . . . . 92

5 Competition versus Collusion: The Impact of Consumer Inertia $\quad 95$

5.1 Introduction . . . . . . . . . . . . . . . . . 95

5.2 Model . . . . . . . . . . . . . . . . . . . . . . . . . . 98

5.3 Results . . . . . . . . . . . . . . . . . . . . . 100

5.4 Discussion . . . . . . . . . . . . . . . . . 106

5.5 Appendix A: explicit collusion . . . . . . . . . . . . . . . 109

5.6 Appendix B: proofs . . . . . . . . . . . . . . . . 111

\section{Welfare-Enhancing Cartels 115}

6 Welfare-Enhancing Hard Core Cartels 117

6.1 Introduction . . . . . . . . . . . . . . 117

6.2 Model and conditions . . . . . . . . . . . . . . . . . . 121

6.3 Analysis and results . . . . . . . . . . . . . . . . . 125

6.3.1 Weak cartels . . . . . . . . . . . . . . . . . . 125

6.3 .2 Strong cartels . . . . . . . . . . . . . . . 127

6.4 Applications . . . . . . . . . . . . . . . . . . . . . 129

6.4 .1 Price competition . . . . . . . . . . . . 129

6.4 .2 Quantity competition . . . . . . . . . . . . . 131

6.5 Discussion . . . . . . . . . . . . . . . . . . . . . . . 132

6.6 Appendix A: negative externalities . . . . . . . . . . 135

6.7 Appendix B: proofs . . . . . . . . . . . . . . . 139 
Contents

$\begin{array}{lr}\text { Bibliography } & 147\end{array}$

$\begin{array}{ll}\text { Nederlandse Samenvatting } & 153\end{array}$

$\begin{array}{ll}\text { Curriculum Vitae } & 157\end{array}$ 



\section{Chapter 1}

\section{Introduction}

This thesis deals with one of the fundamental topics in (industrial) economics: the outcome of strategic competition between firms in oligopoly. The roots of the academic literature on this topic can be traced back to the nineteenth century contributions of Antoine Augustin Cournot and Joseph Louis François Bertrand, who were among the first to theoretically analyze what the most likely outcome is of competition between oligopolists. An oligopoly is a market situation in which only a few firms are active. This situation is of special interest for scientific analysis, because each firm's decision influences the observed market outcome, in particular price and total production output. ${ }^{1}$ In an oligopoly, firms can thus act strategically and we therefore need to define what the strategic variable is that we are interested in. The strategic variable is essentially the product characteristic on which the firms compete. This can be, for instance, total production output (quantity competition), product quality, advertising expenses or the product's price, in which case we speak of price competition. Although an oligopoly is considered to be an example of imperfect competition, it is one of the most widespread market forms found in real life. Examples include the wireless telecommunication market (which is almost entirely divided between KPN, Vodafone and TMobile in the Netherlands), the airplane manufacturing market (Boeing and Airbus) and the worldwide accounting and auditing market (dominated by the "Big Four": PricewaterhouseCoopers, Deloitte Touche Tohmatsu, Ernst \& Young and KPMG).

The focus of this thesis is on oligopolistic (price) competition and deals

\footnotetext{
${ }^{1}$ This is in contrast to a situation of perfect competition, in which no firm has any power to influence the prevailing market price.
} 
Chapter 1. Introduction

with several of its most relevant questions. We analyze how price competition affects the observed market outcome. This outcome may depend on characteristics of the firms in the market and the type of product they sell. It can be influenced by the state of the economy or the prices of substitute products. The question of what the normal competitive outcome is has therefore been a big part of the academic debate on price competition since Bertrand's basic model of price competition. In particular, an important issue to consider is when are we likely to see extreme outcomes of price competition. The two ends of the competitive spectrum in this case are, at one end, collusive behavior or price agreements between firms (cartel formation) and, at the other end, price wars in which prices are driven down to the lowest possible point. These extreme forms of price competition are often assumed to be bad for social welfare. It is therefore particularly relevant to be able to distinguish between normal competitive behavior and overly collusive or aggressive pricing behavior. This is an important focal point of this thesis and we will therefore first clarify what is meant by a cartel (collusion) and price wars.

A cartel is characterized by agreements that are made between competing firms, for example on price. Such agreements are usually made to limit competition. This can be done by jointly raising prices, agreeing not to compete in each other's home market or to jointly limit production. The general point of view is that such anti-competitive agreements are bad for social welfare and for that reason cartels are deemed illegal. National and international competition authorities therefore spend large amounts trying to detect cartel behavior. Those authorities would thus benefit greatly from accurate predictions when price agreements are likely to take place. Whenever firms are convicted of price fixing, they can usually expect very large fines. For instance, when in 2007 four beer breweries operating in the Netherlands were proved guilty of cartel membership, they were given a total fine of $€$ $273.7 \mathrm{~m}$, of which the largest part ( $€ 219.3 \mathrm{~m}$ ) had to be paid by market leader Heineken. $^{2}$

A price war is a phenomenon in which firms rapidly lower their prices to either increase or protect their market share. Sometimes this lowering of prices can take such drastic forms that products are sold below cost price. This is in the short run clearly very beneficial for consumers, who have to pay (much) less for the product. However, a price war can potentially have very bad long-term effects. If firms lower their prices, they typically have to

2 http://www.guardian.co.uk/business/2007/apr/18/7 
cut costs in other parts of their organization. Price wars could therefore lead to higher unemployment, lower product quality and less innovation. Furthermore, if firms go bankrupt or have to leave the market, the resulting situation could be one in which the remaining firms have so much market power that they are able to raise prices above initial levels. For these reasons, so-called predatory price wars (price wars which are started with the intention to drive other firms out of the market) are usually illegal.

Before we introduce the results of this thesis, it is instructive to briefly discuss a selection of the most important and influential existing literature relevant for this thesis.

As has already been mentioned, the first to theoretically model price competition in an oligopolistic setting was Joseph Bertrand. ${ }^{3}$ The simplest version of his model was the basis of many contributions that followed. The model includes several firms, each of which produces an equivalent product and faces equal and constant unit costs of production (marginal costs). The firm with the lowest price attracts all consumers willing to pay that price. If there are several firms which set the lowest price, they share the demand equally. Bertrand's prediction was that in such a situation, the prices that are set by the firms would eventually be equal to marginal costs. The reason for this is that if prices were higher than marginal costs, there would be an opportunity for a firm to slightly undercut the lowest price and attract all demand against a profitable price. If prices were lower than marginal costs, firms would make a loss on their production and would thus be better off not selling any products at all.

An influential moment in the history of literature on price competition was the development of game theory in the 1940s and 1950s. Game theory is essentially a mathematical tool to analyze strategic situations and can therefore be used to make behavioral predictions in several social and life sciences, such as economics, psychology and biology. In game theory, a strategic situation is represented by a number of players (decision makers), actions (the possible decisions available to the players) and payoffs (specifying the outcome for each player, depending on the combination of actions chosen). Game theory's most well-known solution concept is the Nash equilibrium, named after 1994 Nobel Prize winner John Forbes Nash, who proved in his 1951 article "Non-cooperative games" that every game possesses such

\footnotetext{
${ }^{3}$ See Bertrand, J. (1883) "Théorie des Richesses: revue de Théories mathématiques de la richesse sociale par Léon Walras et Recherches sur les principes mathématiques de la théorie des richesses par Augustin Cournot”, Journal des Savants 67: 499-508.
} 
an equilibrium. A Nash equilibrium is a combination of actions, such that there is no player who can increase his payoff by unilaterally changing his action. The strategic dilemmas faced by firms could now be analyzed as a game, with firms as players, prices as actions and resulting profits as payoffs. The outcome of Bertrand's model indeed constitutes a Nash equilibrium, as no firm can increase its payoff by unilaterally changing its price, keeping all other prices constant. The temptation to undercut rival firms to capture all consumers in the market drives prices down in any one-shot game (a game that is played only once) that is based on Bertrand's assumptions, a phenomenon that is now called the Bertrand paradox.

Realizing that in real life we do see firms making positive profits (contrary to Bertrand's predictions), a new idea was needed about how firms set their prices, capturing the fact that firms interact more than once. This was provided by Stigler (1964), who analyzed the idea that firms can sustain high prices if they operate under a sort of mutual understanding that deviations from the high price will be followed by reversion to low prices by all firms (a price war). Stigler argued that, the higher consumer loyalty, the easier deviations are to detect and the easier it becomes to sustain high prices. Such a form of a mutual understanding is called tacit collusion as it requires no actual explicit agreement to be implemented.

In 1971, Friedman formalized the concept of tacit collusion in a game theoretical model. To analyze repeated interaction, Friedman used a repeated game, which is a game that is played a finite or infinite number of times. An important refinement of the Nash equilibrium solution concept in repeated games is the subgame perfect equilibrium. This requires that a combination of strategies is not only optimal against each other at the start of the game (which would be a Nash equilibrium), but also at every other time point in the game and for any history of play until that point. Friedman showed that high prices can be sustained as a subgame perfect equilibrium in an infinitely repeated game if firms make use of so-called trigger strategies. Such strategies specify that a firm sets high prices as long as its opponents have done so in all previous periods. If it observes a deviation by one of the rivals, the firm reverts to Bertrand Nash equilibrium pricing (equal to marginal costs), which can be seen as punishment in the form of a price war. Firms need to value their future profits sufficiently for this to be an equilibrium, as they need to be sufficiently "afraid" of the punishment period. This is captured by a firm's discount factor, which is a value between 0 and 1 with which future profits are multiplied to obtain their present value. 
The higher the discount factor, the more a firm values its future profits.

In Friedman's model, firms either always (tacitly) collude or they immediately deviate and prices drop to marginal cost level. In other words, there can be no switch during the game from high prices to low prices on the equilibrium path. The actual occurrence of price wars thus cannot be explained by this model. In a seminal contribution by Green and Porter (1984), it was shown for the first time that price wars can indeed occur on the equilibrium path. In this paper, firms only observe their own actions and profits. A decrease in profits can be caused either by a decrease in demand or by a deviation from collusion by one of the rival firms. In order to keep high prices sustainable, there must be a credible threat that a price war will follow a deviation. Therefore, firms always temporarily revert to one-shot game Nash equilibrium strategies if they observe a drop in profits. In the equilibrium, price wars occur with certainty but only following periods of low market demand (recession).

At first sight, an opposite result was found by Rotemberg and Saloner (1986). In their paper, they argue that deviations from collusion are most likely when the temptation to deviate is highest, which is when market demand is high (booms). If this is the case, capturing the entire market by undercutting the rival firms is most rewarding, especially if one assumes that demand will go down again in the future. However, if market demand is observable for everyone in the market, colluding firms can reduce the temptation to deviate by lowering their price jointly and voluntarily when demand is high. In this way a complete breakdown of collusion can be avoided. However, there is some disagreement in the literature about whether the periods of lower prices that result in equilibrium can truly be called price wars. Several extensions of this model were developed in later years.

This thesis contains three distinct parts, all of which aim to provide a specific contribution to the literature and to a better understanding of the reasons why we observe either high or low prices as the outcome of oligopolistic price competition. While the first part extends and re-evaluates existing literature to explain and remedy some of its apparent contradictions, the second part takes an entirely different approach and shows that if a different perspective is taken on the direct and indirect effects of price competition, many of the previously accepted predictions seem to change. In the third part, we critically discuss the sometimes rigid standpoint taken by competition authorities regarding collusive and competitive behavior. The chapters can be read independently of each other. We will now provide a 
Chapter 1. Introduction

short overview of their main results.

\section{The role of information and stability}

The first part of this thesis is directly connected to the existing literature, in particular the work of Stigler (1964), Green and Porter (1984), and Rotemberg and Saloner (1986). Throughout this part, we make use of a Bertrand type model of price competition in which market shares fluctuate. Chapter 2 deals with the apparent contradictions that exist among these three papers regarding the prerequisites for stable collusion. As Stigler focuses on consumer loyalty as a measure of fluctuations in individual demand, he argues that higher consumer loyalty improves the sustainability of collusive prices. Green and Porter show in a model of imperfect monitoring of opponent's actions that high prices are maintained as long as market demand is high. Rotemberg and Saloner find that collusion actually becomes unsustainable if market demand is high, when firms are able to observe the market situation. We show that the logic of Rotemberg and Saloner presupposes two determinants for collusion, namely (1) market shares are publicly observable, and (2) volatility of market shares due to exogenous factors is limited. Following Rotemberg and Saloner, we show that if these two conditions are satisfied, firms can collude using dynamic price adjustment strategies. We show that when the first condition (public observability) is violated, we revert to the logic of Green and Porter. When the second condition (limited volatility of market shares) is violated, for example when consumer loyalty has decreased, we also observe that collusion can no longer be sustained, in line with the arguments in Stigler. We conclude that these three classic models do not necessarily represent opposing views, but rather complement each other, and each view has its own consistent logic that indeed applies under different, mutually exclusive, conditions within our model.

In chapter 3 we turn our attention to the occurrence of price wars on the equilibrium path. As most models of price competition analyze a situation in which all firms in the market face the same decision problem, they do not explain intentional price wars. Intentional price wars are price wars that are consciously started by a specific price war leader. For such an individual initiative to take place, we need to have some form of asymmetry in the market, which is why models in which firms are symmetric are not applicable to this type of price war. We show that for intentional price wars to exist on the equilibrium path, two elements are necessary regarding the information on which the firms base their decisions: (1) interperiod fluctuations and (2) 
informational asymmetries. The results show a clear connection between collusion and price wars. We find that the possibility of intentional price wars on the equilibrium path depends on the prerequisite that the firms' discount factor is sufficiently high to sustain collusion. These results show that if we allow for a sensible element of selfishness in the usual trigger strategy (making the strategy essentially quasi-collusive), we find that equilibria are possible in which, with certainty, an intentional price war occurs at some point. This questions the necessity of (always) intervening in such markets.

\section{The impact of consumer inertia}

In part 2 of the thesis, we change some of the basic assumptions regarding the direct and indirect effects of price differences on firms' profits. Essentially, in the traditional models of price competition that are based either on Bertrand's assumptions or on Friedman's model, firms face a particular time-tradeoff when deciding whether to set a high or low price. If they undercut their opponents, they can capture the entire market immediately, resulting in an immediate relative profit increase. However, a price war will follow during which their profits will be lower than in the collusive situation. Thus, the tradeoff is one of immediate profit increase vs. future profit decrease. Many well-known results (for example that firms need to be sufficiently patient for collusion to be stable) are a direct result of this particular tradeoff.

However, in real life, firms may not always be able to attract enough additional customers after a price decrease for their profits to go up immediately. Instead, consumers may be inert: they may be unwilling or unable to switch. This can be caused by switching costs, long-term contracts, lack of price information, loyalty etc. There are many reasons why consumers do not switch suppliers immediately but possibly switch only later in time. Consumer inertia, however, drastically changes the time-tradeoff faced by the firm. In the presence of consumer inertia, they know that decreasing their prices will lead to lower profits immediately, as they will make less money off their already existing consumer base. However, they might be able to increase their future profits, if they succeed in attracting extra customers from their rivals. The tradeoff in this situation is thus one of immediate profit decrease vs. potential future profit increase. We analyze the qualitative impact this reversed time-tradeoff has on the predictions when to expect high and low prices, and on the sustainability of collusion. 
Chapter 1. Introduction

In chapter 4 , we analyze what the normal competitive outcomes would be in a model with consumer inertia. We show that firms face two powerful incentives in this model: the incentive to exploit their current demand by setting a high price (harvesting incentive) and the incentive to try to increase future demand by setting a low price (investment incentive). Additionally, there are two clear motives to choose a low price: to try to attract customers of other firms (offensive motive) or to avoid losing customers to another firm (defensive motive). Many of our results can be explained by referring to these forces. For sufficiently low discount factors, the harvesting incentive dominates the investment incentive, which results in the unique equilibrium prediction of firms charging high prices. When the discount factor is sufficiently large, this dominance relation among incentives reverts and firms will opt for the lower price. Surprisingly, coordination on high prices can no longer be supported as stationary subgame perfect equilibrium when the discount factor is high, which contrasts starkly with results found in the traditional literature on dynamic price competition, where high discount factors induce sustainability of high prices. For intermediate values of the discount factor, we show that it is possible on the equilibrium path to have endogenous market share fluctuations or even monopolization in the long run.

In chapter 5, we specifically look at the possibilities of collusion when consumers are inert, in particular when firms use trigger strategies. We show that three main differences can be found compared to the standard model of collusion. First, sustainability of high prices does not require punishment strategies when firms are sufficiently myopic, a result which holds for all customer preferences and any degree of consumer inertia. Moreover, high prices can be sustained for all discount factors when consumer inertia is sufficiently large. Finally, we find that the ability to maintain high prices might depend non-monotonically on the level of the discount factor. That is, collusion may be sustainable for extreme values of the discount factor, but not when firms are moderately patient. For this to occur, it is required that the industry exhibits network externalities and that buyers are sufficiently inert. These results raise important questions about how to distinguish between competitive and collusive behavior, how to effectively incentivize firms to set low prices and how to change levels of inertia (by, for instance, disallowing long-term contracts) to induce a situation in which firms no longer set high prices. Furthermore, we show that firms can benefit from taking joint measures to influence inertia levels and that direct communication on 
prices can be beneficial when consumers are inert. This result is possible when, counterintuitively, the antitrust authority is sufficiently effective but fines are not too large. This result contrasts with findings from standard models of collusion, in which direct communication has no direct benefit over tacit collusion.

\section{Welfare-enhancing cartels}

Chapter 6 discusses one of the basic assumptions of antitrust legislation: cartels that result in higher prices and lower total output are bad for social welfare. This is reflected in the fact that most countries have declared such hard core cartels illegal per se. In this chapter, we explore the extent to which this assumption is generally valid. We provide necessary and sufficient conditions for the existence of a hard core cartel that is beneficial for firms and society at large. We consider both strong (with side payments) and weak (without side payments) hard core cartel contracts and find that (i) both strong and weak welfare-enhancing cartels exist when at least one firm makes a loss on part of its sales in competition, (ii) a welfare-enhancing strong cartel exists whenever there is a difference in unit costs at competitive production levels, and (iii) a welfare-enhancing weak cartel exists when this difference is sufficiently large. We show that our results hold in textbook price and quantity competition models. These results give rise to the interesting and important question what optimal antitrust enforcement looks like in a setting where the (unknown) pool of potential cartels contains both "good cartels" and "bad cartels". 



\section{Part I}

\section{The Role of Information and Stability}





\section{Chapter 2}

\section{Collusion under Exogenous Demand Fluctuations}

\subsection{Introduction}

This chapter is a contribution to the ongoing discussion on the stability of collusion and the conditions under which pricing agreements among oligopolists can be sustained in equilibrium. ${ }^{1}$

It is well known in the industrial organization literature that fluctuations in levels of both individual and market demand play an important role in the stability of collusion and the occurrence of price wars. An early contribution in this context is Stigler (1964). In the model of Stigler firms face uncertainty regarding their individual demand, and they cannot directly observe their opponents' behavior. An unexpectedly large drop in a firm's own individual demand may therefore be attributed to an (unobserved) deviation from collusion by one of the opponents, and a price war is seen as the reversion to competitive behavior to punish such deviations. Stigler argued that, in a market with high consumer loyalty, deviations from a collusive agreement are relatively easy to detect. Therefore collusion is easier to sustain in markets with high consumer loyalty than in markets with low consumer loyalty.

The first equilibrium based paper showing how price wars can occur on the equilibrium path is Green and Porter (1984). In their model, a firm can experience a period of unexpectedly bad performance both as a result of de-

\footnotetext{
${ }^{1}$ This chapter is based on Pot, Peeters, Peters and Vermeulen (2009).
} 
Chapter 2. Collusion under Exogenous Demand Fluctuations

viating behavior by one of the firms and as a result of (unobservable) low aggregate demand. Since, because of unobservability, firms are unable to distinguish between these two scenarios, they have to revert to retaliatory behavior in either case in order to discourage deviating behavior. Price wars will thus occur with certainty in periods of low demand, even when deviations did not occur.

Another milestone in the discussion is the paper by Rotemberg and Saloner (1986). In a model with volatile aggregate demand and fixed market shares they show that partial collusion can be sustained in equilibrium using countercyclical pricing strategies. The logic of their argument is that, during a boom, the temptation for firms to deviate from the collusive agreement to attract consumers starts to outweigh the decrease in profits resulting from the ensuing retaliatory price war. To counterbalance this threat to collusion, in equilibrium firms consequently employ a gradual and coordinated downward adjustment of the price levels in response to the increased level of demand in periods where the market is booming. Since the decision to decrease prices during a boom is taken jointly by all competitors as part of the collusive agreement such an orchestrated and voluntary decrease in prices is in fact not a price war, but can better be viewed as a form of dynamic collusion where prices are deliberately adjusted to the circumstances, precisely with the intention to stabilize collusion. A full blown price war in the sense of full reversion to marginal cost pricing does not occur on the equilibrium path. This was concisely put by Ellison (1994): "Rotemberg and Saloner (1986), is commonly associated with the statement that price wars are more likely to occur during booms, and therefore viewed as somehow in opposition to the Green and Porter theory. The actual Rotemberg and Saloner model, however, is really about countercyclical pricing - firms have perfect information and adjust prices smoothly in response to demand conditions."

In this chapter we present a model where firms interact repeatedly in a Bertrand type model based on price competition. Each firm can choose to collude, to price at marginal cost, or to deviate from collusion (undercutting the collusive price). We assume that aggregate demand is inelastic and that the division of market shares may fluctuate over time. Fluctuations of market shares model exogenous factors such as for example consumer loyalty (or better: lack thereof) and location effects. Typically such factors are outside the control of the firms and are known to affect collusive opportunities (Stigler (1964), Green and Porter (1984)). 
Within this model, both with private information on individual market shares and with public information, we derive the conditions under which strategy profiles in trigger strategies where each firm chooses to collude unless a deviation has been detected in the past (in which case firms revert to marginal cost pricing) can be sustained as a perfect Bayesian Nash equilibrium.

In both the case of private and the case of public information we find that collusive behavior in trigger strategies is harder to sustain when market shares have high volatility over time, and periods with low individual demand are possible. Moreover, in the public information case, opportunities for partial collusion enhance collusion. The logic driving these results is fairly intuitive. Collusive behavior can be sustained in equilibrium by trigger strategies precisely when expected profits for firms adhering to the collusive agreement are higher than the single period gains from deviation. This condition is particularly stringent for periods where individual demand is low, since in such periods the expected profits when a firm follows the agreement are minimal, while the immediate gains from deviation (undercutting) are high. In addition, when a firm also expects its individual demand to be low in the future, which is more likely when current individual demand is low, the punishment ensuing the breaking of the agreement is relatively small. Hence, high volatility of individual market shares hampers collusion. On the other hand, when partial collusion is possible, and market shares are observable, a countercyclical pricing policy with partial collusion as in Rotemberg and Saloner can be applied to enhance sustainability of collusive behavior in equilibrium.

These results can be seen as an attempt to reconcile the views expressed in Stigler (1964) and Green and Porter (1984) with the arguments in Rotemberg and Saloner (1986). In our model with private information, increased volatility of market shares prevents collusion. This is in line with the view of Green and Porter, who argue that collusion is most likely to break down in periods of low demand, and the view of Stigler, who argued that high consumer loyalty, which is directly related to low volatility of market shares, is one of the stabilizing factors for collusion.

On the other hand, in our model with public observability of market shares, the basic logic of the arguments in Rotemberg and Saloner is still valid. Firms easily collude when differences in individual demand remain relatively small. However, in the presence of fluctuations of market shares collusion becomes more difficult to sustain. The cartel is then stabilized in 
periods of high fluctuations in market shares by using a coordinated price adjustment scheme. When market shares are out of balance, a policy of lower collusive price setting discourages deviations by firms with lower market shares. $^{2}$

Thus, our argument here is that the driving force behind the results of Rotemberg and Saloner is not the presence of shocks on total demand per se, but more in general the public observability of market shares in conjunction with low volatility of these market shares. Public observability of market shares is essential to the implementation of dynamic price strategies and hence partial collusion, while low volatility of market shares guarantees that dynamic adjustment of prices via a collusive agreement can sufficiently decrease gains from deviation.

Note that both conditions, public observability and low volatility, are fulfilled in Rotemberg and Saloner. They assume that total demand is publicly observed, and moreover that total demand is always equally divided over firms, so that implicitly the division of market shares over firms is common knowledge. Thus, firms are assumed to have full information on market shares. And indeed, in an environment where firms can make binding agreements on market shares, the full force of Rotemberg and Saloner's arguments applies, and collusion, at least partial collusion, can be sustained in equilibrium using countercyclical pricing strategies.

However, we show that in addition to this basic observation, the logic of Rotemberg and Saloner breaks down as soon as one of the two conditions is violated. When in our model market shares are no longer publicly observable, collusion via dynamic price schemes is no longer possible, and we effectively revert to a model where the logic of Green and Porter applies. Hence, the conclusions of Green and Porter versus Rotemberg and Saloner are not contradictory, but rather complement each other, and can be observed under different conditions within a single dynamic model of Bertrand competition.

Also, when market shares are still observable but the volatility of market shares is sufficiently high, dynamic pricing schemes can no longer be sustained in equilibrium. This is due to the fact that large changes in mar-

\footnotetext{
${ }^{2}$ Despite the differences between the R\&S model and our model, the intuition is the same in both models. The central issue is changes in potential gains from deviation. In the model of $R \& S$ these changes are the result of changes in aggregate demand under fixed market shares. In our model these changes are conversely the result of changes in individual demand (market shares) under constant aggregate demand. Nevertheless the effect is the same: both in the case of high aggregate demand with fixed market shares and in the case of constant aggregate demand with low market shares gains from deviation are increased.
} 
2.2. Basic model

ket shares can no longer be compensated for by a countercyclical collusive price adjustment scheme. The gains from deviation for firms with low individual demand simply can no longer be counterbalanced in that case. Then, in line with the findings of Stigler, collusion breaks down.

In conclusion, the logic of Rotemberg and Saloner not only presupposes observability of market shares; also low volatility of individual demand, for example via a sufficient amount of control over individual demand, is essential to their argument. So, mere observability is not sufficient. When market shares cannot be enforced collectively and are subject to large exogenous fluctuations that are outside the control of the firms, the conclusions of Rotemberg and Saloner are mitigated by the volatility of market shares, and collusion will be harder, or even impossible, to sustain.

\subsection{Basic model}

In this section we present the basic model we use in our analysis. In our model firms interact repeatedly in a Bertrand-type pricing game. We first define the one-shot game played between firms in each period of time. In each period firms simultaneously and independently choose one out of three pricing strategies, namely collusion, marginal cost pricing, and undercutting. Based on the choice of strategies of the firms each firm receives a profit. This basic game is then repeated over an infinite time horizon. Firms use discounting to evaluate the resulting profit streams.

\subsubsection{The one-shot game}

The one-shot game is based on a Bertrand model in which $n$ firms compete on price in a market for a homogeneous good. In the one-shot game each firm has three available actions it could possibly take, namely to collude $(C)$, to undercut $(U)$, or to price at marginal cost $(M)$. Thus, each firm chooses an action $a_{i} \in\{U, C, M\}$ without prior information on the choices of the other firms. A second ingredient of the model is a vector $\varphi=\left(\varphi_{1}, \ldots, \varphi_{n}\right)$ of market shares, where $\varphi_{i} \geq 0$ represents the market share of firm $i$. The market share vector prescribes how total profits are divided among firms when all firms choose the same action. Market shares divide the total market, so $\sum_{i} \varphi_{i}=1$.

To be precise, profits are determined as follows. Given a profile $a=$ $\left(a_{i}\right)_{i \in N}$ of chosen actions, the resulting profit of firm $i$ is denoted by $\Pi_{i}(a)$. 
When $a_{i}=C$ for all $i$, then $\Pi_{i}(a)=\varphi_{i} \Pi$, where $\Pi$ represents the monopoly profit in the market. Thus, in this case, firms act monopolistically and profits are divided according to market share. When there is a firm $k$ with $a_{k}=U$ and $a_{i}=C$ for all $i \neq k$, then $\Pi_{k}(a)=\Pi$ and $\Pi_{i}(a)=0$ for all $i \neq k$. In all other cases all profits are zero.

Although our model is based on the model of Bertrand competition, it obviously deviates from the standard approach in modeling Bertrand competition in two aspects. First, our approach starts with the observation that, even though in the original model each firm can choose any price, only three strategies for price setting are relevant for the dynamics of the Bertrand model. These three choices are (a) collusive pricing, (b) price setting slightly below collusive pricing to exploit collusive behavior and to capture the market, and (c) competitive (marginal cost) pricing. In our approach we discard other possible choices and only focus on these three crucial price setting strategies. That way we try to keep the analysis of the one-shot game simple while we preserve the essential ingredients of the Bertrand model.

The second aspect regards our choice of the profits in the one-shot model. It is clear that profits are zero when at least one of the firms chooses to use marginal cost pricing. The firm that uses this action attracts the market, but does not make any profit, while the other firms do not have any customers. In the case that more than one firm undercuts the collusive price, one might assume that the undercutting firms take their share of the monopoly profit. However, for simplicity we adopt the more radical assumption that also in this case all profits are zero.

The one-shot game has several Nash equilibria. Evidently the action profile in which all firms play $M$ is a Nash equilibrium. However, when there are at least three firms, an action profile in which for example one firm plays $C$ and all other firms play $M$ is also a Nash equilibrium. Nevertheless, the two important observations to make here are (1) that the action profile in which all firms play $C$, the collusion strategy profile, is not a Nash equilibrium, and (2) that in any symmetric Nash equilibrium (either all firms playing $M$ or all firms playing $U$ ) of the one-shot game all firms receive zero profit.

\subsubsection{The repeated game}

In the repeated game the one-shot game is repeated over an infinite time horizon. At the start of each period $t=0,1,2, \ldots$ the vector $\varphi_{t}=\left(\varphi_{1 t}, \ldots, \varphi_{n t}\right)$ of market shares is determined. This vector is stochastic, and it could in 
general depend on both the actions taken previously by the firms and on the realizations of market shares in earlier periods. Nevertheless, for simplicity we only study exogenous processes where the realizations do not depend on the actions taken by the firms.

Next, when $\varphi_{t}$ is realized, each firm receives information $h_{i t}$. Typically $h_{i t}$ is a record of all actions taken by firms in earlier periods, the realized market shares of all firms in earlier periods, and either a firm's own market share in the current period (private information), or all realized market shares in the current period (public information).

A strategy for firm $i$ in the repeated game is a function $s_{i}$ that prescribes for each history $h_{i t}$ the action $s_{i}\left(h_{i t}\right) \in\{U, C, M\}$ that firm $i$ chooses. We require $s_{i}\left(h_{i t}\right)$ to be specified for any conceivable history $h_{i t}$, not just for those that are actually realized by previous actions of the firms. This is standard practice in game theoretic models and facilitates defining the concept of (subgame perfect) Nash equilibrium. In particular, a firm should not only specify what it will do when all firms act according to agreement, but also how it will react to conceivable deviations from the agreement (and by extension also to deviations from deviations from the agreement, etc).

We write $s\left(h_{t}\right)=\left(s_{1}\left(h_{1 t}\right), \ldots, s_{n}\left(h_{n t}\right)\right)$ for the profile of actions that is played at time $t$ given the information $h_{t}=\left(h_{1 t}, \ldots, h_{n t}\right)$. Let $s^{t}$ denote the map $h_{t} \mapsto s\left(h_{t}\right)$. The initial division of market shares is given by $\varphi_{0}=$ $\left(\varphi_{10}, \ldots, \varphi_{n 0}\right)$. Further, the associated information to the firms is denoted by $h_{0}=\left(h_{10}, \ldots, h_{n 0}\right)$. The density function $f_{i t+1}\left(\varphi_{i t+1} \mid \varphi_{i t}\right)$ denotes the density of the probability distribution of $\varphi_{i t+1}$ conditional on the event that at time $t$ the market share of firm $i$ is $\varphi_{i t}$. By $\mathbb{E}\left(\Pi_{i}\left(s^{t}\right) \mid h_{i 0}\right)$ we denote the expected value of the profit to firm $i$ at time $t$, given the strategy profile $s$ and the initial information $h_{i 0}$ of firm $i$.

Given the profile $s=\left(s_{1}, \ldots, s_{n}\right)$ of strategies, firm $i$ evaluates the resulting stream of expected profits

$$
\mathbb{E}\left(\Pi_{i}\left(s^{0}\right) \mid h_{i 0}\right), \mathbb{E}\left(\Pi_{i}\left(s^{1}\right) \mid h_{i 0}\right), \ldots
$$

via the discounted criterion defined by

$$
\Pi_{i}\left(s \mid h_{i 0}\right)=\sum_{t=0}^{\infty} \delta^{t} \cdot \mathbb{E}\left(\Pi_{i}\left(s^{t}\right) \mid h_{i 0}\right)
$$

Given a strategy profile $s$ and a strategy $s_{i}^{\prime}$ for firm $i$, let $\left(s, s_{i}^{\prime}\right)$ denote the strategy profile where all firms $j \neq i$ play according to the strategy $s_{j}$, while 
firm $i$ plays according to strategy $s_{i}^{\prime}$. A strategy profile $s$ is a Bayesian Nash equilibrium when for every firm $i$

$$
\Pi_{i}\left(s \mid h_{i 0}\right) \geq \Pi_{i}\left(\left(s, s_{i}^{\prime}\right) \mid h_{i 0}\right)
$$

holds for every strategy $s_{i}^{\prime}$ of firm $i$ and any initial information $h_{i 0}$.

Analogously, let $\mathbb{E}\left(\Pi_{i}\left(s^{t+k}\right) \mid h_{i t}\right)$ denote the present value of the profit of firm $i$ at time $t+k$, given the strategy profile $s$ and information $h_{i t}$ to firm $i$ at time $t$. Write

$$
\Pi_{i}\left(s \mid h_{i t}\right)=\sum_{k=0}^{\infty} \delta^{k} \cdot \mathbb{E}\left(\Pi_{i}\left(s^{t+k}\right) \mid h_{i t}\right)
$$

for the present value of the stream of profits to firm $i$ at information set $h_{i t}$. A Nash equilibrium $s$ is a perfect Bayesian Nash equilibrium when, at every information set $h_{i t}$,

$$
\Pi_{i}\left(s \mid h_{i t}\right) \geq \Pi_{i}\left(\left(s, s_{i}^{\prime}\right) \mid h_{i t}\right)
$$

holds for every strategy $s_{i}^{\prime}$ of firm $i$.

\subsection{Collusive equilibria under private information}

In this section we assume private information. Thus, for every $i$ and $t, h_{i t}$ consists of $\varphi_{i t}$ together with all realizations of market shares and all actions taken by the firms in all previous rounds. ${ }^{3}$ We also assume that all realizations of market shares $\varphi_{i t}$ are within an interval $[\underline{\varphi}, \bar{\varphi}]$ with $0 \leq \varphi<\bar{\varphi} \leq 1$. We first analyze under what conditions collusion can be sustained as a perfect Bayesian Nash equilibrium via trigger strategies.

TRIGGER STRATEGIES The trigger strategy $T_{i}$ of firm $i$ is defined by

$$
T_{i}\left(h_{i t}\right)= \begin{cases}C & \text { if all firms chose action } C \text { in all previous rounds } \\ & \text { according to } h_{i t} \\ M \quad \text { otherwise }\end{cases}
$$

and $T=\left(T_{i}\right)_{i \in N}$ denotes the profile of trigger strategies. We derive the following necessary and sufficient condition for $T$ to be a perfect Bayesian Nash equilibrium.

\footnotetext{
${ }^{3}$ Note that for these assumptions to imply that firms have private information, $n$ should be larger than 2 .
} 
Theorem 2.3.1. The strategy profile $T$ is a perfect Bayesian Nash equilibrium precisely when

$$
\sum_{k=0}^{\infty} \delta^{k} \cdot \mathbb{E}\left(\varphi_{i t+k} \mid \varphi_{i t}\right) \geq 1
$$

holds for any possible market share $\varphi_{i t} \in[\underline{\varphi}, \bar{\varphi}]$ at time $t$, for all firms $i$ and at every time $t$.

Proof. Due to the one deviation property (see e.g. Hendon et al. (1996)), the trigger strategy profile is a perfect Bayesian Nash equilibrium exactly when every firm $i$, at every time $t$, and at every information set $h_{i t}$ the trigger strategy renders at least the same expected profit as an instantaneous deviation. Thus, consider firm $i$, at time $t$, having a market share $\varphi_{i t}$. Given that in the punishment phase firms make zero profit, the expected loss in this phase equals the discounted sum of expected market shares times $\Pi$

$$
\delta \cdot \mathbb{E}\left(\varphi_{i t+1} \mid \varphi_{i t}\right) \cdot \Pi+\delta^{2} \cdot \mathbb{E}\left(\varphi_{i t+2} \mid \varphi_{i t}\right) \cdot \Pi+\ldots=\sum_{k=1}^{\infty} \delta^{k} \cdot \mathbb{E}\left(\varphi_{i t+k} \mid \varphi_{i t}\right) \cdot \Pi .
$$

The gain from optimal deviation is equal to $\left(1-\varphi_{i t}\right) \cdot \Pi$. So the collusive strategy yields at least the same profit when

$$
\sum_{k=1}^{\infty} \delta^{k} \cdot \mathbb{E}\left(\varphi_{i t+k} \mid \varphi_{i t}\right) \geq 1-\varphi_{i t}
$$

This concludes the proof.

As a consequence of this result we derive analogues in our context of the results of Green and Porter (1984) and Stigler (1964). In the remainder of this section we show that, when firms experience low market shares, collusion becomes more difficult to sustain and reversion to non-collusive behavior is more likely to occur. In particular we find that the smaller a firm's market share can get, the higher the discount factor needs to be to guarantee that the trigger strategy profile is an equilibrium for all possible market share realizations. Also, since consumer loyalty reduces the volatility of market shares over time, we find in agreement with Stigler that collusion becomes easier to sustain when consumer loyalty is high.

In order to derive these analogues of Stigler and Green and Porter we need a bit more notation together with a mild assumption. Specifically, we assume for the conditional density function $f_{i t+1}\left(\varphi_{i t+1} \mid \varphi_{i t}\right)$ that $f_{i t+1}\left(\varphi_{i t+1} \mid\right.$ $\left.\varphi_{i t}\right)=0$ outside the interval $[\varphi, \bar{\varphi}]$ and that $f_{i t+1}\left(\varphi_{i t+1} \mid \varphi_{i t}\right)>0$ on the interior of the interval $[\underline{\varphi}, \bar{\varphi}]$. 
Further, in accordance with the intuition that a higher market share today increases one's chances to have a higher market share in the future, we assume for the collection of cumulative probability distributions

$$
F_{\varphi_{i t}}(\varphi)=\int_{0}^{\varphi} f_{i t+1}\left(\varphi_{i t+1} \mid \varphi_{i t}\right) d \varphi_{i t+1}
$$

that $\varphi_{i t} \leq \widetilde{\varphi}_{i t}$ implies $F_{\varphi_{i t}}(\varphi) \geq F_{\widetilde{\varphi}_{i t}}(\varphi)$ for every $\varphi$. Put slightly differently, when $\varphi_{i t} \leq \widetilde{\varphi}_{i t}$, the probability distribution $F_{\widetilde{\varphi}_{i t}}$ of $\varphi_{i t+1}$ given $\widetilde{\varphi}_{i t}$ stochastically dominates the probability distribution $F_{\varphi_{i t}}$ of $\varphi_{i t+1}$ given $\varphi_{i t}$. Under this assumption we can show the following fact. A sketch of its proof can be found in section 2.7 .

Lemma 2.3.2. For any $k \geq 1, \mathbb{E}\left(\varphi_{i t+k} \mid \varphi_{i t}\right)$ is increasing in $\varphi_{i t}$.

The intuition of this result is clear. It states that the expectation of a firm's future market share is an increasing function of today's market share. In other words, higher market shares today increase the expected value of tomorrow's market share. ${ }^{4}$ Under this condition we have the following Corollary.

Corollary 2.3.3. The strategy profile $T$ is a perfect Bayesian Nash equilibrium precisely when

$$
\sum_{k=0}^{\infty} \delta^{k} \cdot \mathbb{E}\left(\varphi_{i t+k} \mid \varphi_{i t}=\underline{\varphi}\right) \geq 1
$$

holds for every firm $i$ at every time $t$.

Proof. Due to Theorem 2.3.1 we know that $T$ is a perfect Bayesian Nash equilibrium precisely when

$$
\sum_{k=0}^{\infty} \delta^{k} \cdot \mathbb{E}\left(\varphi_{i t+k} \mid \varphi_{i t}\right) \geq 1
$$

holds for all firms $i$, at every time $t$, for any possible market share $\varphi_{i t} \in[\varphi, \bar{\varphi}]$ at time $t$. However, by Lemma 2.3.2 we know that the left-hand side of the above inequality is increasing in $\varphi_{i t}$. Hence, the above inequality is satisfied for all $\varphi_{i t} \in[\underline{\varphi}, \bar{\varphi}]$ precisely when it is satisfied for $\varphi_{i t}=\underline{\varphi}$.

\footnotetext{
${ }^{4}$ In fact this statement itself is all we need to derive our results. However, we did not want to use this condition on expected market shares as a basic assumption. Instead we chose to derive it from the more basic assumption on cumulative probability distributions.
} 
2.4. Collusive equilibria under public information

This is a direct analogue of the result of Green and Porter that the possibility of low market shares hamper collusion in our context. This possibility is reflected in a low value of $\varphi$. Then, by our assumption expressed in Lemma 2.3.2 the left-hand side of the inequality in Corollary 2.3.3 is low. Thus, it will become harder to satisfy the condition for $T$ to be a perfect Bayesian Nash equilibrium, and hence collusion is harder to sustain. It is also in agreement with Stigler (1964), since high consumer loyalty reduces the volatility of market shares. Hence high consumer loyalty increases $\underline{\varphi}$, and collusion becomes easier to sustain.

\subsection{Collusive equilibria under public information}

We now focus on the setting of Rotemberg and Saloner (1986). We show that when firms have public information on realized market shares, the incentives to deviate for a firm that has a low market share can be reduced by jointly choosing a lower collusive price. Thus, public availability of information enables firms to sustain (partial) collusion even in situations where full collusion would break down. The price to pay for this enhancement of collusion is, as also argued in Rotemberg and Saloner, a lower collusive price, and hence (at least in our model with fixed aggregate demand) lower profits.

We model the phenomenon of partial collusion by slightly changing the one-shot game. Since under public information the colluding firms observe the vector $\varphi_{t}=\left(\varphi_{1 t}, \ldots, \varphi_{n t}\right)$ of market shares at the start of each period $t$, the profit function in the one-shot game can now be made contingent on the specific realization of $\varphi_{t}$. Before the start of the game, the colluding firms agree on a threshold level $\varphi^{*}$ and a collusive joint profit $\Pi^{*}<\Pi$. The agreement is that, as long as all realized market shares $\varphi_{i t}$ are above the threshold $\varphi^{*}$, firms collude at a price level generating joint profits $\Pi$, while as soon as one or more firms have a realized market share below the threshold, firms collude at a price level that generates joint profits $\Pi^{*}$ (partial collusion).

Effectively the collusive agreement is modeled via the one-shot profit functions $\Pi_{i}$. Given a profile $a=\left(a_{i}\right)_{i \in N}$ of chosen actions, the resulting profit of firm $i$ is denoted by $\Pi_{i}(a)$. The profits are now defined contingent on the realization of the vector $\varphi_{t}=\left(\varphi_{1 t}, \ldots, \varphi_{n t}\right)$.

In case $\varphi_{j t} \geq \varphi^{*}$ for all $j$. When $a_{i}=C$ for all $i$, then $\Pi_{i}(a)=\varphi_{i} \Pi$. When there is a firm $k$ with $a_{k}=U$ and $a_{i}=C$ for all $i \neq k$, then $\Pi_{k}(a)=\Pi$ and $\Pi_{i}(a)=0$ for all $i \neq k$. For all other strategy profiles all profits are zero.

In case $\varphi_{j t}<\varphi^{*}$ for some $j$. When $a_{i}=C$ for all $i$, then $\Pi_{i}(a)=\varphi_{i} \Pi^{*}$. 
Chapter 2. Collusion under Exogenous Demand Fluctuations

When there is a firm $k$ with $a_{k}=U$ and $a_{i}=C$ for all $i \neq k$, then $\Pi_{k}(a)=\Pi^{*}$ and $\Pi_{i}(a)=0$ for all $i \neq k$. For all other strategy profiles all profits are zero.

Note that firms need public information on market shares in order to implement these profits.

TRIGGER STRATEGIES The trigger strategy $T_{i}^{*}$ of firm $i$ is defined by

$$
T_{i}^{*}\left(h_{i t}\right)= \begin{cases}C \quad \text { if all firms chose action } C \text { in all previous rounds } \\
\text { according to } h_{i t} \\
M \quad \begin{array}{l}
\text { otherwise }
\end{array}\end{cases}
$$

We write $T^{*}=\left(T_{i}^{*}\right)_{i \in N}$ for the profile of trigger strategies. ${ }^{5}$ Given $h_{t}$, let $p_{t+k}\left(h_{t}\right)$ denote the probability that $\varphi_{j t+k} \geq \varphi^{*}$ for all $j$.

Theorem 2.4.1. The strategy profile $T^{*}$ is a perfect Bayesian Nash equilibrium precisely when for every firm $i$ and for every information set $h_{t}$ at every time $t$, the condition

$$
\sum_{k=1}^{\infty} \delta^{k} \cdot \mathbb{E}\left(\varphi_{i t+k} \mid \varphi_{i t}\right) \cdot\left(p_{t+k}\left(h_{t}\right) \Pi+\left(1-p_{t+k}\left(h_{t}\right)\right) \Pi^{*}\right) \geq\left(1-\varphi_{i t}\right) \Pi
$$

holds when $\varphi_{j t} \geq \varphi^{*}$ for all $j$, and the condition

$$
\sum_{k=1}^{\infty} \delta^{k} \cdot \mathbb{E}\left(\varphi_{i t+k} \mid \varphi_{i t}\right) \cdot\left(p_{t+k}\left(h_{t}\right) \Pi+\left(1-p_{t+k}\left(h_{t}\right)\right) \Pi^{*}\right) \geq\left(1-\varphi_{i t}\right) \Pi^{*}
$$

holds when $\varphi_{j t}<\varphi^{*}$ for some $j$.

Proof. The proof generally follows the same steps as the proofs of Theorem 2.3.1 and Corollary 2.3.3. Consider a firm $i$ at time $t$ with market share $\varphi_{i t}$. If the firm would play $U$, the expected loss from the punishment period would be

$$
\sum_{k=1}^{\infty} \delta^{k} \cdot \mathbb{E}\left(\varphi_{i t+k} \mid \varphi_{i t}\right) \cdot\left(p_{t+k}\left(h_{t}\right) \Pi+\left(1-p_{t+k}\left(h_{t}\right)\right) \Pi^{*}\right)
$$

The expected gain when $\varphi_{j t} \geq \varphi^{*}$ for all $j$ is $\left(1-\varphi_{i t}\right) \Pi$. So, in this case the equilibrium condition becomes

$$
\sum_{k=1}^{\infty} \delta^{k} \cdot \mathbb{E}\left(\varphi_{i t+k} \mid \varphi_{i t}\right) \cdot\left(p_{t+k}\left(h_{t}\right) \Pi+\left(1-p_{t+k}\left(h_{t}\right)\right) \Pi^{*}\right) \geq\left(1-\varphi_{i t}\right) \Pi .
$$

\footnotetext{
${ }^{5}$ Although the definition of $T^{*}$ looks identical to the definition of the profile of trigger strategies $T$, due to the different information structures the set of histories on which $T^{*}$ is defined differs from the set of histories on which $T$ is defined.
} 
2.5. Collusive equilibria when market shares form a martingale

When $\varphi_{j t}<\varphi^{*}$ for some $j$ the expected gain is $\left(1-\varphi_{i t}\right) \Pi^{*}$. So, in this case the equilibrium condition becomes

$$
\sum_{k=1}^{\infty} \delta^{k} \cdot \mathbb{E}\left(\varphi_{i t+k} \mid \varphi_{i t}\right) \cdot\left(p_{t+k}\left(h_{t}\right) \Pi+\left(1-p_{t+k}\left(h_{t}\right)\right) \Pi^{*}\right) \geq\left(1-\varphi_{i t}\right) \Pi^{*}
$$

The above theorem shows that in the setting with public information we can, similarly to Rotemberg and Saloner, implement partial collusion as a perfect Bayesian Nash equilibrium in trigger strategies. Also, as in R\&S, strategies are based on a collusive dynamic price adjustment strategy.

This form of partial collusion under public information allows for collusion in more environments than the full collusion under private information studied in section 2.3. The argument, here as well as in R\&S, is straightforward: when we choose $\Pi^{*}=\Pi$ and $\varphi^{*}=\varphi$ the above conditions are exactly equivalent to the condition in Theorem $2 . \overline{3} .1$.

Thus, when full observability of market shares in not possible, this type of partial collusion cannot be implemented, and the results from Rotemberg and Saloner reduce to the results in Green and Porter. Hence, full observability enhances collusion in our model. Partial collusion incorporates the opportunities that full collusion offers, and extends to environments where full collusion is no longer sustainable.

Consumer loyalty guarantees to firms a certain fixed minimum number of consumers. Thus, when the threshold $\varphi^{*}$ is sufficiently low, an increase in consumer loyalty tends to increase the probability $p_{t+k}\left(h_{t}\right)$ that $\varphi_{j t+k} \geq \varphi^{*}$ for all $j$ given the history $h_{t}$. All other things being equal, this shows that an increase in consumer loyalty makes it easier to satisfy the conditions in the above Theorem, which is in line with the observations in Stigler.

\subsection{Collusive equilibria when market shares form a martingale}

An interesting special case in which we can take the above analysis a step further, and give explicit formulas for the breakdown of collusion under both private and public information, is when the stochastic process that governs the market shares forms a martingale. ${ }^{6}$

\footnotetext{
${ }^{6}$ For firm $i$, the stochastic process $\left(\varphi_{i t}\right)_{t=0}^{\infty}$ is a martingale when $\mathbb{E}\left(\varphi_{i t+k} \mid \varphi_{i t}\right)=\varphi_{i t}$ for every $t$ and $k$. Formally, a martingale does not satisfy the condition in section 2.3 that $f_{i t+1}\left(\varphi_{i t+1} \mid \varphi_{i t}\right)>0$. However, Theorem 2.3.1 also holds for martingales.
} 
Chapter 2. Collusion under Exogenous Demand Fluctuations

We start with the case of private information. In this setting, as a consequence of Theorem 2.3.1, we find that the trigger strategy profile is a perfect Bayesian Nash equilibrium precisely when the discount factor exceeds 1 minus the minimum market share. Thus, when the minimum market share is relatively high, and hence uncertainty is relatively low, it is easy for the firms to sustain collusion.

Corollary 2.5.1. Assume private information. When the stochastic variables $\varphi_{i}$ form a martingale, the trigger strategy profile $T$ is a perfect Bayesian Nash equilibrium precisely when $\delta \geq 1-\underline{\varphi}$.

Proof. When the stochastic variables $\varphi_{i}$ form a martingale, we have

$$
\mathbb{E}\left(\varphi_{i t+k} \mid \varphi_{i t}=\underline{\varphi}\right)=\underline{\varphi}
$$

for all $t$ and $k .^{7}$ Thus, the equilibrium condition in Corollary 2.3.3 reduces to

$$
\sum_{k=0}^{\infty} \delta^{k} \cdot \underline{\varphi} \geq 1
$$

which can be rewritten to $\delta \geq 1-\underline{\varphi}$.

We now turn to the case of public information. It turns out there is an appropriate choice of $\varphi^{*}$ such that, given $\delta$, the adaptive trigger strategies $T^{*}$ form an equilibrium whenever the profile of trigger strategies $T$ is an equilibrium.

Corollary 2.5.2. Assume public information. Suppose that the stochastic variables $\varphi_{i}$ form a martingale. Let $\delta$ be given. Suppose further that

$$
\varphi^{*} \geq \frac{(1-\delta) \Pi}{\delta \Pi^{*}+(1-\delta) \Pi} .
$$

Then the trigger strategy profile $T^{*}$ is a perfect Bayesian Nash equilibrium.

Proof. Rewriting of $(*)$ yields

$$
\sum_{k=1}^{\infty} \delta^{k} \cdot \varphi^{*} \cdot \Pi^{*} \geq\left(1-\varphi^{*}\right) \Pi
$$

\footnotetext{
${ }^{7}$ For a martingale it even holds that $\varphi_{i t+1}=\underline{\varphi}$ with probability one when $\varphi_{i t}=\underline{\varphi}$.
} 
Since the left-hand side of the inequality is increasing in $\varphi^{*}$ and the righthand side is decreasing, we obtain

$$
\sum_{k=1}^{\infty} \delta^{k} \cdot \varphi_{i t} \cdot \Pi^{*} \geq\left(1-\varphi_{i t}\right) \Pi
$$

for all $\varphi_{i t} \geq \varphi^{*}$. Thus, since the stochastic variables $\varphi_{i}$ form a martingale, we find that

$$
\sum_{k=1}^{\infty} \delta^{k} \cdot \mathbb{E}\left(\varphi_{i t+k} \mid \varphi_{i t}\right) \cdot \Pi^{*} \geq\left(1-\varphi_{i t}\right) \Pi
$$

for all $\varphi_{i t} \geq \varphi^{*}$. Hence, since $\Pi^{*}<\Pi$, also

$$
\sum_{k=1}^{\infty} \delta^{k} \cdot \mathbb{E}\left(\varphi_{i t+k} \mid \varphi_{i t}\right) \cdot\left(p_{t+k}\left(h_{t}\right) \Pi+\left(1-p_{t+k}\left(h_{t}\right)\right) \Pi^{*}\right) \geq\left(1-\varphi_{i t}\right) \Pi
$$

for all $\varphi_{i t} \geq \varphi^{*}$, which shows that the first set of inequalities of Theorem 2.4.1 is satisfied. In order to obtain the second set of inequalities, notice that the strategy profile $T$ is a perfect Bayesian Nash equilibrium by assumption. So, by Theorem 2.3.1

$$
\sum_{k=0}^{\infty} \delta^{k} \cdot \mathbb{E}\left(\varphi_{i t+k} \mid \varphi_{i t}\right) \geq 1
$$

for all $t$ and all market shares $\varphi_{i t}$. Therefore also

$$
\sum_{k=1}^{\infty} \delta^{k} \cdot \mathbb{E}\left(\varphi_{i t+k} \mid \varphi_{i t}\right) \cdot \Pi^{*} \geq\left(1-\varphi_{i t}\right) \Pi^{*}
$$

for all $t$ and all market shares $\varphi_{i t}$. The second set of conditions now follows from the observation that $\Pi^{*}<\Pi$.

Finally note that the condition $\varphi^{*} \geq \frac{(1-\delta) \Pi}{\delta \Pi^{*}+(1-\delta) \Pi}$ can be satisfied for any given $\delta<1$ by appropriate choices of $\varphi^{*}<1$ and $\Pi^{*}<\Pi$.

\subsection{Conclusion}

We presented a model in which firms repeatedly engage in a Bertrand type competition model. Depending on the strategies chosen, per period profits are distributed among firms according to market shares. Market shares are allowed to fluctuate over time.

Within this model with public information on market shares we derived the conditions under which partial collusion can be implemented via trigger strategies with a dynamic price adjustment policy. Implementability of 
Chapter 2. Collusion under Exogenous Demand Fluctuations

partial collusion in equilibrium is in line with the logic of Rotemberg and Saloner.

Using the model we argue that both public observability of market shares and low volatility of market shares are essential for the implementation of partial collusion. Absence of public observability prevents firms from using dynamic pricing strategies, and we revert to the logic of Green and Porter. On the other hand, in line with Stigler, we see that in our basic model with full observability, low consumer loyalty also prevents firms from using dynamic pricing strategies. Such strategies can in principle still be executed, but under low consumer loyalty, and hence high volatility of market shares, this form of partial collusion fails to satisfy the equilibrium conditions, and collusion breaks down.

Thus, our model can be seen as reconciliation of the three classical models of Stigler, Rotemberg and Saloner, and Green and Porter. We conclude that these models do not necessarily represent opposing views, but rather complement each other, and each view has its own consistent logic that indeed applies under different, mutually exclusive, conditions within our model.

\subsection{Appendix}

In this appendix we provide a sketch of the proof of Lemma 2.3.2. It is well known that stochastic dominance implies the following statement for monotone transformations of $\varphi_{i t+1}$.

Lemma 2.7.1. Let $g\left(\varphi_{i t+1}\right) \geq 0$ be (strictly) increasing in $\varphi_{i t+1}$. Then

$$
\mathbb{E}\left(g \mid \varphi_{i t}\right)=\int g\left(\varphi_{i t+1}\right) \cdot f_{i t+1}\left(\varphi_{i t+1} \mid \varphi_{i t}\right) d \varphi_{i t+1}
$$

is (strictly) increasing in $\varphi_{i t}$.

Now write

$$
\mathbb{E}\left(\varphi_{i t+1} \mid \varphi_{i t}\right)=\int \varphi_{i t+1} \cdot f_{i t+1}\left(\varphi_{i t+1} \mid \varphi_{i t}\right) d \varphi_{i t+1} .
$$

By the previous Lemma, $\mathbb{E}\left(\varphi_{i t+1} \mid \varphi_{i t}\right)$ is a strictly increasing function of $\varphi_{i t}$. Thus, iterating the same argument, also

$$
\mathbb{E}\left(\varphi_{i t+2} \mid \varphi_{i t}\right)=\mathbb{E}\left(\mathbb{E}\left(\varphi_{i t+2} \mid \varphi_{i t+1}\right) \mid \varphi_{i t}\right)
$$


is a strictly increasing function of $\varphi_{i t}$. In general we find that $\mathbb{E}\left(\varphi_{i t+k} \mid \varphi_{i t}\right)$ is increasing in $\varphi_{i t}$ for any $k \leq 1$. This shows Lemma 2.3.2.

The above equation

$$
\mathbb{E}\left(\varphi_{i t+2} \mid \varphi_{i t}\right)=\mathbb{E}\left(\mathbb{E}\left(\varphi_{i t+2} \mid \varphi_{i t+1}\right) \mid \varphi_{i t}\right) .
$$

that we used to derive Lemma 2.3.2 is not a definition, it is in fact a result. In order to see why this result is true it is convenient to derive the above equation for a discrete process. Let $M_{1}, M_{2}$ and $M_{3}$ be three finite sets. Suppose we have transition probabilities $P\left(m_{2} \mid m_{1}\right)$ and $P\left(m_{3} \mid m_{2}\right)$ for all $m_{1} \in M_{1}, m_{2} \in M_{2}$, and $m_{3} \in M_{3}$. Then

$$
P\left(m_{3} \mid m_{1}\right)=\sum_{m_{2}} P\left(m_{2} \mid m_{1}\right) \cdot P\left(m_{3} \mid m_{2}\right) .
$$

So,

$$
\begin{aligned}
\mathbb{E}\left(m_{3} \mid m_{1}\right) & =\sum_{m_{3}} P\left(m_{3} \mid m_{1}\right) \cdot m_{3} \\
& =\sum_{m_{3}} \sum_{m_{2}} P\left(m_{2} \mid m_{1}\right) \cdot P\left(m_{3} \mid m_{2}\right) \cdot m_{3} \\
& =\sum_{m_{2}}\left[\sum_{m_{3}} m_{3} \cdot P\left(m_{3} \mid m_{2}\right)\right] \cdot P\left(m_{2} \mid m_{1}\right) \\
& =\sum_{m_{2}} \mathbb{E}\left(m_{3} \mid m_{2}\right) \cdot P\left(m_{2} \mid m_{1}\right) \\
& =\mathbb{E}\left(\mathbb{E}\left(m_{3} \mid m_{2}\right) \mid m_{1}\right) .
\end{aligned}
$$

The equation we used above to compute $\mathbb{E}\left(\varphi_{i t+2} \mid \varphi_{i t}\right)$ is the continuous variant of the same result. The formula for the continuous case can be shown using the Theorem of Radon-Nikodym and Tonelli's Theorem. For further information we refer to Davidson (1994). 



\section{Chapter 3}

\section{Intentional Price Wars on the Equilibrium Path}

\subsection{Introduction}

A price war is one of the most extreme outcomes of price competition between oligopolists. ${ }^{1}$ Price wars are known to lead to erosion of revenues, profits, loss of innovative capabilities and even the collapse of entire industries (Rao, Bergen and Davis 2000). Equilibrium explanations provided by theoretical models have focused on fluctuations in market demand or, more generally, shocks to market characteristics. ${ }^{2}$ However, many price wars that can be observed in real life cannot be explained by symmetric models, as they are deliberately initiated by one particular firm, the price war leader. In this chapter, we therefore analyze such intentional price wars. An episode of low prices classifies as an intentional price war if it follows a period of high prices which was ended intentionally by one of the firms in the market (the price war leader). To provide a rational explanation for why this type of price war is observed, we show that for intentional price wars to exist on the equilibrium path, two elements are essential in the information on which firms base their decisions: (1) interperiod fluctuations and (2) asymmetries. We illustrate this by means of a model in which price wars of this type occur with certainty on the equilibrium path.

A price war is, as the name already suggests, a period of conflict, poten-

\footnotetext{
${ }^{1}$ This chapter is based on Pot, Peeters, Peters and Vermeulen (2008).

${ }^{2} C f$. Heil and Helsen (2001) for an overview of theoretical and empirical literature on price wars.
} 
tially leading to disastrous effects to firms and industries as a whole. Although it is arguably possible that parties in conflict are thrown into a price war without their consent, in reality we can observe price wars that were deliberately initiated by one of the firms in the market. The next examples show that intentional price wars take place and can have severe effects.

In 1992, a fierce price war on bus services between New York City and Washington DC was initiated by Peter Pan Trailways, after acquiring a Washington DC terminal. ${ }^{3}$ Peter Pan lowered their initial fare of $\$ 25$ to $\$ 9.95$, to "turn some heads". Their main rival, Greyhound, responded by cutting their fare to $\$ 7$, after which Peter Pan lowered their fare to $\$ 6.95$. Greyhound once more responded with a fare cut to $\$ 5$, which Peter Pan then matched, resulting in both firms operating below cost price.

In October 2003, Dutch multinational company Ahold decided to lower the prices of 1000 products in all branches of its supermarket chain Albert Heijn to regain its lost reputation and market share that it had suffered because of accounting scandals and other bad publicity the year before. Since this price drop was responded to by a similar lowering of prices by their competitors in the market, this marked the beginning of a price war which continued intensely for a few years, resulting in a combined net loss of revenue of around $€ 18$ million a week at the end of November 2003. ${ }^{4}$ In April 2005 , it was estimated that there had been a total loss of revenue in the Dutch food industry of $€ 1.7$ billion, of which half had directly influenced profits. ${ }^{5}$

More examples of intentional price wars in the airline industry are presented by Busse (2002), who empirically analyzes the question whether a firm is likely to intentionally start a price war because of its financial situation. Busse finds that the firm's individual situation plays an important role in its decision to intentionally start a price war, in line with industry insiders, who "identify the financial troubles of an individual carrier as an important motivation in initiating the fare cuts that trigger price wars". Busse mentions that this aspect is often ignored by existing models of oligopolistic competition that provide explanations for price wars.

Existing theoretical literature that explains the emergence of price wars

\footnotetext{
3 http://www.nytimes.com/1992/08/08/business/new-yorkwashington-5-is-cheaper-fare-since-1952.html?pagewanted=1

$4_{\text {http: //www.rtl.nl/ (/financien/rtlz/nieuws/)/components/ }}$ financien/rtlz/2003/11_november/25-supermarkt_omzet_lager.xml

$5_{\text {http }}$ ///www.elsevier.nl/web/Nieuws/Economie/29348/ Duizenden-banen-weg-door-prijzenoorlog.htm
} 
usually analyzes a variation on the oligopoly model introduced by Friedman (1971). Firms repeatedly face a trade-off between collusive or aggressive behavior. Undercutting colluding opponents gives the deviator an immediate profit increase. However, this is followed by a punishment by the rivals in the form of pricing according to the one-shot game Nash equilibrium, which decreases long-run profits, relative to the collusive situation.

Realizing that a shock to the system is necessary to make firms switch from a high price to a low price regime, more elaborate models were developed in which firms face changing circumstances due to, for example, fluctuating market demand. In a branch of literature started by Green and Porter (1984), firms cannot directly observe their opponents' behavior. A drop in one's own performance may be interpreted as being caused by a secret deviation from collusive behavior by one of the opponents, even though it also might be caused by a decrease in market demand. On the equilibrium path, price wars only occur because of decreased market demand and never as a result of a deviation. The second category of literature focuses on price wars in periods when market demand is such that deviation is most profitable: during booms. Rotemberg and Saloner (1986) show that when market demand is high, prices go down to counterbalance the increased incentive to deviate. ${ }^{6}$ Another type of variation is to introduce capacity setting or capacity constraints. An important contribution of this type is Staiger and Wolak (1992), who introduce a capacity-setting stage at the beginning of each period in a model based on that of Rotemberg and Saloner. This paper shows that when demand is low, and capacity is unused, a price war is most likely. ${ }^{7}$ These papers have all contributed to a better understanding of the dilemmas faced by firms when deciding to price high or low. However, because of their symmetric nature, they cannot predict which firm is likely to deviate (first) in equilibrium strategies. In equilibrium, firms either deviate jointly and simultaneously, or no firm deviates at all.

We can characterize an oligopolistic situation by the incentive situation the firms face, which is represented by the information a firm possesses at the moment decisions have to be made. In Friedman's model, information

\footnotetext{
${ }^{6}$ The model was later extended in various ways (see for instance Kandori (1991), Haltiwanger and Harrington (1991) and Bagwell and Staiger (1997)).

${ }^{7}$ While the above strands of literature focus on the impact of changing market conditions, an important contribution by Athey, Bagwell and Sanchirico (2004) investigates the impact of private cost shocks on the stability of collusion. Although their focus is on collusive, rigid pricing schemes without price wars, their model does satisfy the conditions under which intentional price wars could be found in equilibrium strategies.
} 
Chapter 3. Intentional Price Wars on the Equilibrium Path

never changes. If firms repeatedly face the same situation, their decision will always be the same: they either collude or not, as deviation will either always be found profitable or never be found profitable. No price war will thus be possible on the equilibrium path, as there will never be a switch from periods with high prices to periods with lower prices. In order for such distinct episodes of high and low prices to occur, we may introduce shocks to the information firms receive. It is then possible that there are periods in which firms find it in their best interest to collude and later periods in which at least one of the firms finds it optimal to deviate. This change in the firms' information situation is what causes price wars on the equilibrium path. If a firm's information is such that it induces a decision to deviate from collusion, this firm is a candidate to be price war leader. However, if all firms face the same - albeit fluctuating - information (i.e., information is symmetric), intentional price wars on the equilibrium path are still unlikely. If firms receive the same information as all the other firms, they could predict whether there exists a firm that on the basis of that information prefers to deviate. If this is the case, the others can jointly reduce the incentive to deviate by decreasing the collusive price. We would thus observe adaptive pricing like in Rotemberg and Saloner. If such an adaptation is impossible, we would see a simultaneous deviation by all firms in the market (if you know a firm will undercut, it is better to undercut yourself), which implies that no price war leader is present. However, if firms do not observe whether or not one of their rivals has an incentive to deviate (i.e., information is asymmetric), they cannot jointly adapt their strategies to it and it would be impossible to prevent a price war which is started by a firm that, on the basis of its private information, prefers to undercut. Thus, for a model to be able to explain intentional price wars in equilibrium, firms need to have fluctuating asymmetric information. We present a model that includes such features, and show that in such a model intentional price wars can occur in equilibrium.

\subsection{Model}

The model is based on Pot, Peeters, Peters and Vermeulen (2008) and chapter 2 of this thesis. ${ }^{8}$ Changing information comes in the form of fluctuating market shares. The level of information firms have depends on whether they

\footnotetext{
${ }^{8}$ Although this chapter employs a similar model to the one used in chapter 2 to analyze collusive stability, in the current chapter it is used to focus on the possibility of price wars on the equilibrium path.
} 
are able to observe all realized market shares or only their own, before making their respective decisions. This way, we are able to study the effects of symmetric and asymmetric fluctuating information.

\subsubsection{The one-shot game}

In our model, $n$ firms compete on price. To keep things tractable, we focus on the three relevant types of actions, namely collude $(C)$, undercut $(U)$, or price at marginal cost $(M)$. Thus, firms simultaneously choose an action $a_{i} \epsilon$ $\{C, M, U\}$. When firms divide the market, a vector $\varphi=\left(\varphi_{1}, \ldots, \varphi_{n}\right)$ of market shares denotes the market share distribution, where $\varphi_{i} \geq 0$ represents the market share of firm $i$. Market shares divide the total market, so $\sum_{i} \varphi_{i}=1$ and we assume that each $\varphi_{t}=\left(\varphi_{1 t}, \varphi_{2 t}, \cdots, \varphi_{n t}\right)$ is drawn from a uniform and i.i.d. distribution. This implies that tomorrow's market share division is independent of today's.

Given the action profile $a=\left(a_{i}\right)_{i \in N}$, each firm $i$ 's profit is denoted by $\Pi_{i}(a)$. By $\Pi$, we denote the highest attainable (monopoly) profit in the market. When $a_{i}=C$ for all $i$, then $\Pi_{i}(a)=\varphi_{i} \Pi$, as the firms divide this monopoly profit according to their market shares. For simplicity, we assume that undercutting is only profitable when it is done unilaterally. Thus, when there is a firm $k$ with $a_{k}=U$ and $a_{i}=C$ for all $i \neq k$, then $\Pi_{k}(a)=\Pi$ and $\Pi_{i}(a)=0$ for all $i \neq k$. In all other cases all profits are zero.

\subsubsection{The repeated game}

We are primarily interested in the occurrence of (intentional) price wars when firms repeat this one-shot game infinitely often. The timing in each period is modeled as follows. At the start of each period $t=0,1,2, \ldots$ the vector $\varphi_{t}=\left(\varphi_{1 t}, \ldots, \varphi_{n t}\right)$ of market shares is determined. Next, each firm receives information $h_{i t}$, which includes all realized market shares and all actions taken in all periods, and either a firm's own market share in the current period (private information), or all realized market shares in the current period (public information). At the beginning of the game, the initial division of market shares is given by $\varphi_{0}=\left(\varphi_{10}, \ldots, \varphi_{n 0}\right)$ and the associated information to the firms is denoted by $h_{0}=\left(h_{10}, \ldots, h_{n 0}\right)$.

We write $s\left(h_{t}\right)=\left(s_{1}\left(h_{1 t}\right), \ldots, s_{n}\left(h_{n t}\right)\right)$ for the profile of actions that is played at time $t$ given the information $h_{t}=\left(h_{1 t}, \ldots, h_{n t}\right)$. Let $s^{t}$ denote the map $h_{t} \mapsto s\left(h_{t}\right)$. By $\mathbb{E}\left(\Pi_{i}\left(s^{t}\right) \mid h_{i 0}\right)$ we denote the expected value of the profit 
Chapter 3. Intentional Price Wars on the Equilibrium Path

to firm $i$ at time $t$, given the strategy profile $s$ and the initial information $h_{i 0}$ of firm $i$.

Analogously, let $\mathbb{E}\left(\Pi_{i}\left(s^{t+k}\right) \mid h_{i t}\right)$ denote the expected value of the profit of firm $i$ at time $t+k$, given the strategy profile $s$ and information $h_{i t}$ to firm $i$ at time $t$. Write

$$
\Pi_{i}\left(s \mid h_{i t}\right)=\sum_{k=0}^{\infty} \delta^{k} \cdot \mathbb{E}\left(\Pi_{i}\left(s^{t+k}\right) \mid h_{i t}\right)
$$

for the present value of the stream of profits to firm $i$ at information set $h_{i t}$. A strategy profile $s$ is a perfect Bayesian Nash equilibrium when, at every information set $h_{i t}$,

$$
\Pi_{i}\left(s \mid h_{i t}\right) \geq \Pi_{i}\left(\left(s, s_{i}^{\prime}\right) \mid h_{i t}\right)
$$

holds for every strategy $s_{i}^{\prime}$ of firm $i$.

\subsubsection{Incentives and strategies}

The model presented above incorporates changing information which influences the incentives to collude or deviate. Clearly, these fluctuations can have an effect on the firms' behavior. Suppose the firms are in a collusive phase, but the realized market share division results in a very low level of demand for one of the firms in the market. That firm does not benefit much from collusion in that period as it will get only a small share of the total collusive profit. However, by undercutting the firm can try to capture the entire market. Compared to a situation in which market shares are symmetric, the firm thus has more to gain from successful undercutting of the rivals' collusive price. In other words, the changing individual situation causes that sometimes collusion is no longer rewarding enough for the firms to continue.

Since we are looking for intentional price wars on the equilibrium path, we need to define what type of strategy in our game corresponds to the definition of an intentional price wars we provided. Since a price war leader should be identifiable, the individual fluctuations should be critical in determining whether a firm starts a price war or not. In this model, these individual fluctuations are related to the market share, and as we have argued, if the market share is low, it is relatively more profitable to deviate. A sensible strategy should therefore prescribe to collude as long as firms receive information that their individual demand (market share) is high, and to deviate (start a price war) when individual demand is sufficiently low. Thus, a strategy giving rise to intentional price wars is essentially quasi-collusive and should look as follows: 
Definition 3.2.1. Let $\widetilde{\varphi} \leq \frac{1}{n}$. The quasi-collusive strategy $Q_{i}$ (with threshold level $\widetilde{\varphi}$ ) of firm $i$ is defined by

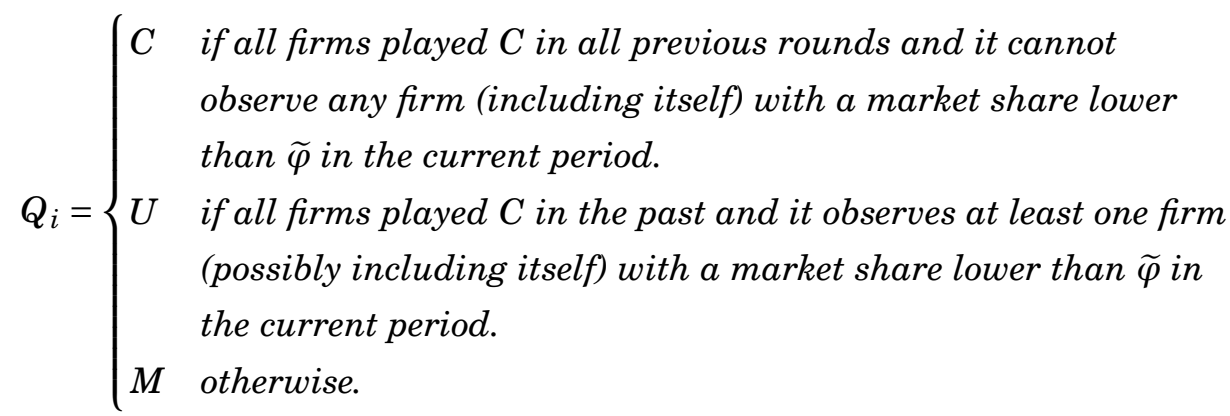

In this definition, we denote by $\widetilde{\varphi}$ the minimum market share (endogenous to the strategy) at which a firm is still willing to continue collusion. We write $Q=\left(Q_{i}\right)_{i \in N}$ for the profile of quasi-collusive strategies. ${ }^{9}$

\subsection{Results}

In this section, we present results on when the profile of quasi-collusive strategies constitutes a perfect Bayesian Nash equilibrium. In particular, we investigate when these strategies give rise to (intentional) price wars in this model. To illustrate the importance of information, we first look at the situation where the information a firm receives at the beginning of each period includes all firms' market share realizations (public information). This situation resembles existing literature on price wars in its results. We demonstrate the link with the results from Green and Porter (1984), Rotemberg and Saloner (1986) and Staiger and Wolak (1992). Subsequently, we show what happens when firms can only observe their own market share (private information) and we find that intentional price wars on the equilibrium path are possible. All proofs can be found in section 3.5.

\subsubsection{Market shares are public information}

First we analyze the case in which firms learn the entire realization of $\varphi_{t}$ at the beginning of period $t$. That is, $\varphi_{t}$ is included in $h_{i t}$ for all $i$ and $t$.

We would like to know if and when quasi-collusive strategy profile $Q$ is a perfect Bayesian Nash equilibrium. The next theorem shows the result.

\footnotetext{
${ }^{9}$ Assuming that the punishment phase lasts a finite number $T$ periods would only quantitatively change our results.
} 
Chapter 3. Intentional Price Wars on the Equilibrium Path

Theorem 3.3.1. The strategy profile $Q$ is a perfect Bayesian Nash equilibrium if and only if

$$
\widetilde{\varphi}+\frac{\delta(1-n \widetilde{\varphi})^{n-1}}{1-\delta(1-n \widetilde{\varphi})^{n-1}} \cdot \frac{1}{n} \geq 1
$$

The following corollary states for which discount factors there exists a strategy profile $Q$ that forms a perfect Bayesian Nash equilibrium.

Corollary 3.3.2. When $\delta<\frac{n}{n+1}$, there exists no $\widetilde{\varphi} \leq \frac{1}{n}$ for which the strategy profile $Q$ forms a perfect Bayesian Nash equilibrium. When $\delta=\frac{n}{n+1}, Q$ forms a perfect Bayesian Nash equilibrium precisely when $\widetilde{\varphi}=0$. When $\delta>\frac{n}{n+1}$, there exists a $\varphi^{*} \in\left[0, \frac{1}{n}\right]$, which is increasing in $\delta$, such that $Q$ forms a perfect Bayesian Nash equilibrium precisely when $\widetilde{\varphi} \in\left[0, \varphi^{*}\right]$.

This corollary shows that when the discount factor is sufficiently high, strategy profile $Q$ can be a perfect Bayesian Nash equilibrium. The minimum level of the market share at which firms still collude is bounded from above by a maximum level $\varphi^{*}$ which depends on the discount factor and from below by 0 . High prices will be visible as long as the market share realization is such that each firm has a market share above $\widetilde{\varphi}$. As soon as a realization occurs where this is no longer the case, however, all firms will observe this and, knowing that deviation is unavoidable, deviate themselves. This will occur with probability 1 in our model in the long run and causes prices to break down to marginal cost level.

These unavoidable episodes of low prices are no intentional price wars. Although they follow a period of high prices, they do not satisfy the criterion that a price war leader can be identified. They should therefore be seen as breakdowns of collusion similar to the price wars in Green and Porter (1984) and Staiger and Wolak (1992).

Furthermore, we know already from chapter 2 of this thesis that if firms have perfect information about the market shares of their opponents at the beginning of each period, an adaptive collusive strategy can also be an option. Such a strategy "adapts" the collusive price to the incentive situation of the worst-off firm, making it unprofitable to undercut. This type of strategy is comparable to the one we see in Rotemberg and Saloner (1986) and gives rise to periods of slightly lower prices, not classifiable as intentional price wars. 


\subsubsection{Market shares are private information}

We now turn to the case in which firms only observe their own market share at the beginning of the period. Formally, $\varphi_{i t}$ is part of $h_{i t}$ for all $i \in N$, but the vector $\varphi_{t}$ in its entirety is not. We show that the quasi-collusive strategy profile can be a perfect Bayesian Nash equilibrium. Because firms cannot observe their opponents' situations, this strategy profile gives rise to intentional price wars on the equilibrium path, as unilateral deviations then occur at some moment with certainty.

The next theorem indicates precisely when $Q$ constitutes a perfect Bayesian Nash equilibrium.

Theorem 3.3.3. If $\widetilde{\varphi}>0$, the strategy profile $Q$ is a perfect Bayesian Nash equilibrium precisely when

$$
\widetilde{\varphi}+\delta \cdot \frac{n \cdot(1-(n-1) \widetilde{\varphi})^{n-1}-(n-1) \cdot(1-n \widetilde{\varphi})^{n-1}}{n \cdot\left(1-\delta \cdot(1-n \widetilde{\varphi})^{n-1}\right)}=1 .
$$

If $\widetilde{\varphi}=0, Q$ is a perfect Bayesian Nash equilibrium precisely when $\delta \geq \frac{n}{n+1}$.

The following corollary states for which discount factors there exists a strategy profile $Q$ that forms a perfect Bayesian Nash equilibrium.

Corollary 3.3.4. When $\delta<\frac{n}{n+1}$, there exists no $\widetilde{\varphi}$ for which the quasi-collusive strategy profile $Q$ forms a perfect Bayesian Nash equilibrium. When $\delta=\frac{n}{n+1}$, $Q$ forms a perfect Bayesian Nash equilibrium precisely when $\widetilde{\varphi}=0$. When $\delta>\frac{n}{n+1}$, there are precisely two values of $\widetilde{\varphi}$ for which $Q$ forms a perfect Bayesian Nash equilibrium, namely $\widetilde{\varphi}=0$, and a unique solution $0<\widetilde{\varphi}<\frac{1}{n(n-1)}$ to the equation

$$
\varphi+\delta \cdot \frac{n \cdot(1-(n-1) \varphi)^{n-1}-(n-1) \cdot(1-n \varphi)^{n-1}}{n \cdot\left(1-\delta \cdot(1-n \varphi)^{n-1}\right)}=1 .
$$

This corollary shows that when the discount factor is sufficiently high, strategy profile $Q$ can be a perfect Bayesian Nash equilibrium, also when firms have private information. There are two types of equilibrium in quasicollusive strategies. First, the threshold level below which firms deviate can be 0 . In this case, deviation never takes place and this strategy can essentially be seen as fully collusive. Second, the minimum level of the market 
Chapter 3. Intentional Price Wars on the Equilibrium Path

share at which firms still collude can be strictly positive. High prices will be visible as long as the market share realization is such that each firm has a market share above $\widetilde{\varphi}$. However, as soon as a realization occurs where this is no longer the case, the firm which market share is lower than the threshold level deviates. This will occur with probability 1 in our model in the long run. Furthermore, as it cannot be observed by the rivals that the firm is in this position, it cannot be prevented.

The intuition why there are only two threshold levels that are possible in a perfect Bayesian Nash equilibrium (instead of the range of threshold levels when market shares are public information) is that when a firm has a market share below the threshold level which is unobservable to the other firms, the firm has the option to continue collusive play. The lower the threshold market share is, the larger the probability that the firm is the only one with a market share below the threshold level. Continuing collusion will then be more attractive. This creates an additional constraint to the equilibrium strategy and profit.

The realization of events when firms follow the quasi-collusive strategy profile $Q$ with threshold $\widetilde{\varphi}$ as in Corollary 3.3.4 is an example of an intentional price war. Low prices follow a period of high prices, as aggressive pricing only occurs when there is a market share realization which renders a sufficiently low market share for at least one of the firms. A price war leader can be identified, as undercutting will only be done by a firm with a sufficiently low market share. Moreover, undercutting is done to increase profits, as the strategy is part of a perfect Bayesian Nash equilibrium. As one can see from the strategy, both the fluctuating information on market shares and the fact that this information is private play a critical role in facilitating this type of price wars.

\subsection{Concluding remarks}

We argued that fluctuations and asymmetries in the firms' information are critical elements if we try to explain intentional price wars. The model we presented and its results support this. Note, however, that the way we chose to model asymmetric fluctuations in information is not the only possibility to represent such a situation. Another possibility is that the market characteristics are stable, but that firms in each period receive different (possibly false) signals about these characteristics.

We have argued that the information a firm possesses represents the 
3.4. Concluding remarks

decision problem a firm faces. There are various factors, both inside and outside of the firm's control, that influence the position of the firm. Reputation effects, changing loyalties or random behavior on part of the consumers could change the outcome of competition even though prices remain constant. Information the firm receives about these factors might therefore change over time and this could gradually or drastically change the firm's preferred course of action.

If we look at one of the examples of an intentional price war mentioned in the introduction, the Dutch supermarket price war, the price war leader suffered from a decreasing market share because of reputational problems. In press statements this was also indicated by the firm as the main reason for its aggressive pricing. Also in the New York - Washington fare war, a change in the individual situation seems to have triggered the price war. Acquiring the new terminal changed Peter Pan Trailways' individual situation in such a way that it deemed a price war more profitable than (continued) collusion. Finally, our results confirm the conclusion made in Busse (2002) that firms in an adverse individual (financial) situation are more likely to start a price war. In our model, this is represented by the bad collusive profit resulting from a low realized market share. To look at changes in the individual information situation thus seems appropriate when trying to explain intentional price wars.

We also show that this information should be asymmetric. If all firms would receive the same information, rival firms would either be able to decrease incentives to deviate or they would deviate en masse themselves. The condition of private, asymmetric information seems natural in real life. For any firm it can be argued that it might have a general idea about the situation its competitors face, but to always be able to determine whether it is in the best interest of the rival to continue collusion or to deviate seems unlikely. Especially regarding issues of financial stability, it seems hard to exactly determine the position of all rival firms without being able to see their (financial) accounts. It could be argued, though, that if firms have to make guesses about their competitors' situations, mutual distrust might cause firms to deviate even sooner than predicted in our model.

The results show a clear connection between collusion and price wars. Even though these two outcomes of price competition seem to be complete opposites, it is clear that in Bertrand-type models of oligopolistic competition the two phenomena are necessarily linked to enable the possibility of a switch between a period of high prices and one of low prices, the typical 
Chapter 3. Intentional Price Wars on the Equilibrium Path

characteristic of a price war. ${ }^{10}$ However, our results show a more subtle connection. A price war does not necessarily occur if collusion is not sustainable (at all). Instead, the possibility of intentional price wars actually depends on the prerequisite that the firms' discount factor is sufficiently high to sustain collusion. This is something which might be counterintuitive as high discount factors are usually associated with persisting high prices as a consequence of collusion. These results show that if we allow for a sensible element of selfishness to the usual trigger strategy (making the strategy essentially quasi-collusive), we find that when the discount factor is high, equilibria are possible in which with certainty an intentional price war occurs at some point. This questions the need for intervention in such markets.

\subsection{Proofs}

Before we present the proofs of the theorems and corollaries from the text, we derive three lemmas.

We first compute the probability of a market share realization such that no firm prefers undercutting to colluding.

Lemma 3.5.1. The probability that all firms have at least a market share of $\widetilde{\varphi} \leq \frac{1}{n}$ is equal to

$$
P^{+} \equiv \mathbb{P}\left[\varphi_{i t} \geq \widetilde{\varphi}, \forall i \in N\right]=(1-n \widetilde{\varphi})^{n-1} .
$$

Proof. Consider a standard $(n-1)$-dimensional simplex with vertices

$$
(1,0, \ldots, 0) ;(0,1, \ldots, 0) ; \ldots ;(0,0, \ldots, 1) \text {. }
$$

This simplex represents all possible market share realizations. The barycenter of this simplex is $\left(\frac{1}{n}, \frac{1}{n}, \ldots, \frac{1}{n}\right)$. The distance from the barycenter to a vertex equals

$$
\sqrt{(n-1)\left(\frac{1}{n}\right)^{2}+\left(\frac{1-n}{n}\right)^{2}}=\sqrt{\frac{n-1}{n}} .
$$

Now consider the $(n-1)$-dimensional simplex with vertices

$$
(1-(n-1) \widetilde{\varphi}, \widetilde{\varphi}, \ldots, \widetilde{\varphi}) ;(\widetilde{\varphi}, 1-(n-1) \widetilde{\varphi}, \ldots, \widetilde{\varphi}) ; \ldots ;(\widetilde{\varphi}, \widetilde{\varphi}, \ldots, 1-(n-1) \widetilde{\varphi}) .
$$

\footnotetext{
${ }^{10}$ For a model in which high and low prices occur naturally in competition, see Pot, Flesch, Peeters and Vermeulen (2009) and chapter 4 of this thesis.
} 
This simplex represents all possible market share realizations in which each firm has at least a market share of $\widetilde{\varphi}$ and has the barycenter at $\left(\frac{1}{n}, \frac{1}{n}, \ldots, \frac{1}{n}\right)$ as well. The distance from the barycenter to a vertex of this simplex is

$$
\sqrt{(n-1)\left(\frac{1}{n}-\widetilde{\varphi}\right)^{2}+\left(\frac{1}{n}-(1-(n-1) \widetilde{\varphi})\right)^{2}}=(1-n \widetilde{\varphi}) \sqrt{\frac{n-1}{n}} .
$$

As the simplex has $(n-1)$ dimensions, the volume of the second simplex is $(1-n \widetilde{\varphi})^{n-1}$ times the volume of the first one.

We write $P_{i t}$ for the probability that $\varphi_{j t} \geq \widetilde{\varphi}$ for all $j \neq i$ given $\varphi_{i t}$. The following lemma specifies $P_{i t}$ for general $\varphi_{i t}$ and $\widetilde{\varphi}$.

Lemma 3.5.2. Let $\widehat{\varphi}=1-(n-1) \widetilde{\varphi}$ and suppose that $\varphi_{i t} \leq \widehat{\varphi}$. Then, given $\varphi_{i t}$,

$$
P_{i t}=\left(1-\frac{(n-1) \widetilde{\varphi}}{1-\varphi_{i t}}\right)^{n-2} \text {. }
$$

Proof. Consider an $(n-1)$-dimensional simplex with vertices

$$
\left(\varphi_{i t}, 1-\varphi_{i t}, 0, \ldots, 0\right) ;\left(\varphi_{i t}, 0,1-\varphi_{i t}, \ldots, 0\right) ; \ldots ;\left(\varphi_{i t}, 0,0, \ldots, 1-\varphi_{i t}\right) .
$$

This simplex represents all possible market share realizations in which the first firm has a market share of $\varphi_{i t}$. The barycenter of this simplex is $\left(\varphi_{i t}, \frac{1-\varphi_{i t}}{n-1}, \ldots, \frac{1-\varphi_{i t}}{n-1}\right)$. The distance from the barycenter to a vertex is

$$
\sqrt{(n-2)\left(\frac{1-\varphi_{i t}}{n-1}\right)^{2}+\left(\frac{1-\varphi_{i t}}{n-1}-\left(1-\varphi_{i t}\right)\right)^{2}}=\sqrt{\frac{(n-2)\left(\varphi_{i t}-1\right)^{2}}{n-1}} .
$$

Now consider the $(n-1)$-dimensional simplex with vertices

$$
\left(\varphi_{i t}, 1-\varphi_{i t}-(n-2) \widetilde{\varphi}, \widetilde{\varphi}, \ldots, \widetilde{\varphi}\right) ; \ldots \ldots ;\left(\varphi_{i t}, \widetilde{\varphi}, \widetilde{\varphi}, \ldots, 1-\varphi_{i t}-(n-2) \widetilde{\varphi}\right) .
$$

This simplex represents all possible market share realizations in which the first firm has market share $\varphi_{i t}$ and all other firms have at least a market share of $\widetilde{\varphi}$. The barycenter of this simplex is also at $\left(\varphi_{i t}, \frac{1-\varphi_{i t}}{n-1}, \ldots, \frac{1-\varphi_{i t}}{n-1}\right)$. Straightforward calculation shows that the distance from the barycenter to a vertex of this simplex is

$$
\left(1-\frac{(n-1) \widetilde{\varphi}}{1-\varphi_{i t}}\right) \sqrt{\frac{(n-2)\left(\varphi_{i t}-1\right)^{2}}{n-1}} .
$$

As the simplices differ in $(n-2)$ dimensions, the volume of the second simplex is $\left(1-\frac{(n-1) \widetilde{\varphi}}{1-\varphi_{i t}}\right)^{n-2}$ times the volume of the first one.

The next lemma shows the cumulative distribution of a firm's market share $\varphi_{i t}$. 
Chapter 3. Intentional Price Wars on the Equilibrium Path

Lemma 3.5.3. The cumulative distribution function of $\varphi_{i t}$ is

$$
F\left(\varphi_{i t}\right)=1-\left(1-\varphi_{i t}\right)^{n-1} \text {. }
$$

Proof. Consider the standard $(n-1)$-dimensional simplex with vertices

$$
(1,0, \ldots, 0) ;(0,1, \ldots, 0) ; \ldots ;(0,0, \ldots, 1) .
$$

If we intersect this simplex by the halfspace $\varphi_{i} \geq \varphi^{*}$ we get a smaller simplex of dimension $(n-1)$. Multiplication by a factor of $\frac{1}{1-\varphi^{*}}$ using the $i^{t h}$ unit vector as the origin transforms the smaller simplex into the larger one. Thus, because these simplices have $(n-1)$ dimensions, the volume of the second simplex is $\left(1-\varphi^{*}\right)^{n-1}$ times the first one. Hence, since the value $F\left(\varphi^{*}\right)$ of the cumulative distribution function evaluated at $\varphi_{i}=\varphi^{*}$ equals 1 minus the probability of the smaller simplex, we find that $F\left(\varphi_{i}\right)=1-\left(1-\varphi_{i t}\right)^{n-1}$.

Proof of Theorem 3.3.1. $\quad$ Let $\Phi$ denote the set of market share realizations with $\varphi_{i} \geq \widetilde{\varphi}$ for all firms $i \in N$. Due to the one deviation property, the quasi-collusive strategy profile is a perfect Bayesian Nash equilibrium exactly when every firm $i$, at every time $t$, and at every information set $h_{i t}$ the quasi-collusive strategy yields at least the same expected profit as an instantaneous deviation. Thus, consider firm $i$, at time $t$, at information set $h_{i t}$. Let $\mathbb{E}\left[Q \mid h_{i t}\right]$ denote the expected profit of following the quasi-collusive strategy, and $\mathbb{E}\left[D \mid h_{i t}\right]$ the expected profit of an instantaneous optimal deviation, both given market share vector $\varphi_{t}$ and given that the opponents play according to $Q$. We need to analyze two separate situations.

A. $\varphi_{t} \notin \Phi$. Given that the opponents play $M$ forever according to $Q$, firm $i$ will get an expected profit of 0 , no matter what its strategy is. The equilibrium condition

$$
\mathbb{E}\left[Q \mid h_{i t}\right] \geq \mathbb{E}\left[D \mid h_{i t}\right]
$$

is therefore trivially satisfied in this case.

B. $\varphi_{t} \in \Phi$. Deviation from $Q$ will yield a one-period monopoly profit after which profits will be equal to 0 . Therefore $\mathbb{E}\left[D \mid \varphi_{t} \in \Phi\right]=\Pi$. On the other hand the expected profit of following $Q$ is equal to

$$
\begin{aligned}
\mathbb{E}\left[Q \mid \varphi_{t} \in \Phi\right]=\varphi_{i t} \Pi & +\delta \mathbb{P}\left[\varphi_{t+1} \notin \Phi\right] \cdot \mathbb{E}\left[Q \mid \varphi_{t+1} \notin \Phi\right] \\
& +\delta \mathbb{P}\left[\varphi_{t+1} \in \Phi\right] \cdot \mathbb{E}\left[Q \mid \varphi_{t+1} \in \Phi\right] .
\end{aligned}
$$


According to Lemma 3.5.1, $\mathbb{P}\left[\varphi_{t+1} \in \Phi\right]=(1-n \widetilde{\varphi})^{n-1}$. Furthermore, $\mathbb{E}[Q \mid$ $\left.\varphi_{t+1} \notin \Phi\right]=0$. Since the expectation of future market shares and profit is independent from the current situation, $\mathbb{E}\left[Q \mid \varphi_{t+k} \in \Phi\right]$ is constant for any $k \geq 1$ and equal to

$$
\frac{1}{n} \cdot \frac{\Pi}{1-\delta(1-n \widetilde{\varphi})^{n-1}} .
$$

Substitution and rewriting yields

$$
\mathbb{E}\left[Q \mid \varphi_{t} \in \Phi\right]=\left(\varphi_{i t}+\frac{\delta(1-n \widetilde{\varphi})^{n-1}}{1-\delta(1-n \widetilde{\varphi})^{n-1}} \cdot \frac{1}{n}\right) \Pi .
$$

The equilibrium condition $\mathbb{E}\left[Q \mid \varphi_{t} \in \Phi\right] \geq \mathbb{E}\left[D \mid \varphi_{t} \in \Phi\right]$ is thus satisfied when

$$
\left(\varphi_{i t}+\frac{\delta(1-n \widetilde{\varphi})^{n-1}}{1-\delta(1-n \widetilde{\varphi})^{n-1}} \cdot \frac{1}{n}\right) \geq 1 .
$$

Finally notice that the left-hand side of the above inequality is increasing in $\varphi_{i t}$. Since the condition should hold for all possible $\varphi_{i t}$ with $\varphi_{t} \in \Phi$, it suffices to require that the inequality holds for $\varphi_{i t}=\widetilde{\varphi}$.

Proof of Corollary 3.3.2. Consider the function

$$
f(\varphi)=1-\frac{\delta(1-n \varphi)^{n-1}}{1-\delta(1-n \varphi)^{n-1}} \cdot \frac{1}{n}
$$

on the domain $\left[0, \frac{1}{n}\right]$. From Theorem 3.3.1 we know that $Q$ is an equilibrium precisely when $\widetilde{\varphi} \geq f(\widetilde{\varphi})$. We check when this condition is satisfied.

Since $f$ is strictly increasing and concave on its domain, and since $f\left(\frac{1}{n}\right)>$ $\frac{1}{n}$, if $f(\widetilde{\varphi}) \geq \widetilde{\varphi}$, then $f(\varphi)>\varphi$ for all $\varphi \in\left(\widetilde{\varphi}, \frac{1}{n}\right]$. Thus, the set of $\varphi$ with $\varphi \geq f(\varphi)$ is of the form $\left[0, \varphi^{*}\right]$ (possibly empty) for some $\varphi^{*}$.

If $\delta<\frac{n}{n+1}$, then $f(0)>0$. Thus there are no $\varphi$ with $\varphi \geq f(\varphi)$.

If $\delta=\frac{n}{n+1}$, then $f(0)=0$, and $\varphi \geq f(\varphi)$ only holds for $\varphi=0$.

If $\delta>\frac{n}{n+1}$, then $f(0)<0$, and by the Intermediate Value Theorem there exists a point $\varphi^{*}$ with $f\left(\varphi^{*}\right)=\varphi^{*}$. Since $f$ is strictly increasing and concave, this point $\varphi^{*}$ is unique, and the set $\left[0, \varphi^{*}\right]$ is exactly the set of solutions $\varphi$ of the inequality $\varphi \geq f(\varphi)$.

Proof of Theorem 3.3.3. We use the following notation. Let $\widehat{\varphi}=1-(n-$ 1) $\widetilde{\varphi}$. We write $P_{i t}$ for the probability that $\varphi_{j t} \geq \widetilde{\varphi}$ for all $j \neq i$ given $\varphi_{i t}$. Note that, when $\varphi_{i t}>\widehat{\varphi}$, we have at least one firm $j \neq i$ with $\varphi_{j t}<\widetilde{\varphi}$. Hence, $P_{i t}=0$ in that case. 
Chapter 3. Intentional Price Wars on the Equilibrium Path

Due to the one deviation property, the quasi-collusive strategy profile is a perfect Bayesian Nash equilibrium exactly when every firm $i$, at every time $t$, and at every information set $h_{i t}$ the quasi-collusive strategy yields at least the same expected profit as an instantaneous deviation. Thus, consider firm $i$, at time $t$, having a market share $\varphi_{i t}$. Let $\mathbb{E}\left[Q \mid \varphi_{i t}\right]$ denote the expected profit of following the quasi-collusive strategy, and $\mathbb{E}\left[D \mid \varphi_{i t}\right]$ the expected profit of an instantaneous optimal deviation, both given information set $h_{i t}$ and given that the opponents play according to $Q$. We analyze three separate situations, A, B and C.

A. $\varphi_{i t}>\widehat{\varphi}$. In this case, according to $Q$, there will be at least one opponent playing $U$ in the next period, after which $M$ will be played forever. Thus, firm $i$ will get an expected profit of 0 , no matter what its strategy is. Hence in this case, $\mathbb{E}\left[Q \mid \varphi_{i t}\right]=0=\mathbb{E}\left[D \mid \varphi_{i t}\right]$, and the equilibrium condition $\mathbb{E}\left[Q \mid \varphi_{i t}\right] \geq \mathbb{E}\left[D \mid \varphi_{i t}\right]$ is trivially satisfied.

Cases $\mathrm{B}$ and $\mathrm{C}$ require more attention. We start with deriving expressions for both expected profits $\mathbb{E}\left[D \mid \varphi_{i t}\right]$ and $\mathbb{E}\left[Q \mid \varphi_{i t}\right]$ for the these two cases.

B. $\widetilde{\varphi} \leq \varphi_{i t} \leq \widehat{\varphi}$. In this situation, deviation from $Q$ will yield a oneperiod profit of $\Pi$, provided there is no firm with a market share less than $\widetilde{\varphi}$, after which the firm will receive a profit of 0 infinitely. Thus we find that

$$
\mathbb{E}\left[D \mid \varphi_{i t}\right]=P_{i t} \cdot \Pi \text {. }
$$

Following $Q$ yields an expected profit $\mathbb{E}\left[Q \mid \varphi_{i t}\right]$ equal to

$$
\begin{aligned}
P_{i t} \cdot \varphi_{i t} \cdot \Pi & +\delta \cdot P_{i t} \cdot \mathbb{P}\left[\varphi_{i t+1}<\widetilde{\varphi}\right] \cdot \mathbb{E}\left[Q \mid \varphi_{i t+1}<\widetilde{\varphi}\right] \\
& +\delta \cdot P_{i t} \cdot \mathbb{P}\left[\widetilde{\varphi} \leq \varphi_{i t+1} \leq \widehat{\varphi}\right] \cdot \mathbb{E}\left[Q \mid \widetilde{\varphi} \leq \varphi_{i t+1} \leq \widehat{\varphi}\right] .
\end{aligned}
$$

We write

$$
\mathbb{E}\left[Q \mid \varphi_{i t}\right]=P_{i t} \cdot\left(\varphi_{i t} \cdot \Pi+Y\right)
$$

with

$Y=\delta \cdot \mathbb{P}\left[\varphi_{i t+1}<\widetilde{\varphi}\right] \cdot \mathbb{E}\left[Q \mid \varphi_{i t+1}<\widetilde{\varphi}\right]+\delta \cdot \mathbb{P}\left[\widetilde{\varphi} \leq \varphi_{i t+1} \leq \widehat{\varphi}\right] \cdot \mathbb{E}\left[Q \mid \widetilde{\varphi} \leq \varphi_{i t+1} \leq \widehat{\varphi}\right]$.

C. $\varphi_{i t}<\widetilde{\varphi}$. The optimal deviation from $Q$ in this case is playing $C$. Playing $C$ ensures continuation of collusion, provided no other firm plays $U$ in the next period. Therefore, using the same reasoning as above, we find that in this case

$$
\mathbb{E}\left[D \mid \varphi_{i t}\right]=P_{i t} \cdot\left(\varphi_{i t} \cdot \Pi+Y\right) .
$$


Following $Q$ in this case, and thereby attracting the entire market for one period unless there is also another deviator, yields, as it does for $\mathbb{E}\left[D \mid \varphi_{i t}\right]$ in case $\mathrm{A}$,

$$
\mathbb{E}\left[Q \mid \varphi_{i t}\right]=P_{i t} \cdot \Pi \text {. }
$$

We have derived expressions for $\mathbb{E}\left[D \mid \varphi_{i t}\right]$ and $\mathbb{E}\left[Q \mid \varphi_{i t}\right]$ for both cases. Notice that the expression $P_{i t} \cdot \Pi$ equals $\mathbb{E}\left[D \mid \varphi_{i t}\right]$ in case $\mathrm{B}$ and $\mathbb{E}\left[Q \mid \varphi_{i t}\right]$ in case C. The expression $P_{i t} \cdot\left(\varphi_{i t} \cdot \Pi+Y\right)$ equals $\mathbb{E}\left[D \mid \varphi_{i t}\right]$ in case $\mathrm{C}$ and $\mathbb{E}\left[Q \mid \varphi_{i t}\right]$ in case B. Thus, we get two conditions:

$$
\begin{aligned}
& \varphi_{i t} \cdot \Pi+Y \geq \Pi \text { when } \widetilde{\varphi} \leq \varphi_{i t} \leq \widehat{\varphi}, \text { and } \\
& \varphi_{i t} \cdot \Pi+Y \leq \Pi \text { when } \varphi_{i t}<\widetilde{\varphi} .
\end{aligned}
$$

$\Pi$ is a constant, while $\varphi_{i t} \cdot \Pi+Y$ is linearly increasing in $\varphi_{i t}$. Therefore, since $P_{i t}$ is non-negative and continuous in $\varphi_{i t}$, we can deduce that the equilibrium condition

$$
\mathbb{E}\left[Q \mid \varphi_{i t}\right] \geq \mathbb{E}\left[D \mid \varphi_{i t}\right] \quad \text { for all } \varphi_{i t}
$$

is equivalent to the requirement that

$$
\mathbb{E}\left[Q \mid \varphi_{i t}=\widetilde{\varphi}\right]=\mathbb{E}\left[D \mid \varphi_{i t}=\widetilde{\varphi}\right] .
$$

This equality boils down to the equation

$$
\widetilde{\varphi} \cdot \Pi+Y=\Pi \text {. }
$$

We compute $Y$ as follows. Write $V=\mathbb{E}\left[Q \mid \widetilde{\varphi} \leq \varphi_{i t} \leq \widehat{\varphi}\right]$ and $P_{1}=\mathbb{P}\left[\widetilde{\varphi} \leq \varphi_{i t+1} \leq\right.$ $\widehat{\varphi}]$. Then, since $\widehat{\varphi}=1-(n-1) \widetilde{\varphi}$,

$$
P_{1} \cdot V=\int_{\widetilde{\varphi}}^{1-(n-1) \widetilde{\varphi}} \mathbb{E}\left[Q \mid \varphi_{i t}\right] \cdot F^{\prime}\left(\varphi_{i t}\right) d \varphi_{i t},
$$

where $\mathbb{E}\left[Q \mid \varphi_{i t}\right]$ is given by the expression in case $\mathrm{B}$, and

$$
F^{\prime}\left(\varphi_{i t}\right)=(n-1) \cdot\left(1-\varphi_{i t}\right)^{n-2}
$$

is the density of the cumulative probability distribution in Lemma 3.5.3. Using the formula from Lemma 3.5.2 for $P_{i t}$ we find that the integrand is

$$
\mathbb{E}\left[Q \mid \varphi_{i t}\right] \cdot F^{\prime}\left(\varphi_{i t}\right)=(n-1) \cdot\left(1-(n-1) \widetilde{\varphi}-\varphi_{i t}\right)^{n-2} \cdot\left(\varphi_{i t} \cdot \Pi+Y\right) .
$$

Thus, computing the integral, we find that

$$
P_{1} \cdot V=(1-n \widetilde{\varphi})^{n-1} \cdot\left(\frac{\Pi}{n}+Y\right) .
$$


Chapter 3. Intentional Price Wars on the Equilibrium Path

We compute $Y$, using its definition in B. To do so, write $P_{2}=\mathbb{P}\left[\varphi_{i t+1}<\widetilde{\varphi}\right]$. Further, since $V$ does not depend on time, we can also write $V=\mathbb{E}[Q \mid \widetilde{\varphi} \leq$ $\left.\varphi_{i t+1} \leq \widehat{\varphi}\right]$. Using this notation, we have

$$
Y=\delta \cdot P_{2} \cdot \mathbb{E}\left[Q \mid \varphi_{i t+1}<\widetilde{\varphi}\right]+\delta \cdot P_{1} \cdot V .
$$

Combining this with the above expression for $P_{1} \cdot V$ we find that

$$
Y=\delta \cdot P_{2} \cdot \mathbb{E}\left[Q \mid \varphi_{i t+1}<\widetilde{\varphi}\right]+\delta \cdot(1-n \widetilde{\varphi})^{n-1} \cdot\left(\frac{\Pi}{n}+Y\right) .
$$

Solving for $Y$ yields

$$
\left(1-\delta \cdot(1-n \widetilde{\varphi})^{n-1}\right) \cdot Y=\frac{\delta \cdot(1-n \widetilde{\varphi})^{n-1} \cdot \Pi}{n}+\delta \cdot P_{2} \cdot \mathbb{E}\left[Q \mid \varphi_{i t+1}<\widetilde{\varphi}\right] .
$$

Thus,

$$
Y=\delta \cdot \frac{(1-n \widetilde{\varphi})^{n-1} \cdot \Pi+n \cdot P_{2} \cdot \mathbb{E}\left[Q \mid \varphi_{i t+1}<\widetilde{\varphi}\right]}{n \cdot\left(1-\delta \cdot(1-n \widetilde{\varphi})^{n-1}\right)} .
$$

Now we compute that

$$
\begin{aligned}
P_{2} \cdot \mathbb{E}\left[Q \mid \varphi_{i t+1}<\widetilde{\varphi}\right] & =\int_{0}^{\widetilde{\varphi}} \mathbb{E}\left[Q \mid \varphi_{i t}\right] \cdot F^{\prime}\left(\varphi_{i t}\right) d \varphi_{i t} \\
& =\int_{0}^{\widetilde{\varphi}} P_{i t} \cdot \Pi \cdot(n-1) \cdot\left(1-\varphi_{i t}\right)^{n-2} d \varphi_{i t} \\
& =\int_{0}^{\widetilde{\varphi}}\left(1-\frac{(n-1) \widetilde{\varphi}}{1-\varphi_{i t}}\right)^{n-2} \cdot \Pi \cdot(n-1) \cdot\left(1-\varphi_{i t}\right)^{n-2} d \varphi_{i t} \\
& =\int_{0}^{\widetilde{\varphi}}(n-1) \cdot \Pi \cdot\left(1-(n-1) \widetilde{\varphi}-\varphi_{i t}\right)^{n-2} d \varphi_{i t} \\
& =\Pi \cdot\left((1-(n-1) \widetilde{\varphi})^{n-1}-(1-n \widetilde{\varphi})^{n-1}\right)
\end{aligned}
$$

Substituting and rewriting yields

$$
Y=\delta \cdot \Pi \cdot \frac{n \cdot(1-(n-1) \widetilde{\varphi})^{n-1}-(n-1) \cdot(1-n \widetilde{\varphi})^{n-1}}{n \cdot\left(1-\delta \cdot(1-n \widetilde{\varphi})^{n-1}\right)}
$$

Substituting this expression for $Y$ into the equilibrium condition

$$
\widetilde{\varphi} \cdot \Pi+Y=\Pi
$$

yields

$$
\widetilde{\varphi}+\delta \cdot \frac{n \cdot(1-(n-1) \widetilde{\varphi})^{n-1}-(n-1) \cdot(1-n \widetilde{\varphi})^{n-1}}{n \cdot\left(1-\delta \cdot(1-n \widetilde{\varphi})^{n-1}\right)}=1
$$


Finally, if $\widetilde{\varphi}=0, \varphi_{i t}<\widetilde{\varphi}$ cannot occur. Hence, the equilibrium condition boils down to $\widetilde{\varphi} \cdot \Pi+Y \geq \Pi$. Substitution of $\widetilde{\varphi}=0$ and rewriting yields $\delta \geq \frac{n}{n+1}$.

Proof of Corollary 3.3.4. $\quad$ From Theorem 3.3.3 we already know that for every $\delta \geq \frac{n}{n+1}$ the strategy profile $Q$ is a Bayesian Nash equilibrium for $\widetilde{\varphi}=0$. Consider the function

$$
f(\varphi, \delta)=\delta \cdot \frac{T}{n \cdot\left(1-\delta \cdot(1-n \varphi)^{n-1}\right)}
$$

where $T=n \cdot(1-(n-1) \varphi)^{n-1}-(n-1) \cdot(1-n \varphi)^{n-1}$. From the equilibrium condition in Theorem 3.3.3 we know that $\varphi>0$ yields a Bayesian Nash equilibrium precisely when $f(\varphi, \delta)=1-\varphi$. We show that this equation has a unique solution on the interior of interval $\left[0, \frac{1}{n}\right]$ precisely when $\delta>\frac{n}{n+1}$.

First note that $f(0, \delta)=\frac{\delta}{n(1-\delta)}$. So, at $\varphi=0$ we have $f(\varphi, \delta)>1-\varphi$ precisely when $\delta>\frac{n}{n+1}$ and $f(\varphi, \delta)=1-\varphi$ precisely when $\delta=\frac{n}{n+1}$. Further, $f\left(\frac{1}{n}, \delta\right)=\delta\left(\frac{1}{n}\right)^{n-1}<1-\frac{1}{n}$. So, at $\varphi=\frac{1}{n}$ we have $f(\varphi, \delta)<1-\frac{1}{n}$. Thus, by the Intermediate Value Theorem, for $\delta \geq \frac{n}{n+1}$ there is at least one point of intersection of the respective graphs of $f(\varphi, \delta)$ and $1-\varphi$ on the interval $\left[0, \frac{1}{n}\right]$. Moreover, when $\delta>\frac{n}{n+1}$, the point of intersection is at the interior of the interval $\left[0, \frac{1}{n}\right]$. We show that the point of intersection must be unique in two steps. First we show that $f(\varphi, \delta)<1-\varphi$ on the interval $\left[\frac{1}{n(n-1)}, \frac{1}{n}\right]$. So, there are no points of intersection on the interval $\left[\frac{1}{n(n-1)}, \frac{1}{n}\right]$ and, because $f(0, \delta)>1$, there is at least one point of intersection on the interval $\left(0, \frac{1}{n(n-1)}\right)$. Then we show that $\frac{\partial f}{\partial \varphi}<-1$ on the interval $\left[0, \frac{1}{n(n-1)}\right]$, which establishes the fact that the point of intersection on the interval $\left(0, \frac{1}{n(n-1)}\right)$ is unique. Notice that

$$
\frac{\partial T}{\partial \varphi}=n \cdot(n-1)^{2} \cdot\left((1-n \varphi)^{n-2}-(1-(n-1) \varphi)^{n-2}\right) .
$$

It is easy to check that $\frac{\partial T}{\partial \varphi}<0$.

A. Consider the interval $\left[\frac{1}{n(n-1)}, \frac{1}{n}\right]$. We show that

$$
f(\varphi, \delta)<1-\varphi
$$

on this interval. Using the definition of $f(\varphi, \delta)$, it suffices to show that

$$
T<n \cdot(1-\varphi) \cdot\left(1-\delta \cdot(1-n \varphi)^{n-1}\right) .
$$


Since $\varphi \geq \frac{1}{n(n-1)}$, we know that

$$
\delta \cdot(1-n \varphi)^{n-1}<(1-n \varphi)^{n-1} \leq\left(\frac{n-2}{n-1}\right)^{n-1} .
$$

Thus, since also $\varphi \leq \frac{1}{n}$, it suffices to show that

$$
T \leq n \cdot \frac{n-1}{n} \cdot\left(1-\left(\frac{n-2}{n-1}\right)^{n-1}\right)
$$

or equivalently

$$
T \leq(n-1) \cdot\left(1-\left(\frac{n-2}{n-1}\right)^{n-1}\right) .
$$

Since $\frac{\partial T}{\partial \varphi}<0$ and $\varphi \geq \frac{1}{n(n-1)}$, we can deduce that

$$
T \leq n \cdot\left(\frac{n-1}{n}\right)^{n-1}-(n-1) \cdot\left(\frac{n-2}{n-1}\right)^{n-1} .
$$

Thus, it suffices to check that

$$
n \cdot\left(\frac{n-1}{n}\right)^{n-1}-(n-1) \cdot\left(\frac{n-2}{n-1}\right)^{n-1} \leq(n-1) \cdot\left(1-\left(\frac{n-2}{n-1}\right)^{n-1}\right)
$$

which is equivalent to

$$
n \cdot\left(\frac{n-1}{n}\right)^{n-1} \leq n-1 .
$$

Since $\left(\frac{n}{n-1}\right)^{n-1}$ is increasing in $n$ (monotonically converging to $e$ ), we know that $\left(\frac{n-1}{n}\right)^{n-1} \leq \frac{4}{9}$ for all $n \geq 3$. Hence

$$
n \cdot\left(\frac{n-1}{n}\right)^{n-1} \leq \frac{4}{9} n \leq n-1
$$

for all $n \geq 3$, which concludes the proof of $\mathrm{A}$.

B. We show that $\frac{\partial f}{\partial \varphi}<-1$ on the interval $\left[0, \frac{1}{n(n-1)}\right]$. Notice that

$$
\begin{aligned}
\frac{\partial f}{\partial \varphi} & =\delta \cdot \frac{\frac{\partial T}{\partial \varphi} \cdot n \cdot\left(1-\delta \cdot(1-n \varphi)^{n-1}\right)-\delta \cdot T \cdot n^{2} \cdot(n-1) \cdot(1-n \varphi)^{n-2}}{n^{2} \cdot\left(1-\delta \cdot(1-n \varphi)^{n-1}\right)^{2}} \\
& =\frac{\delta \cdot \frac{\partial T}{\partial \varphi}}{n \cdot\left(1-\delta \cdot(1-n \varphi)^{n-1}\right)}-\frac{\delta^{2} \cdot T \cdot(n-1) \cdot(1-n \varphi)^{n-2}}{\left(1-\delta \cdot(1-n \varphi)^{n-1}\right)^{2}}
\end{aligned}
$$

Since $\frac{\partial T}{\partial \varphi}<0$, the first term of this expression is negative. We show that

$$
\frac{\delta^{2} \cdot T \cdot(n-1) \cdot(1-n \varphi)^{n-2}}{\left(1-\delta \cdot(1-n \varphi)^{n-1}\right)^{2}} \geq 1
$$


which is equivalent to

$$
\delta^{2} \cdot T \cdot(n-1) \cdot(1-n \varphi)^{n-2} \geq\left(1-\delta \cdot(1-n \varphi)^{n-1}\right)^{2} .
$$

Since $\delta \geq \frac{n}{n+1}, \varphi \leq \frac{1}{n(n-1)}$, and $T$ is a decreasing function, it suffices to show that

$$
\begin{aligned}
\left(\frac{n}{n+1}\right)^{2} \cdot(n-1) \cdot\left(\frac{n-2}{n-1}\right)^{n-2} & \cdot\left(n \cdot\left(\frac{n-1}{n}\right)^{n-1}-(n-1) \cdot\left(\frac{n-2}{n-1}\right)^{n-1}\right) \\
\geq & \left(1-\frac{n}{n+1} \cdot\left(\frac{n-2}{n-1}\right)^{n-1}\right)^{2}
\end{aligned}
$$

which is equivalent to

$$
\begin{aligned}
\left(\frac{n}{n+1}\right)^{2} \cdot(n-1) \cdot\left(\frac{n-1}{n-2}\right) & \cdot\left(n \cdot\left(\frac{n-2}{n}\right)^{n-1}-(n-1) \cdot\left(\frac{n-2}{n-1}\right)^{2(n-1)}\right) \\
\geq & \left(1-\frac{n}{n+1} \cdot\left(\frac{n-2}{n-1}\right)^{n-1}\right)^{2} .
\end{aligned}
$$

Since $\frac{n-2}{n} \geq\left(\frac{n-2}{n-1}\right)^{2}$, we have

$$
n \cdot\left(\frac{n-2}{n}\right)^{n-1}-(n-1) \cdot\left(\frac{n-2}{n-1}\right)^{2(n-1)} \geq\left(\frac{n-2}{n-1}\right)^{2(n-1)} .
$$

Thus, it suffices to show that

$$
\left(\frac{n}{n+1}\right)^{2} \cdot(n-1) \cdot\left(\frac{n-1}{n-2}\right) \cdot\left(\frac{n-2}{n-1}\right)^{2(n-1)} \geq\left(1-\frac{n}{n+1} \cdot\left(\frac{n-2}{n-1}\right)^{n-1}\right)^{2}
$$

which can be rewritten to

$$
n^{2} \cdot(n-1)^{2} \geq(n-2) \cdot\left((n+1) \cdot\left(\frac{n-1}{n-2}\right)^{n-1}-n\right)^{2}
$$

Now, since $\left(\frac{n-1}{n-2}\right)^{n-1} \uparrow e$ as $n \rightarrow \infty$, it suffices to show that

$$
n^{2} \cdot(n-1)^{2} \geq(n-2) \cdot((e-1) \cdot n+e)^{2}
$$

It is straightforward to verify that this inequality holds for all $n \geq 5$. Since the inequality ( $*$ ) also holds for $n=4$, the only remaining case is $n=3$. For this case we directly compute that on the interval on the interval $\left[0, \frac{1}{3}\right]$ the equation $f(\delta, \varphi)=1-\varphi$ has a unique solution $\varphi^{*}$, and that $\varphi^{*} \leq \frac{1}{6}$.

The equation $f(\varphi, \delta)=1-\varphi$ can be rewritten to $g(\varphi, \delta)=0$ with

$$
g(\varphi, \delta)=27 \delta \varphi^{3}-39 \delta \varphi^{2}+(21 \delta-3) \varphi+3-4 \delta .
$$


Chapter 3. Intentional Price Wars on the Equilibrium Path

Thus $\frac{\partial g}{\partial \varphi}=81 \delta \varphi^{2}-78 \delta \varphi+21 \delta-3$, which for $\delta>\frac{3}{4}$ is a strictly positive function on the interval $\left[0, \frac{1}{3}\right]$. So, for $\delta>\frac{3}{4}, g(\varphi, \delta)$ is strictly increasing in $\varphi$ on the interval $\left[0, \frac{1}{3}\right]$. This implies that the equation $g(\varphi, \delta)=0$ has at most one solution on the interval $\left[0, \frac{1}{3}\right]$. It is moreover straightforward to check that $g(0, \delta)=3-4 \delta<0$. Hence, by A, the equation has a unique solution $\varphi^{*}<\frac{1}{6}$. 


\section{Part II}

\section{The Impact of Consumer Inertia}





\section{Chapter 4}

\section{Dynamic Competition with Consumer Inertia}

\subsection{Introduction}

An important goal of research on price competition in oligopolistic markets is to determine which circumstances are associated with high prices and which ones with low prices. ${ }^{1}$ Often these two modes of pricing behavior are connected; for instance, when firms revert to low prices for a fixed or unlimited period in response to a deviation from a coordinated (possibly via a collusive agreement) high price (Friedman, 1971). ${ }^{2}$ Such trigger strategies are known to sustain high prices when firms are sufficiently future-oriented (i.e. the discount factor is sufficiently high). Moreover, firm and market characteristics should be sufficiently stable, since periods of low prices (or, price war behavior) can occur on the equilibrium path when exogenous shocks in market demand (Rotemberg and Saloner, 1986), individual demand (Pot et al., 2008 and chapters 2 and 3 of this thesis), or individual marginal cost level (Athey et al., 2004) are possible. A common design property of the models that predict high prices for high discount factors is the particular time-tradeoff, where a price undercut leads to an immediate demand and profit increase, but to a decrease in future profits due to reversion to profit eroding marginal cost pricing in response to the undercut.

However, a price decrease may not always lead to an immediate increase

\footnotetext{
${ }^{1}$ This chapter is based on Pot, Flesch, Peeters and Vermeulen (2009).

${ }^{2}$ Excessive pricing may result from collusive agreements, but might as well arise naturally as a consequence of situational characteristics (Porter and Zona, 1999).
} 
in demand that suffices to increase immediate profit, although it may induce increased clientele and profit opportunities in the future. Reasons for this include presence of brand loyalty, switching costs, or demand inertia (Fishman and Rob, 2003). When the market is characterized by this property, firms are constantly exposed to a reverted time-tradeoff. Each period, firms have on the one hand the incentive to exploit currently installed market share by setting a high price (harvesting incentive), and on the other hand the incentive to set a low price, thereby foregoing immediate profit opportunities in exchange for an increased future market share (investment incentive). ${ }^{3}$ There are two prominent motives for low pricing: a firm may price low in an attempt to increase market share (offensive motive), but could as well price low to avoid loss of market share (defensive motive). These incentives and motives are important and recurrent aspects in our study.

Our model contains two duopolists that compete over a discrete infinite time horizon under possibly varying states of the market. The states are represented by a finite number of possible market shares divisions, including two monopolistic states. At each period, given a competitive state where both firms have a positive market share, firms have the option to either charge a high price or a low price. Since we assume sales in a particular period to equal the market share in that particular period, the high price yields a higher immediate profit. But, by charging the high price a firm runs the risk of losing part of its market share in the subsequent period in case the opponent opts for a low price. Hence, our model explicitly assumes consumers to be inert. We allow for monopolization and bankruptcy by assuming that the two monopolistic states are absorbing. Our model falls within the class of finite discounted stochastic games and we adopt known methods and techniques from that literature in our equilibrium analysis. In doing so, we restrict our attention to (symmetric pure) stationary subgame perfect equilibria. This provides us with the following results and insights.

For sufficiently low discount factors the harvesting incentive dominates the investment incentive which results in the unique equilibrium prediction of firms charging high prices. When the discount factor is sufficiently large this dominance relation among incentives reverts and firms will opt for the low price. The outcomes with high prices and low prices uniformly over states typically do not co-exist as a stationary subgame perfect equilibrium. Surprisingly, coordination on high prices can no longer be supported as sta-

\footnotetext{
${ }^{3}$ Farrell and Klemperer (2007) provides a detailed overview of different incentives and effects that appear in oligopolistic markets.
} 
tionary subgame perfect equilibrium. This may even be true when we allow for trigger strategies. ${ }^{4}$

This result contrasts starkly with that found in the standard literature on dynamic price competition, where high discount factors induce sustainability of high prices. Those models typically have the low price outcome as the unique equilibrium prediction of the state game, whereas in our model it is the high price outcome. So, where a high discount factor facilitates high prices in those models, it knocks it down in our model. Hence, after augmenting the standard model with a realistic market characteristic we obtain precisely the opposite expectations on firm behavior and market performance.

Finally, our model is able to give an explanation for monopolization and enduring market share and price fluctuations (price wars) as an equilibrium path phenomenon without the presence of exogenous shocks in market or firm characteristics. Equilibria that induce one of these interesting price dynamics only exist for intermediate values of the discount factors. When the discount factor is too low, firms have no incentive to incur costs today in exchange for future market share, while simultaneously firms do not fear a loss of market share due to the similar lack of offensive motives of the opponent. Hence, both firms exploit their customer base by demanding high prices. When the discount factor is too high, firms resort to aggressive pricing in all states. Incentives to increase market share (or even to monopolize the market) are high and so is the fear for loss of market share.

A noteworthy paper in the light of our findings is Chen and Rosenthal (1996), in which it is also noted that the predicted outcome of traditional Bertrand competition is affected in a crucial yet unrealistic way by the fact that consumers are (too) extremely price-sensitive. Chen and Rosenthal therefore model price competition as a stochastic game in which a state represents a certain proportion of the consumer population that is 'loyal' to a firm. If prices are unequal, there is a shift in consumer loyalty from the higher price firm to the lower price firm. This shift occurs deterministically and at a constant rate. Our model can thus be seen as an extension of theirs, as we assume that a price reduction should be treated as an investment with an uncertain but possibly positive long-term effect. This way, the timetradeoff is not only reversed as compared to traditional repeated Bertrand competition, but also stripped of its rigid deterministic component. We are able to confirm some of Chen and Rosenthal's results, in particular that, the

\footnotetext{
${ }^{4}$ See also Bos, Peeters and Pot (2010) and chapter 5 of this thesis.
} 
greater consumer loyalty (in our model represented by transition probabilities and the distances between neighbouring states), the less intense the price competition. Furthermore, we can confirm and, in addition, provide some more intuition to the fact that in some cases, asymmetric discount factors can lead to a lower normalized profit for the more patient firm. The higher the discount factor for a firm, the more attractive it becomes for this firm to choose the low price for offensive reasons. The less patient firm anticipates on this by putting more weight on playing the low price itself (for defensive reasons), thereby decreasing the offensive incentives of the more patient firm. Finally, unlike Chen and Rosenthal, we provide a full specification of the set of stationary subgame perfect equilibria in a simple but intuitively general setting.

In Radner (2003), demand is 'viscous', by which is meant the notion that consumers switch slowly over time from a higher price firm to a lower price firm. In a duopoly model, Radner is able to prove the existence of a specific family of stationary equilibria. In our model, we focus less on the exact process of how consumers 'flow' from one firm to the other. Instead, we concentrate on the decision problem the firms face, and are consequently able to acquire a deeper understanding of the qualitative impact the changed timetradeoff has on firms' pricing behavior. Our results confirm Radner's insight that in such situations, competitive outputs might mimic collusive behavior. Furthermore, we find more results on when to expect low prices or mixed behavior in stationary strategies.

The chapter proceeds as follows. In the next section, we present our model of dynamic price competition with endogenous market share transitions. In Section 4.3, we restrict attention to the version of the model that has just one competitive state. This is the most concise and analytically tractable version of the model. Within this limited framework we are able to derive some of the main properties of the general model. Moreover, we are able to make some behavioral inferences by investigating the influence of the discount factor on the firms' incentives. In Section 4.4 we show illustrating examples that provide extra intuition behind the results presented in Section 4.3. Next, in Section 4.5, we add two more competitive states. Within this framework we are able to illustrate some of the interesting market share dynamics that are induced by equilibria of our general model. Finally, in Section 4.6, we generalize the main equilibrium properties found in the earlier sections for the full version of our model. In the final section, we discuss the scope of applicability of our model, and hence our results. 
4.2. General framework

\subsection{General framework}

Two duopolists are repeatedly involved in price competition over a discrete infinite time horizon with possibly varying market circumstances. Market circumstances are captured by the state space, consisting of a finite number of states representing market share divisions between the two firms (shares add up to 1). Besides competitive states in which both firms have a positive market share there are also monopolistic states in which one firm serves the full demand. We assume that the two monopolistic states are absorbing; that is, once a firm has reached a state in which it serves the full market it will continue as a monopolist and the opponent has no possibility to regain demand.$^{5}$ For simplicity, we assume for our state space a set of equidistant states: $S=\left\{\left(\frac{k}{K}, 1-\frac{k}{K}\right) \mid k=0,1, \ldots, K\right\}$. We denote the state $\left(\frac{k}{K}, 1-\frac{k}{K}\right)$ by $s_{k}$.

Each period, in common knowledge of the present state, the firms simultaneously and independently set prices. Chosen prices have an immediate impact on the profits earned and a delayed effect on the state dynamics. To keep analyses tractable, in our model, we only allow firms to choose between two prices: a high price (action $H$ ) and a low price (action $L$ ). The instantaneous profit of a firm equals its market share times $h$ or $\ell$ (with $h>\ell$ ), depending on the firm choosing action $H$ or $L$ respectively. In particular, a chosen price has no immediate impact on current sales and hence our model explicitly assumes consumers to be inert. Regarding the consequences for state dynamics, no change in market share division will occur in case the firms choose identical prices. However, in case the firms choose different prices there is a probability that in next period competition resumes in the state where the firm with the lower price has gained $\frac{1}{K}$ in market share. ${ }^{6}$ With the remaining probability mass the process resumes in the same state. Hence, from a state $s_{k}$ (with $k=1, \ldots, K-1$ ) only the states $s_{k-1}$ and $s_{k+1}$ are directly accessible. We allow firms to randomize their behavior by application of a mixed action. Expected profits and transitions are defined in the usual multilinear fashion.

The competition proceeds as follows. In each period both firms observe

\footnotetext{
${ }^{5}$ In Section 4.4 we show by means of an example that our results also hold when monopoly states are non-absorbing. In the Concluding Remarks we provide a further discussion why this assumption is non-critical for qualitative predictions.

${ }^{6}$ Notice that this approach is in essence identical to an overlapping generations approach with newborn and dying consumers, and where consumers are assumed to behave strategically, though often myopically (cf. Farrell and Shapiro, 1988; Beggs and Klemperer, 1992; Burdett and Coles, 1997; and Cabral, 2007).
} 
the current market share division and decide on their respective prices to charge. Next, depending on the prices chosen, both firms observe the actions chosen and receive their profit. Then the transition of market share divisions for the next period is realized. In the next period, the realized market share is observed by the firms and, again, they have to decide on the price to charge. This procedure continues ad infinitum. At each period firms aim to maximize the present value of the future stream of (expected) profits, discounted by application of the discount factor $\delta \in[0,1)$.

Firms are in each period facing the tradeoff between current profits and future market shares. On the one hand there is the incentive to exploit currently installed market share by setting a high price (harvesting incentive). On the other hand there is the incentive to set a low price, thereby foregoing immediate profit opportunities in exchange for an increased future market share (investment incentive). There are, however, two prominent motives for low pricing. First, a firm may price low in an attempt to increase market share or even to obtain a monopoly position (offensive motive). Second, a firm could as well price low to avoid loss of market share and in the extreme case bankruptcy (defensive motive).

The model we study is contained in the class of finite discounted stochastic games and we adopt the conventional concepts and methods in our analyses. The most general kind of strategy that a firm can formulate in this model is a behavior strategy, where decisions (mixed actions) are conditioned on time, state, and full history of all states visited and all actions being chosen. A pair of behavior strategies constitutes a Nash equilibrium if given the initial state neither of the two firms can achieve an improvement in present value by a unilateral deviation to another behavior strategy. When there does not exist any combination of time, state, and history where a firm can achieve such an improvement, then the Nash equilibrium is called subgame perfect.

One particular type of behavior strategy that firms can employ are stationary strategies, where decisions (mixed actions) are independent of time and history, and hence conditioned on state only. A pair of stationary strategies that constitutes a (subgame perfect) Nash equilibrium is called a stationary (subgame perfect) equilibrium. Since a firm always has a stationary best response against a stationarily behaving opponent (Blackwell, 1962), for the validation of a given pair of stationary strategies to form an equilibrium, only stationary deviations have to be considered. For finite discounted stochastic games in general, and our model in particular, a stationary sub- 
4.3. When there is just one competitive state

game perfect equilibrium is guaranteed to exist (Fink (1964); Takahashi (1964); Sobel (1971); Herings and Peeters (2004)).

In this chapter we focus on stationary subgame perfect equilibria. Several motivations for this can be found in Maskin and Tirole (2001). Stationary strategies prescribe the simplest form of behavior that is consistent with rationality, stationarity captures the notion that 'bygones are bygones' more completely than does the concept of subgame perfect equilibrium, and it embodies the principle that 'irrelevant causes should have no effects', that is, only those aspects of the past that are 'significant' should have an appreciable influence on behavior. The pragmatic motivations they give are that in applied theory the focus on stationary strategies allows for clean, unobstructed analysis of the influence of the state variables, that stationary strategies substantially reduce the number of parameters to be estimated in dynamic (econometric) models, and that stationary models can be simulated efficiently.

\subsection{When there is just one competitive state}

In this section we consider the situation where there is one competitive state, in which firms have an equal market share. We analyze the symmetric case where the (exogenously given) probabilities to reach the (absorbing) monopolistic states are equal for the firms. This case is graphically illustrated in Figure 4.1 .

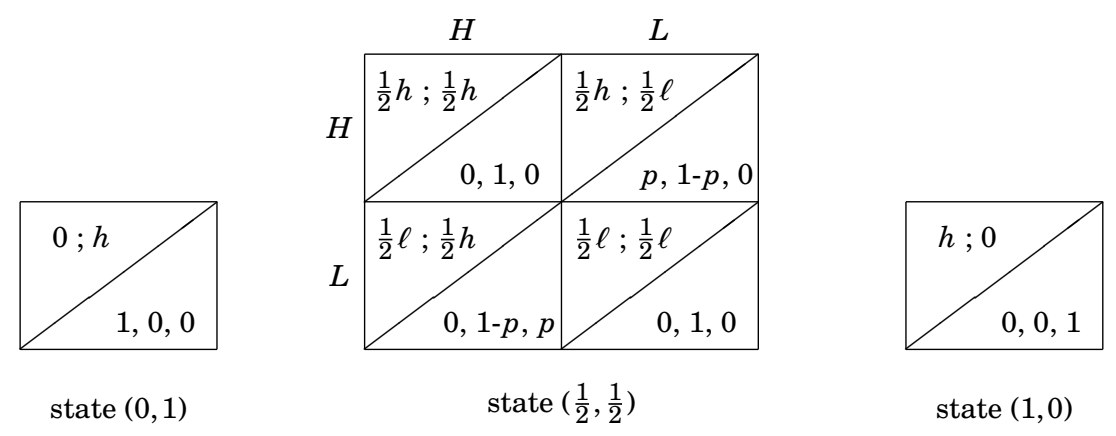

Figure 4.1: The symmetric model with one competitive state. In each cell, the north-west part shows respectively the profit of firm 1 (the row player) and firm 2 (the column player); the south-east part shows respectively the probability to transit to state $(0,1)$, state $\left(\frac{1}{2}, \frac{1}{2}\right)$ and state $(1,0)$. 
Chapter 4. Dynamic Competition with Consumer Inertia

The situation with asymmetric transition probabilities is considered in two examples in Section 4.4. These examples will provide more insight in the precise incentives and motives underlying the firms' behavior.

Obviously, considered as a one-shot game (or when the firms are myopic: $\delta=0$ ), there is a unique Nash equilibrium in dominant actions in which both firms choose the high price. Since this equilibrium leads to the highest payoff in the payoff matrix, the Folk theorem implies that this is also the only Nash equilibrium payoff when this game is played repeatedly. This particular situation is induced when $p$, the probability to transit to a monopolistic state in case of unequal prices, is zero. Things change drastically however when this probability is positive. The following proposition provides for all possible values of $h, \ell, p$, and $\delta$ a complete specification of the stationary subgame perfect equilibria. The notation $[x ; y]$ refers to the situation where firm 1 (2) plays action $H$ with probability $x(y)$. We also use $[H ; H]$ and $[L ; L]$ to indicate strategy pairs $[1 ; 1]$ and $[0 ; 0]$ respectively.

Proposition 4.3.1. The stationary subgame perfect equilibria are as given in Table 4.1.

\begin{tabular}{|c|c|c|c|c|}
\hline discount factor & $\begin{array}{l}\text { symmetric } \\
\text { and pure }\end{array}$ & $\begin{array}{l}\text { symmetric } \\
\text { and mixed }\end{array}$ & $\begin{array}{l}\text { asymmetric } \\
\text { and pure }\end{array}$ & $\begin{array}{c}\text { asymmetric } \\
\text { and mixed }\end{array}$ \\
\hline $0 \leq \delta<\delta_{1}$ & {$[1 ; 1]$} & & & \\
\hline$\delta=\delta_{1}$ & {$[1 ; 1]$} & {$\left[{\sigma^{+}}^{+} \sigma^{+}\right]=\left[\sigma^{-} ; \sigma^{-}\right]$} & & \\
\hline$\delta_{1}<\delta<\delta_{2}$ & {$[1 ; 1]$} & {$\left[\sigma^{+} ; \sigma^{+}\right]$and $\left[\sigma^{-} ; \sigma^{-}\right]$} & & {$\left[\sigma^{+} ; \sigma^{-}\right]$and $\left[\sigma^{-} ; \sigma^{+}\right]$} \\
\hline$\delta=\delta_{2}$ & {$[1 ; 1]$} & {$\left[\sigma^{-} ; \sigma^{-}\right]=\left[\frac{1}{2} ; \frac{1}{2}\right]$} & & {$[t ; 1]$ and $[1 ; t]$ for $0 \leq t \leq \frac{1}{2}$} \\
\hline$\delta_{2}<\delta<\delta_{3}$ & & {$\left[\sigma^{-} ; \sigma^{-}\right]$} & {$[0 ; 1]$ and $[1 ; 0]$} & \\
\hline$\delta=\delta_{3}$ & {$[0 ; 0]$} & & & {$[t ; 0]$ and $[0 ; t]$ for $0 \leq t \leq 1$} \\
\hline$\delta_{3}<\delta<1$ & {$[0 ; 0]$} & & & \\
\hline
\end{tabular}

Table 4.1: The stationary subgame perfect equilibria of the symmetric model with one competitive state.

In this table the probabilities $\sigma^{+}$and $\sigma^{-}$are given by:

$$
\sigma^{+}=\frac{(1-\delta)(h-\ell)+2 p \delta h+\sqrt{\left.((1-\delta)(h-\ell)+2 p \delta h)^{2}-8(1-\delta) h((1-\delta)(h-\ell)-p \delta \ell)\right)}}{4 p \delta h}
$$

and

$$
\sigma^{-}=\frac{(1-\delta)(h-\ell)+2 p \delta h-\sqrt{\left.((1-\delta)(h-\ell)+2 p \delta h)^{2}-8(1-\delta) h((1-\delta)(h-\ell)-p \delta \ell)\right)}}{4 p \delta h} .
$$

The three threshold values of the discount factor are given by:

$$
\delta_{1}=\frac{(7 h+\ell)(h-\ell)+2 p h(h+\ell)-4 p h \sqrt{h(2 h-\ell)}}{(7 h+\ell)(h-\ell)+4 p h((1-p) h+\ell)}, \quad \delta_{2}=\frac{h-\ell}{h-\ell+p h}, \quad \text { and } \quad \delta_{3}=\frac{h-\ell}{h-\ell+p \ell} .
$$


4.3. When there is just one competitive state

Moreover, $0<\delta_{1}<\delta_{2}<\delta_{3}<1$.

Proof . Given that the opponent selects the high price with probability $\sigma$ in a stationary fashion, the present values (derived from the Bellman equations) corresponding to the two pure stationary responses are:

$$
\left\{\begin{array}{l}
V_{H}=\frac{1}{2} h+\delta\left\{\sigma V_{H}+(1-\sigma)(1-p) V_{H}\right\} \\
V_{L}=\frac{1}{2} \ell+\delta\left\{\sigma\left(p \frac{h}{1-\delta}+(1-p) V_{L}\right)+(1-\sigma) V_{L}\right\}
\end{array}\right.
$$

Solving this system yields

$$
V_{H}=\frac{h}{2(1-\delta(1-p+\sigma p))} \quad \text { and } \quad V_{L}=\frac{(1-\delta) \ell+2 \sigma p \delta h}{2(1-\delta)(1-\delta(1-\sigma p))}
$$

If $V_{H}$ is larger/smaller than $V_{L}$, the firm's optimal response is to adopt the high/low price. The firm is indifferent between the two prices precisely when $V_{H}=V_{L}$. The equation $V_{H}=V_{L}$ is quadratic in $\sigma$ and hence has at most two solutions in the unit interval. The solutions for $\sigma$ are precisely the values of $\sigma^{+}$and $\sigma^{-}$given in the proposition. The threshold values for the discount factor $\delta_{1}, \delta_{2}$, and $\delta_{3}$ are attained when $\sigma^{+}=\sigma^{-}, \sigma^{+}=1$, and $\sigma^{-}=0$ respectively. Since $h>\ell>0$ and $p>0$, we have $0<\delta_{1}<\delta_{2}<\delta_{3}<1$.

Despite having only a few number of parameters, the model possesses an interesting equilibrium pattern. Figure 4.2 graphically illustrates the equilibrium pattern for fixed values of $h, \ell$ and $p$ and different values of the discount factor $\delta$ (in the near-far direction). The stationary strategy of firm 1 (the row-player) is depicted on the vertical axis and that of firm 2 (the column-player) on the horizontal axis. Figure 4.3 highlights the symmetric equilibria with the discount factor on the horizontal axis and the common stationary strategy of firms 1 and 2 on the vertical axis.

From the proposition and both figures it becomes apparent that the existence of a particular type of equilibrium heavily depends on the precise value of the discount factor. It is the discount factor that influences the tradeoff between current profits (harvesting incentive) and future market share (investment incentive). For each of the seven configurations listed in the proposition, the corresponding incentive and best response structures and resulting equilibrium configurations are illustrated in Section 4.8 in detail. The best response curves provide insight in the motives underlying aggressive pricing.

Offensive motives to set a low price are totally absent when the opponent sets the low price with probability one and are increasing in the probability 


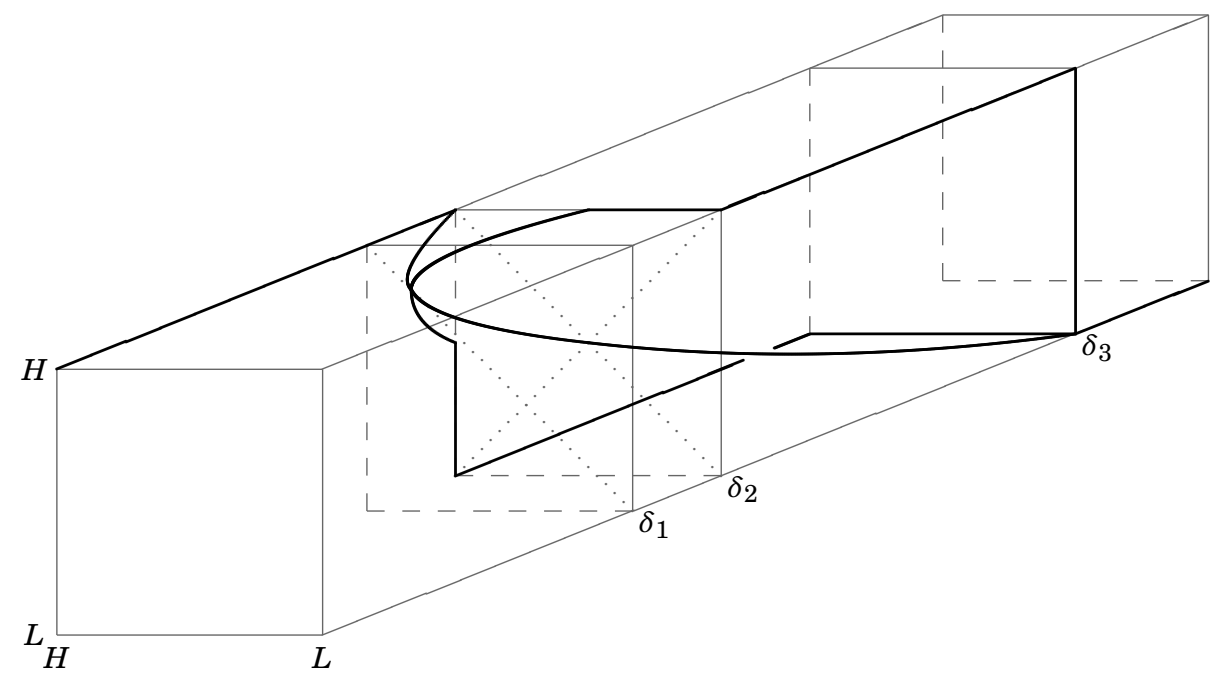

Figure 4.2: The stationary subgame perfect equilibria of the symmetric model with one competitive state.

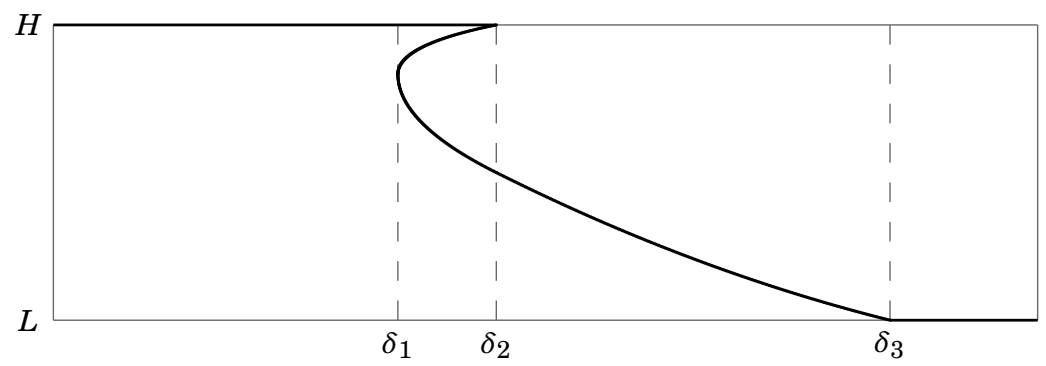

Figure 4.3: The symmetric stationary subgame perfect equilibria of the symmetric model with one competitive state.

by which the opponent selects the high price. For defensive motives the opposite holds: they are absent when the opponent sets the high price with probability one and are increasing in the probability by which the opponent sets the low price. Both motives mutually play a role in the best response for a firm when the opponent randomizes its pricing decision and become more 
4.3. When there is just one competitive state

substantial when the discount factor and hence the investment incentives increase.

For low values of the discount factor $\left(\delta<\delta_{1}\right)$, none of the firms regards an opportunity of monopolization sufficiently attractive to forego current profits; neither would any of the firms ever set a low price in order to prevent monopolization by the opponent. The low discount factor simply eliminates any interest in future market share: the investment incentives are too weak to provide an incentive for aggressive pricing. This results in a unique stationary subgame perfect equilibrium in which both firms exploit installed market share by setting a high price. For sufficiently large discount factors $\left(\delta>\delta_{2}\right)$, the high price outcome $[H ; H]$ fails to be an equilibrium, although it is the unique (subgame perfect) Nash equilibrium prediction of the one-shot game (when $\delta=0$ ) and the repeated game (when $p=0$ ).

For high values of the discount factor $\left(\delta>\delta_{3}\right)$, both firms select the low price. Both the offensive and the defensive motive apply here: firms would grasp any opportunity for monopolization and would prevent against any hostile attempt for monopolization. The high discount factor has changed the firms' focus totally towards future market share. This results in a unique stationary subgame perfect equilibrium in which both firms set a low price.

For intermediate values of the discount factor $\left(\delta_{1}<\delta<\delta_{3}\right)$, firms do not possess a dominant strategy and may consider both prices a feasible action to choose. Although offensive and defensive motives are mutually in force and even interact, the decisive motive for setting a low price appears to change in a subtle manner at $\delta=\delta_{2}$.

For intermediate values of the discount factor less than $\delta_{2}$, firms respond to high prices with high prices. This indicates that in the ideal situation to conduct an offensive act, firms would refuse to do so. This explains the persistence of the high price outcome as an equilibrium. Moreover, firms also respond to low prices with high prices. This indicates that in the most threatening situation, firms do not protect current market share: the firm accommodates a fight by the opponent. However, firms do respond with the low price in case the opponent chooses the high price with a probability larger than $\sigma^{-}$but less than $\sigma^{+}$. When the probability exceeds $\sigma^{+}$, the probability on the opponent's success in achieving a monopoly position is not sufficiently threatening and the defensive motives have become insignificant. When the probability falls below $\sigma^{-}$, the own probability on a successful monopolization becomes too small to offset the costs of an immediate loss in profits and the offensive motives have become insignificant. This explains 
the four mixed equilibria that result from the combinations of mixing with $\sigma^{-}$and $\sigma^{+}$.

For intermediate values of the discount factor larger than $\delta_{2}$, firms respond to high prices with low prices, which clearly hints at an offensive act. Once the opponent chooses the low price with a probability sufficiently large (larger than $1-\sigma^{-}$), once again the probability of acquiring the dominant position becomes too small to continue fighting. This precisely explains the existence of the two asymmetric pure equilibria: high prices are responded by low prices, and vice versa. In addition, there is one symmetric mixed equilibrium where both firms choose the high price with the probability that makes the opponent indifferent between attacking or not.

Corollary 4.3.2. High price equilibria only exist for low values of the discount factor $\left(\delta \leq \delta_{2}\right)$ and low price equilibria only for high discount factors $\left(\delta \geq \delta_{3}\right)$. Moreover, these equilibria never co-exist and there is a proper interval of discount values $\left(\delta \in\left(\delta_{2}, \delta_{3}\right)\right)$ for which neither of these two outcomes constitutes an equilibrium.

Although these statements are formulated as a corollary to Proposition 4.3.1, they refer to general properties of our framework. The generalization of these statements are the topic of Section 4.6.

Notice that the behavioral implications of our model oppose that of the standard literature where high prices (collusion) are only sustainable for high discount factors. The main cause of this conversion of implications is the flip in time-tradeoff. In contrast to our framework, in the standard models of repeated price competition with application of trigger strategies the lower (undercutting) price results in a capturing of the entire market and hence higher instantaneous profit, but in a lower future profit due to the reversal to profit eroding price competition. Our findings show that the main insights from textbook models are not valid in presence of demand inertia when no overly sophisticated behavior like threats or triggers are assumed. Notice that high prices are even not sustainable as an equilibrium by means of trigger strategies for sufficiently high discount factors when $p>\frac{h-\ell}{2 h-\ell} .{ }^{7}$

\footnotetext{
${ }^{7}$ Proof. Suppose $\delta>\delta_{3} \equiv \frac{h-\ell}{h-\ell+p \ell}$ such that in case of a deviation firms can revert to the unique stationary subgame perfect equilibrium $[L ; L]$. Now, $[H ; H]$ is sustainable as a subgame perfect Nash equilibrium if and only if $\frac{1}{2} h \frac{1}{1-\delta} \geq \frac{1}{2} \ell+\delta\left(p h \frac{1}{1-\delta}+(1-p) \frac{1}{2} \ell \frac{1}{1-\delta}\right)$; or equivalently $\delta \leq \delta^{*} \equiv \frac{h-\ell}{p(2 h-\ell)}$. Hence, $[H ; H]$ is not sustainable as an equilibrium when $\delta>\max \left\{\delta_{3}, \delta^{*}\right\}$. For this condition to be feasible, $\delta^{*}$ should be less than 1 , which is the case if and only if $p>\frac{h-\ell}{2 h-\ell}$.
} 
4.3. When there is just one competitive state

For discount factors between the threshold values $\delta_{1}$ and $\delta_{3}$, equilibria exist that imply monopolization in the long run. There are three types of equilibria in which such monopolization is possible: asymmetric equilibria in pure strategies when $\delta \in\left[\delta_{2}, \delta_{3}\right]$, symmetric ones in mixed strategies when $\delta \in\left[\delta_{1}, \delta_{3}\right]$, and asymmetric ones in mixed strategies when $\delta \in\left(\delta_{1}, \delta_{2}\right] \cup\left\{\delta_{3}\right\}$.

Corollary 4.3.3. Monopolization can occur on the equilibrium path unless the discount factor is very low or very high $\left(\delta_{2} \leq \delta \leq \delta_{3}\right)$.

There are two factors in our model that are related to the liquidity of the market, i.e. the difficulty of attracting extra demand. First, the probability of going to another state $p$ is an indicator of the likelihood that a price reduction will succeed in attracting more demand and could be seen as a measure of consumer loyalty. We see that a decrease of $p$ towards zero induces an increase in $\delta_{2}$ and $\delta_{3}$ to one and hence the maximum value of the discount factor for which we only have a stationary subgame perfect equilibrium with high prices. Second, the difference between the high and low immediate profits $h-\ell$ is an indicator of the minimum investment necessary to get any consumers moving and could be seen as a measure of the importance of switching costs. We see that a decrease of $h-\ell$ towards zero induces a decrease in $\delta_{2}$ and $\delta_{3}$ towards zero and hence the minimum value of the discount factor for which we only have a stationary subgame perfect equilibrium with low prices. Thus, when consumer loyalty is high or when high switching costs are involved, firms may be expected to set high prices. Moreover, when $\ell$ vanishes $\delta_{3}$ gradually increases to one and hence the minimum value of the discount factor for which we only have a stationary subgame perfect equilibrium with low prices. The following corollary summarizes these equilibrium properties for limiting cases of our model.

Corollary 4.3.4. (i) $[H ; H]$ is the unique equilibrium if $p=0$. (ii) $[L ; L]$ is the unique equilibrium if $h=\ell$. (iii) $[L ; L]$ never constitutes an equilibrium if $\ell=0$.

The first statement in the corollary implies that only high prices are chosen when monopolization is impossible by construction and hence investment incentives have disappeared. The second statement indicates that when harvesting incentives disappear only low prices are chosen. Finally, the third statement indicates that when the low price is associated with marginal cost pricing, the best response to the opponent setting the low price is to set the high price. 


\subsection{Illustrating examples}

In this section we provide some further intuition behind the results derived above. We do this by means of illustrating examples. The first example discusses comparative statics properties of the symmetric stationary subgameprefect equilibrium when a small asymmetry in the exogenous monopolization strategies is introduced.

Example 4.4.1. (asymmetric monopolization probabilities) Take as parameter specifications $h=5, \ell=3, p=0.25$, and $\delta=0.6713$ (as in the fifth case presented in Section 4.8). In the unique symmetric stationary subgame perfect equilibrium both firms choose the high price with probability 0.1440 . Every period each firm has a probability of 0.0308 to obtain a monopoly position in the subsequent period. Moreover, each firm has a present value of 5.29 .

Next, we consider the asymmetric situation where the exogenously given probability to become monopolist in case of solely opting for the low price increases to 0.3 for firm 1. The equilibrium moves to the event where firm 1 chooses the high price with probability 0.0437 and firm 2 chooses this price with probability 0.1084 . Now, every period firm 1 has a probability of 0.0312 to obtain a monopoly position in the subsequent period, while this probability is 0.0097 for firm 2. Moreover, the present value of firm 1 decreases to 5.23 while that of firm 2 decreases to 4.80 .

We see that in response to an increase in firm 1's exogenously given probability on a successful monopolization, both firms increase the probability by which they select the low price-this increase being more substantial for firm 1 than for firm 2. For firm 1 the motive is clearly offensive, while for firm 2 the motive is defensive. Only for firm 1 the increase in competitiveness leads to an increase in the probability of becoming monopolist in the subsequent period; for firm 2 it even decreases. Both firms do suffer from the increase in competitiveness in terms of present value.

We provide another example in which the asymmetry in the previous example is pushed to the extreme. This extreme case disentangles the offensive and defensive motives for aggressive pricing behavior, since for each of the firms one of the motives is excluded by construction.

Example 4.4.2. (offensive versus defensive motives) Suppose the probability of a successful monopolization for firm 1 when it sets a lower price is 
4.4. Illustrating examples

equal to one, while for firm 2 this probability is zero. In this situation, by construction, firm 1 only opts for the low price out of offensive motives, while firm 2 only opts for the low price out of defensive reasons. Table 4.2 provides a specification of the equilibria corresponding to all different values of the discount factor.

\begin{tabular}{lc}
\hline discount factor & sspe \\
\hline $0 \leq \delta<\frac{h-\ell}{2 h-\ell}$ & {$[1 ; 1]$} \\
$\delta=\frac{h-\ell}{2 h-\ell}$ & {$[t ; 1]$ for $0 \leq t \leq 1$} \\
$\frac{h-\ell}{2 h-\ell}<\delta<\frac{h-\ell}{h}$ & {$[0 ; 1]$} \\
$\delta=\frac{h-\ell}{h}$ & {$[0 ; t]$ for $\frac{(1-\delta)(h-\ell)}{\delta h} \leq t \leq 1$} \\
$\frac{h-\ell}{h}<\delta<1$ & {$\left[\frac{\ell-(1-\delta) h}{\delta \ell} ; \frac{(1-\delta)(h-\ell)}{\delta h}\right]$} \\
\hline
\end{tabular}

Table 4.2: The stationary subgame perfect equilibria of the model in the example.

First, firm 1 will always respond to a low price with a high price. Hence, $[L ; L]$ does not constitute an equilibrium for any value of the discount factor; in particular also not for values near 1. The intuition behind this is as follows. By setting the low price, firm 2 eliminates any opportunity for firm 1 to monopolize the market and thereby firm 1's offensive motives for setting the low price. Since there is, by construction, also no defensive motive for firm 1 to opt for the low price, firm 1 will never respond to a low price with a low price. Second, we see that the firm with offensive intensions (firm 1) turns to a low price already for lower values of the discount factor than the firm with defensive intensions (firm 2). Third, the probability by which firm 1 (firm 2) sets the high price increases (decreases) to one (zero) when the discount factor approaches one. Hence, for high discount factors, the firm that can lose clientele behaves more aggressively in order to defend itself against this threat.

Chen and Rosenthal (1996) shows that a more patient firm might end up with a lower normalized discounted profit. This effect can be nicely shown using the best-response correspondences provided in the Section 4.8 and explained through the incentives present in this model.

Example 4.4.3. (lower normalized profit for the more patient firm) Like in Section 4.8, we fix the following parameters: $h=5, \ell=3$ and $p=0.25$. 
Chapter 4. Dynamic Competition with Consumer Inertia

With these parameters, the three threshold values of the discount factor are $\delta_{1}=0.6052, \delta_{2}=0.6154$ and $\delta_{3}=0.7273$. We look at a situation in which both firms have a discount factor $\delta=0.6713$ and a situation in which firm 2 has a slightly higher discount factor of $\delta=0.7$. Figure 4.4 shows how the best response correspondences change when we move from the symmetric situation to the situation in which firm 2 has a slightly higher discount factor.

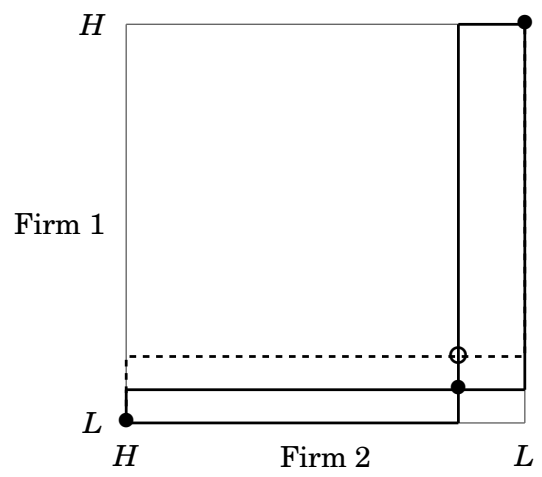

Figure 4.4: A more patient firm can have a lower normalized profit.

As one can see, if firm 2 (whose strategy is depicted on the horizontal axis) has a higher discount factor (i.e. is more patient), firm 1 puts more weight on playing the low price (0.943 instead of 0.856), while firm 2 chooses the same strategy as it would in the symmetric situation. Since, ceteris paribus, one's (normalized) discounted profit always decreases if the opponent puts more weight on $L$, we see that being more patient can indeed decrease one's profits in this mixed equilibrium (in this situation from 1.74 to 1.61). The rationale behind this can be explained as follows. In a mixed equilibrium, both firms choose in such a way that the other firm is willing to randomize between the available actions. If a firm's discount factor goes up, it attaches more value to future profits and would therefore be more inclined to choose a low price for offensive reasons. Therefore, the other firm should reduce these incentives by making it less likely that a price reduction will succeed to increase in future profits. It accomplishes exactly this by putting more weight on the low price itself (for defensive reasons), thereby making the more patient firm indifferent between playing the high or the low price.

The final example shows that making the monopoly states non-absorbing 
does not change the structure of our stationary subgame perfect equilibria.

Example 4.4.4. (non-absorbing monopoly states). Suppose that the two monopolistic states are no longer absorbing but that instead with a probability $q$ the system returns to the 'competitive' state in case the monopolist chooses a high price and its challenger indicates a low price. Figure 4.5 graphically illustrates this situation.
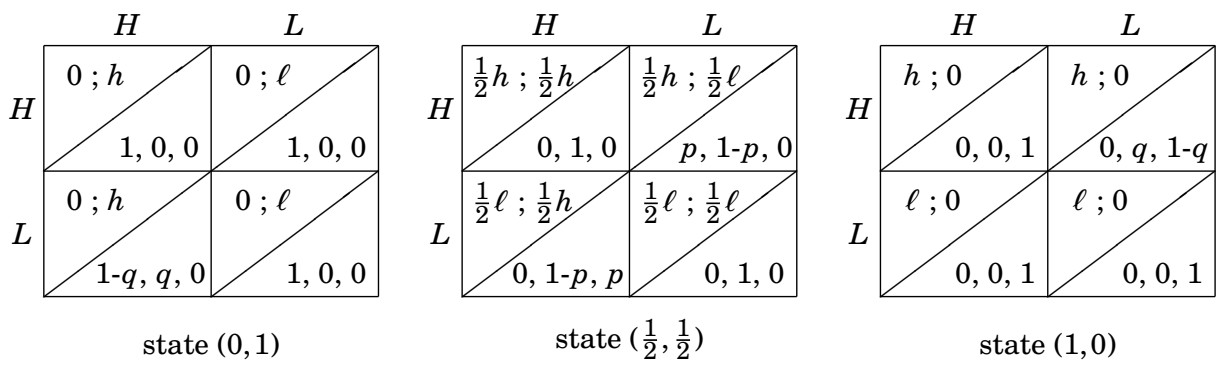

Figure 4.5: Nonabsorbing monopoly states.

Take the following parameter setting: $h=5, \ell=3, p=0.25$ and $q=0.25$. If we focus on the 'competitive' state, we find that the same threshold levels for the discount factor exist as in the setting with absorbing monopoly states: for all discount factors between 0 and $\delta_{1}=0.713$ there is a unique stationary subgame perfect equilibrium where both firms choose the high price. Between $\delta_{1}$ and $\delta_{2}=0.727$ we have four mixed equilibria next to the pure high price equilibrium. Between $\delta_{2}$ and $\delta_{3}=0.842$ we have one mixed equilibrium and the two asymmetric pure equilibria. For discount factors higher than $\delta_{3}$, $[L ; L]$ is the unique stationary subgame perfect equilibrium.

\subsection{Market share dynamics}

Due to the absorbing nature of the monopolistic states, the three state model of the previous section does not facilitate any market share dynamics. Therefore, in this section, we will consider the symmetric model with five states as presented in Figure 4.6. In addition to the state where both firms have equal market share and the two monopoly states, there are two states where both firms have positive but different market shares. From these states, both 
Chapter 4. Dynamic Competition with Consumer Inertia

the state with equal market share and the state where the firm with larger market share obtains a monopoly position are reachable. The additional feature captured in this five state model relative to the three state model is that competitive play continues once the firms leave the symmetric state in which they both serve half of the market. In other words, when the balance is broken and one firm has acquired a dominant position, it is possible for the dominated firm to recapture the lost market share.
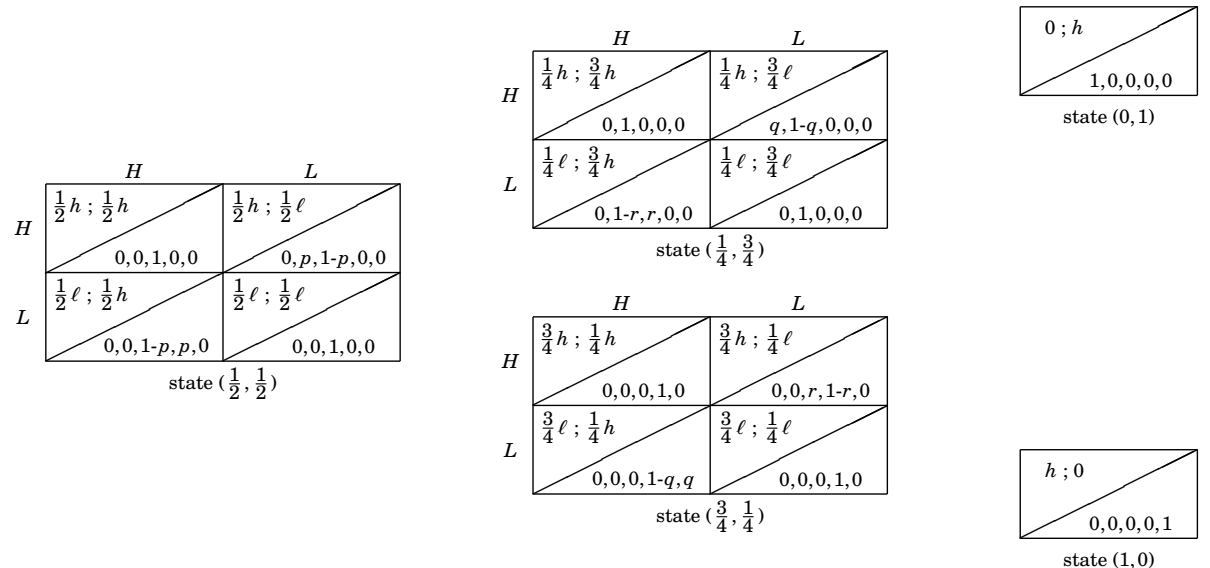

Figure 4.6: The symmetric model with five states.

We restrict our attention to the symmetric pure stationary subgame perfect equilibria, where a pair of stationary strategies is called symmetric if for all states the firms' actions specified by the strategy are mirrored when market shares are mirrored. By $[x y z]$ we denote the symmetric pair of strategies where firm 1 (2) chooses action $x, y$ and $z(z, y$ and $x)$ in state $\left(\frac{1}{4}, \frac{3}{4}\right),\left(\frac{1}{2}, \frac{1}{2}\right)$ and $\left(\frac{3}{4}, \frac{1}{4}\right)$ respectively.

There are three types of equilibria: equilibria in which no state transitions occur ([LLL], $[H H H],[L H L]$ and $[H L H])$, equilibria in which firms move to equal market shares ([LLH] and $[L H H])$ and equilibria that push the market to monopoly ([HLL] and $[H H L]$ ). The following three propositions, each deal with one of these equilibrium types. All equilibria have in common that the symmetric state is 'strategically absorbing', meaning that given the equilibrium strategies play never leaves the symmetric state once it has been reached. This is inherent to the restriction to symmetric pure stationary subgame perfect equilibria. 
4.5. Market share dynamics

Proposition 4.5.1. Symmetric pure stationary subgame perfect equilibria in which all states are strategically absorbing exist when the conditions in Table 4.3 are met.

\begin{tabular}{lccc}
\hline & Market share 0.25 & Market share 0.5 & Market share 0.75 \\
\hline$[H H H]$ & $\delta \leq \frac{h-\ell}{h-\ell+r h}$ & $\delta \leq \frac{2(h-\ell)}{2(h-\ell)+p h}$ & $\delta \leq \frac{3(h-\ell)}{3(h-\ell)+q h}$ \\
{$[L L L]$} & $\delta \geq \frac{h-\ell}{h-\ell+q \ell}$ & $\delta \geq \frac{2(h-\ell)}{2(h-\ell)+p \ell}$ & $\delta \geq \frac{3(h-\ell)}{3(h-\ell)+r \ell}$ \\
{$[H L H]$} & $\delta \leq \frac{2(h-\ell)}{2(h-\ell)+(2 \ell-h)}$ & $\delta \geq \frac{2(h-\ell)}{2(h-\ell)+p(2 \ell-h)}$ & $\delta \leq \frac{3(h-\ell)}{3(h-\ell)+q h}$ \\
{$[L H L]$} & $\delta \geq \frac{h-\ell}{h-\ell+q \ell}$ & $\delta \leq \frac{2(h-\ell)}{2(h-\ell)+p(3 \ell-2 h)}$ & $\delta \geq \frac{3(h-\ell)}{3(h-\ell)+r(3 \ell-2 h)}$ \\
\hline
\end{tabular}

Table 4.3: All states are strategically absorbing.

Proof . Consider the symmetric strategy profile $[L L L]$. For this profile to be an equilibrium no firm should have an incentive to deviate to the high price in any state. So, when a firm has a market share of $\frac{1}{4}$ the condition $\frac{1}{4} \ell \frac{1}{1-\delta} \geq \frac{1}{4} h \frac{1}{1-\delta(1-q)}$ should be satisfied. This condition is equivalent to $\delta \geq \frac{h-\ell}{h-\ell+q \ell}$, the first inequality in the table. The conditions corresponding to market shares $\frac{1}{2}$ and $\frac{3}{4}$ and for the other profiles in this table and those of the next two propositions are obtained in a similar fashion.

The conditions in the table reveal that an equilibrium in which in all states low (high) prices are charged exists when the discount factor is sufficiently high (low). Since the symmetric state is strategically absorbing, the situation in the asymmetric states is strategically equivalent to that in the symmetric state of the three state model of the previous section. Therefore, an explanation of the existence of the other two equilibria for intermediate values of the discount factor boils down to a repetition of earlier arguments.

Proposition 4.5.2. Symmetric pure stationary subgame perfect equilibria in which state dynamics drives to the strategically absorbing symmetric state exist precisely when the conditions in Table 4.4 are met.

\begin{tabular}{lccc}
\hline & Market share 0.25 & Market share 0.5 & Market share 0.75 \\
\hline$[L H H]$ & $\delta \geq \frac{h-\ell}{h-\ell+r h}$ & $\delta \leq \frac{2(h-\ell)}{2(h-\ell)(1-r)+p h}$ & $\delta \leq \frac{3(h-\ell)}{3(h-\ell)+r(3 \ell-2 h)}$ \\
{$[L L H]$} & $\delta \geq \frac{h-\ell}{h-\ell+r(2 \ell-h)}$ & $\delta \geq \frac{2(h-\ell)}{2(h-\ell)(1-r)+p \ell}$ & $\delta \leq \frac{3(h-\ell)}{3(h-\ell)+r \ell}$ \\
\hline
\end{tabular}

Table 4.4: Only the symmetric state is absorbing. 
Chapter 4. Dynamic Competition with Consumer Inertia

We see that equilibria with a tendency to induce equal market share only exist for intermediate values of the discount factor. In these equilibria, the firms opt for the high (low) price when they have the higher (smaller) market share. This implies that in asymmetric states, the firm with the lower market share has a strong incentive to attack (low price is a best response to high price), while the firm with the larger market share has no incentive to defend (high price is a best response to low price). Notice, however, that the conditions for these profiles to be an equilibrium in the symmetric state are mutually exclusive and hence never co-exist as an equilibrium.

Proposition 4.5.3. Symmetric pure stationary subgame perfect equilibria that push state dynamics to monopolization exist precisely when the conditions in Table 4.5 are met. In the table, * and ** refer to the solutions to the

\begin{tabular}{lccc}
\hline & Market share 0.25 & Market share 0.5 & Market share 0.75 \\
\hline$[H L L]$ & $\delta \leq \frac{h-\ell}{h-\ell+q \ell}$ & $*$ & $\delta \geq \frac{3(h-\ell)}{3(h-\ell)+q h}$ \\
{$[H H L]$} & $\delta \leq \frac{h-\ell}{h-\ell+q \ell}$ & $* *$ & $\delta \geq \frac{3(h-\ell)}{3(h-\ell)+q h}$ \\
\hline
\end{tabular}

Table 4.5: Monopolization may result.

quadratic inequalities

$$
\frac{1}{2} \ell \frac{1}{1-\delta} \geq\left(\frac{1}{2} h+\delta p \frac{1}{4} h \frac{1}{1-\delta(1-q)}\right) \frac{1}{1-\delta(1-p)}
$$

and

$$
\frac{1}{2} h \frac{1}{1-\delta} \geq\left(\frac{1}{2} \ell+\delta p\left(\frac{3}{4} \ell+q \frac{\delta}{1-\delta} h\right) \frac{1}{1-\delta(1-q)}\right) \frac{1}{1-\delta(1-p)}
$$

respectively.

Like those of the previous proposition, equilibria with a tendency to induce monopolization only exist for intermediate values of the discount factor. In these equilibria, the firms opt for the low (high) price when they have the higher (smaller) market share. This implies that in asymmetric states, the firm with the higher market share has a strong incentive to fight for the monopoly position (low price is a best response to high price), while the firm with the smaller market share winks (high price is a best response to low price). Given the behavior in the asymmetric competitive states, leaving the symmetric state implies monopolization (sooner or later). Strategically the situation in the symmetric state is therefore not different from that in the model with one competitive state. From this we can conclude that the 
4.5. Market share dynamics

profiles $[H H L]$ and $[H L L]$ only constitute an equilibrium for sufficiently low and respectively high discount factors and never co-exist as an equilibrium.

On basis of the propositions we can formulate the following corollary, which is parallel to Corollary 4.3.2.

Corollary 4.5.4. High price equilibria ( $[H H H]$ ) do only exist for low values of the discount factor and low price equilibria ([LLL]) only for high discount factors. For very low (high) values of the discount factor, the high (low) price equilibrium is unique. Moreover, these equilibria never co-exist and there is a non-degenerate interval of discount values for which none of these two outcomes constitutes an equilibrium.

The following corollary summarizes some properties for limiting cases of the five state model and are easily verified by substitution of the respective limit values in the conditions within the propositions.

Corollary 4.5.5. (i) There is no equilibrium in which a firm plays action $L$ when its market share is $\frac{1}{2}$ if $p=0$. (ii) There is no equilibrium in which a firm plays action $L$ when its market share is $\frac{3}{4}$ if $q=0$. (iii) There is no equilibrium in which a firm plays action $L$ when its market share is $\frac{1}{4}$ if $r=0$. (iv) $[L L L]$ is the unique equilibrium if $h=\ell$. (v) There is no equilibrium in which there is a state where both firms choose action $L$ if $\ell=0$.

The first statement implies that firms harvest when an increase in market share is impossible for both firms. The condition in the second (third) statement implies that monopolization (return to the symmetric state) is impossible. Therefore, the only reason for the larger (smaller) firm to set a low price is to avoid loss of market share. However, the threat of loss in market share is only applicable if the opponent with the smaller (larger) market share would set a low price. But, in anticipation of the opponent protecting its high (low) market share, in absence of the possibility to lose market share, the smaller (larger) firm will set a high price. Hence, in equilibrium the larger (smaller) firm will never choose the low price with probability one. The fourth statement indicates that when harvesting incentives disappear only low prices are chosen. Finally, the fifth statement indicates that when the low price is associated with marginal cost pricing, regardless of the state, the best response to the opponent setting the low price is to set the high price.

We finish this section by two examples that reveal interesting market share dynamics to be embodied by the model with five states. The first example focusses on market share dynamics that induces a monopoly with 
Chapter 4. Dynamic Competition with Consumer Inertia

probability one in the long-run; the second example focusses on enduring market share fluctuations to be possible.

Example 4.5.6. (monopolization) In general, the market share dynamics induces a monopolistic market in the long-run when the (symmetrically behaving) firms randomize their action in the symmetric state and choose action $H$ (L) with positive probability when they have the smaller (larger) market share in the asymmetric states.

One configuration of parameters for which such behavior is part of a stationary subgame perfect equilibrium is when $h=5, \ell=3.25, p=0.5, q=0.15$, $r=0.75$ and $\delta=0.7$. In fact, there is an equilibrium in which firms select the high price with probability $0.5716,0.0427$ and 0.1099 when the market share is $0.25,0.50$ and 0.75 respectively. Figure 4.7 presents the Markov chain generated by this equilibrium.

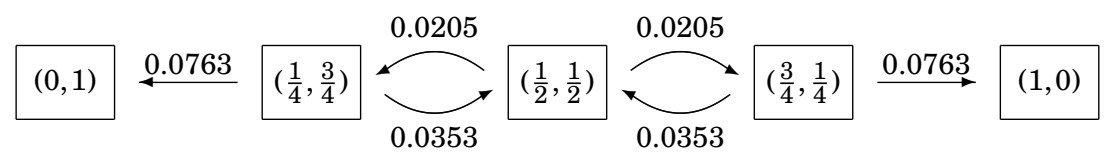

Figure 4.7: Markov chain resulting in monopolization.

Since firms randomize their action in each state, market shares may fluctuate and stagnate for a while, but inevitably reach one of the absorbing monopolistic states. One property that is easily derived from this Markov chain is that when the process starts in an asymmetric state, the probability that it is the firm with the larger installed base that will ultimately end up as monopolist equals 0.8418.

Example 4.5.7. (enduring market share fluctuations) In general, the market share dynamics induces enduring market share fluctuations when the (symmetrically behaving) firms randomize their action in the symmetric state and choose action $L$ with positive probability when it has the smaller market share and choose action $H$ with positive probability when it has the larger market share in the asymmetric states, with at least one of these probabilities being equal to one.

One configuration of parameters for which such behavior is part of a stationary subgame perfect equilibrium is when $h=5, \ell=3, p=0.7, q=0.4$, 
4.6. Generalization of equilibrium properties

$r=0.5$ and $\delta=0.65$. In fact, there is an equilibrium in which firms select the high price with probability 0.0000, 0.7854 and 1.0000 when the market share is $0.25,0.50$ and 0.75 respectively. Figure 4.8 presents the Markov chain generated by this equilibrium.

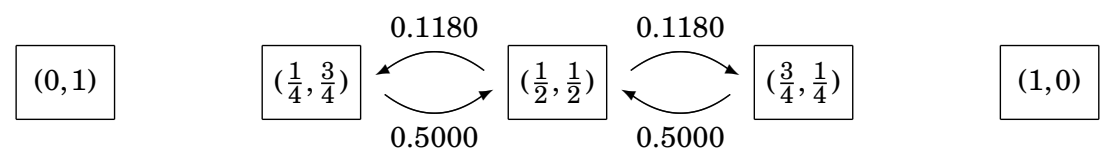

Figure 4.8: Markov chain giving rise to enduring market share fluctuations.

Since firms randomize their action in the symmetric state, a transition to one of the asymmetric states is expected to materialize in finite time. Once an asymmetric state is reached, the firm with the smaller market share starts fighting for gaining back the lost market share, which the firm with the larger market share accommodates. As a result, the process will eventually return to the state with equal market shares. The invariant distribution over states predicts the system to be in the symmetric state with probability 0.6793 in the long-run; with the remaining probability mass the system resists in one of the asymmetric states, each with equal probability.

\subsection{Generalization of equilibrium properties}

In the previous sections, we examined pure stationary subgame perfect equilibria on a small number of competitive states and derived conditions for their existence in terms of the discount factor. A special emphasis was placed on high price and low price equilibria, in which firms set the high price or respectively the low price in every state. In this section, we extend our investigation to the situation where the competition between firms is taking place on an arbitrary number of equidistant states $s_{0}, s_{1}, \ldots, s_{K}$, where $s_{k}$ is the state in which firms 1 and 2 have market shares $\frac{k}{K}$ and $1-\frac{k}{K}$ respectively. The transition probabilities when the firms choose different prices are only assumed to be positive. This means that our analysis also includes asymmetric situations.

Proposition 4.6.1. Assume that two pure stationary subgame perfect equilibria co-exist for a certain discount factor. Then, it cannot be the case that in one equilibrium, both firms set the high prices in two neighboring competitive 
Chapter 4. Dynamic Competition with Consumer Inertia

states, whereas in the other equilibrium, both firms set the low prices in these two states.

Proof . Consider two pairs of pure stationary strategies $\sigma=\left(\sigma^{1}, \sigma^{2}\right)$ and $\tau=\left(\tau^{1}, \tau^{2}\right)$ and two neighboring competitive states $s_{k}$ and $s_{k+1}$. Assume that $\sigma$ prescribes the high price for both firms in $s_{k}$ and $s_{k+1}$, whereas $\tau$ prescribes the low price for both firms in $s_{k}$ and $s_{k+1}$. We show that $\sigma$ and $\tau$ cannot co-exist as equilibria for any discount factor. Due to symmetry, we may assume that $k \leq \frac{K}{2}$.

With regard to $\sigma$, firm 1's discounted profit with starting state $s_{k}$ is $\frac{k}{K} h \frac{1}{1-\delta}$. If firm 1 deviates at the first period by setting the low price in state $s_{k}$ and continues with $\sigma^{1}$ afterwards, then its discounted profit becomes $\frac{k}{K} \ell+\delta\left[p \frac{k+1}{K} h \frac{1}{1-\delta}+(1-p) \frac{k}{K} h \frac{1}{1-\delta}\right]$, where $p$ denotes the transition probability from state $s_{k}$ to state $s_{k+1}$ when firm 1 sets a lower price than firm 2 in state $s_{k}$. For $\sigma$ to be an equilibrium, this deviation by firm 1 should not be profitable, which is exactly the case when $\delta \leq \underline{\delta} \equiv \frac{k(h-\ell)}{k(h-\ell)+p h} .8$

With regard to $\tau$, firm 2's discounted profit with starting state $s_{k}$ is $\frac{K-k}{K} \ell \frac{1}{1-\delta}$. If firm 2 deviates at the first period by setting the high price in state $s_{k}$ and continues with $\tau^{2}$ afterwards, then his discounted profit becomes $\frac{K-k}{K} h+\delta\left[p \frac{K-k-1}{K} \ell \frac{1}{1-\delta}+(1-p) \frac{K-k}{K} \ell \frac{1}{1-\delta}\right]$. For $\tau$ to be an equilibrium, this deviation by firm 2 should not be profitable, which is exactly the case when $\delta \geq \bar{\delta} \equiv \frac{(K-k)(h-\ell)}{(K-k)(h-\ell)+p \ell}$.

Since $h>\ell$ and $k \leq \frac{K}{2}$ by assumption, it is easily verified that $\underline{\delta}<\bar{\delta}$, and therefore there is no discount factor $\delta$ for which both $\sigma$ and $\tau$ constitute an equilibrium.

The next result follows immediately from the previous proposition (for at least two competitive states) and Corollary 4.3.2 (for just one competitive state).

Corollary 4.6.2. High price equilibria $([H H \cdots H])$ and low price $([L L \cdots L])$ equilibria cannot co-exist for any discount factor.

We noticed in the previous sections that high price equilibria corresponded to low discount factors, whereas low price equilibria to high discount factors. This holds true in general, as stated in the next proposition.

\footnotetext{
${ }^{8}$ Here we apply the one-shot deviation principle, which states that for the verification of a certain strategy profile to constitute an equilibrium, for all histories (including time and current state) only the impact of one-period deviations have to be considered.
} 
4.6. Generalization of equilibrium properties

Proposition 4.6.3. There exist threshold values $\delta_{1}, \delta_{2}$ and $\delta_{3}$ for the discount factor such that $0<\delta_{1} \leq \delta_{2}<\delta_{3}$ and the following properties hold:

1. A high price equilibrium ([HH $\cdots H]$ ) exists precisely when the discount factor is at most $\delta_{2}$. Furthermore, if the discount factor is below $\delta_{1}$, then the high price equilibrium is the unique stationary subgame perfect equilibrium.

2. A low price equilibrium ([LL $\cdots L])$ exists precisely when the discount factor is at least $\delta_{3}$.

Proof . In view of Corollary 4.6.2, we only need to show that there exist positive thresholds $\delta_{1}, \delta_{2}$ and $\delta_{3}$ with the above properties. Let $\sigma_{H}^{i}$ and $\sigma_{L}^{i}$ respectively denote the high price strategy and the low price strategy for firm $i$.

1. The existence of $\delta_{1}$. When $\delta=0$, the firms are myopic and choosing the high price is a strictly dominant action in every state. Due to continuity, the high price remains a strictly dominant action on a proper interval $\left[0, \delta_{1}\right]$ of discount factors, and hence $\left(\sigma_{H}^{1}, \sigma_{H}^{2}\right)$ is the unique stationary subgame perfect equilibrium for all $\delta \in\left[0, \delta_{1}\right]$.

2. The existence of $\delta_{2}$. It is sufficient to show that if $\left(\sigma_{H}^{1}, \sigma_{H}^{2}\right)$ constitutes an equilibrium for a certain discount factor, then $\left(\sigma_{H}^{1}, \sigma_{H}^{2}\right)$ remains an equilibrium for lower discount factors. So, assume that $\left(\sigma_{H}^{1}, \sigma_{H}^{2}\right)$ is an equilibrium for some discount factor $\delta>0$. With respect to $\left(\sigma_{H}^{1}, \sigma_{H}^{2}\right)$, firm 1's discounted profit when the starting state is the competitive state $s_{k}$ equals $V(\delta)=\frac{k}{K} h \frac{1}{1-\delta}$. If firm 1 deviates at the first period by setting the low price and continues with $\sigma_{H}^{1}$ afterwards, then firm 1's discounted profit becomes $V^{\prime}(\delta)=\frac{k}{K} \ell+\delta\left[p \frac{k+1}{K} h \frac{1}{1-\delta}+(1-p) \frac{k}{K} h \frac{1}{1-\delta}\right]$, where $p$ denotes the transition probability from state $s_{k}$ to state $s_{k+1}$ when firm 1 sets the low price and firm 2 sets the high price in state $s_{k}$. Since $\left(\sigma_{H}^{1}, \sigma_{H}^{2}\right)$ is an equilibrium for discount factor $\delta$, this deviation by firm 1 cannot be profitable and we must have $V(\delta) \geq V^{\prime}(\delta)$. One can verify that this implies $V\left(\delta^{\prime}\right) \geq V^{\prime}\left(\delta^{\prime}\right)$ for every discount factor $\delta^{\prime}$ below $\delta$. This means that this deviation by firm 1 is not profitable even for discount factors below $\delta$. Consequently, based on the onedeviation principle, $\sigma_{H}^{1}$ is a best response to $\sigma_{H}^{2}$, and similarly, $\sigma_{H}^{2}$ is a best response to $\sigma_{H}^{1}$ for discount factors at most $\delta$. Therefore, $\left(\sigma_{H}^{1}, \sigma_{H}^{2}\right)$ constitutes an equilibrium for all discount factors below $\delta$.

3. The existence of $\delta_{3}$. First we prove that $\left(\sigma_{L}^{1}, \sigma_{L}^{2}\right)$ is an equilibrium for sufficiently large discount factors. With respect to $\left(\sigma_{L}^{1}, \sigma_{L}^{2}\right)$ and some discount factor $\delta$, firm 1's discounted profit when the starting state is a compet- 
Chapter 4. Dynamic Competition with Consumer Inertia

itive state $s_{k}$ equals $\frac{k}{K} \ell \frac{1}{1-\delta}$. If firm 1 deviates at the first period by setting the high price and continues with $\sigma_{L}^{1}$ afterwards, then his discounted profit becomes $\frac{k}{K} h+\delta\left[p \frac{k-1}{K} \ell \frac{1}{1-\delta}+(1-p) \frac{k}{K} \ell \frac{1}{1-\delta}\right]$, where $p$ denotes the transition probability from state $s_{k}$ to state $s_{k-1}$ when firm 1 sets the high price and firm 2 sets the low price in state $s_{k}$. Since the latter amount is smaller for large $\delta$, we may conclude that this deviation by firm 1 is not profitable for large discount factors. Consequently, based on the one-deviation principle, $\sigma_{L}^{1}$ is a best response to $\sigma_{L}^{2}$, and similarly, $\sigma_{L}^{2}$ is a best response to $\sigma_{L}^{1}$ for large discount factors. Therefore, $\left(\sigma_{L}^{1}, \sigma_{L}^{2}\right)$ is an equilibrium for sufficiently large discount factors. One can check, similarly to the part in 2., that if $\left(\sigma_{L}^{1}, \sigma_{L}^{2}\right)$ constitutes an equilibrium for a certain discount factor, then $\left(\sigma_{L}^{1}, \sigma_{L}^{2}\right)$ remains an equilibrium for all higher discount factors. This completes the proof.

In view of the previous proposition, low price strategies constitute a stationary subgame perfect equilibrium for sufficiently large discount factors. However, this equilibrium is not necessarily unique, and there can be other subgame perfect equilibria even in terms of pure stationary strategies. One can verify that if there are four states $(K=3)$ and the transition probabilities, when the firms choose different prices, are all equal, then $[L H]$ is also a symmetric equilibrium for large discount factors (when $h>3 \ell$ ).

\subsection{Concluding remarks}

Our model assumes that consumers are either unable or unwilling to switch firms collectively and immediately when faced with a price difference. This implies that firms are unable to immediately increase demand and profit by decreasing their price. Markets in which it is likely to expect that a price decrease by one of the firms does not lead to an immediate capturing of all demand are those where some or all consumers face (high) switching costs. Klemperer (1989) and Beggs and Klemperer (1992) have identified a few industries in which this is likely: the computer industry (once you have familiarized yourself with one producer's system, you might be unwilling to change to another's) and the banking market (it might be quite a hassle to change one's account to another bank). Other markets that are likely to see such consumer behavior are those in which it might be hard for consumers to immediately become aware of price differences. For instance, it might be difficult for consumers to notice emerged price differences between the su- 
4.7. Concluding remarks

permarket they usually visit and other alternatives in the neighborhood. Finally, loyalty, consumptive externalities, or the presence of (yearly) contracts are alternative reasons for consumers not to switch en masse and immediately. Our model captures all these situations and therefore the behavioral implications of our results are applicable to these markets.

However, not only the assumptions on the demand side drive our results on pricing behavior, but instead it is the particular time-tradeoff induced by these assumptions that matters. Our results seem to apply to any industry that is characterized with strategic decisions having immediate cost consequences and potential future benefits. For example, the particular time-tradeoff manifests in high-tech industries where firms constantly are exposed to decisions to invest in innovative research and development. In our model, the actions in the competitive states are then to be interpreted as high and low R\&D investments and the transition probabilities then represent the likelihood that an investment leads to a successful innovation and an increased attractiveness of the evolved product. As long as the time-tradeoff is preserved our results seem to be robust to an extension to more firms or to a relaxation of the equidistance assumption for the state space. Also the inclusion of absorbing monopolistic states is not critical. Any possibility to increase future profits by pricing aggressively would satisfy the incentives connected to the particular time-tradeoff under investigation. Further evidence that the presence of an absorbing state is not the essential factor driving equilibrium behavior is provided by the last example in Section 4.4. It is also corroborated by the results from the model with five states, our generalization results and the fact that it is easily possible to find equilibria in which high prices prevail, something that we should not expect if the absorbing monopoly states would play such an influential role. Instead, the essential ingredient of our model is the time-tradeoff that we have introduced. Finally, one yet unnoticed, but remarkable, feature of our model is that no assumptions on product homogeneity or heterogeneity were made; the consequences of price differences are directly translated in the state profits and transition probabilities.

An interesting question from a policy maker's perspective is whether market conditions can be regulated in such a way that low prices are implemented. Any policy that facilitates creation of a dominant market position (monopolization), for instance via reduction of switching $\operatorname{costs}^{9}$, leads to a decrease in the minimum discount factor for which low prices result.

\footnotetext{
${ }^{9}$ In our model represented by a higher $p$.
} 
Chapter 4. Dynamic Competition with Consumer Inertia

Such a policy may not actually implement a monopolistic market structure, the mere fact that a monopoly position is possible and reachable (for all firms in the market) is what triggers aggressive pricing. From that viewpoint it seems unwise to use government bailouts since this would at the least decrease the perceived probability of bankruptcy and hence monopoly. Also restrictive antitrust policies would lead to a low probability of actually reaching a dominant market position or even monopoly. These policies would then have an upward effect on prices in equilibrium. In a similar vein, and related to a finding of Chen and Rosenthal (1996), our results show that it might be unwise to use static measures of market power if the underlying competition is of a dynamic nature. The results of our model with five states show that equilibria are possible in which the market situation fluctuates between all three competitive states, while neither firm eventually attains a monopoly situation. If one would assess the competitive situation at a time when the market would find itself in an asymmetric state, one might conclude that intervention would be necessary, even though the equilibrium strategies would naturally lead the market back to the symmetric state.

\subsection{Appendix: incentives, best responses and equi- libria}

In this appendix we illustrate the different incentive and best response structures and resulting equilibrium configurations of our three state model. We fix the following parameters: $h=5, \ell=3, p=0.25$ From this we can derive the three threshold values of the discount factor: $\delta_{1}=0.6052, \delta_{2}=0.6154$, $\delta_{3}=0.7273$. The next seven figures present the seven possible cases that can arise depending on the actual discount factor. The left graph in the figure provides the corresponding incentive structure, where on the vertical axis we plot the normalized present value: $\bar{V}=(1-\delta) V$ (the average expected profit of playing the respective stationary strategies). The middle and right

graphs display the resulting best response correspondence and equilibrium configuration respectively. 
4.8. Appendix: incentives, best responses and equilibria
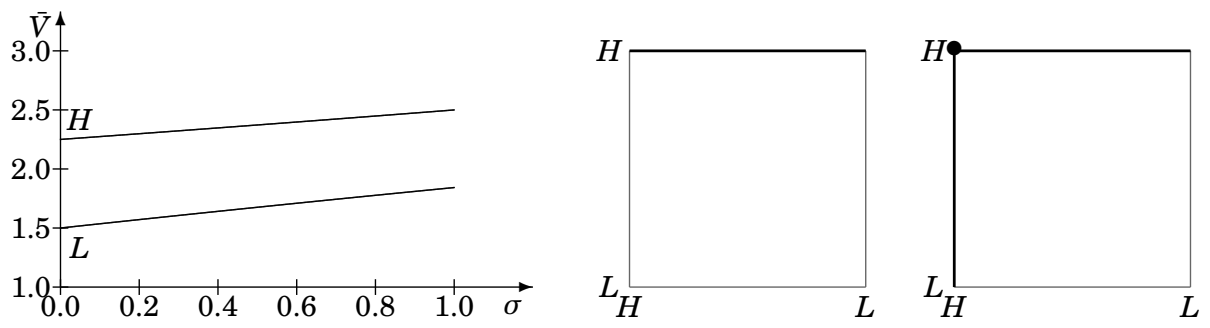

Figure 4.9: $\delta=0.3026<\delta_{1}$.
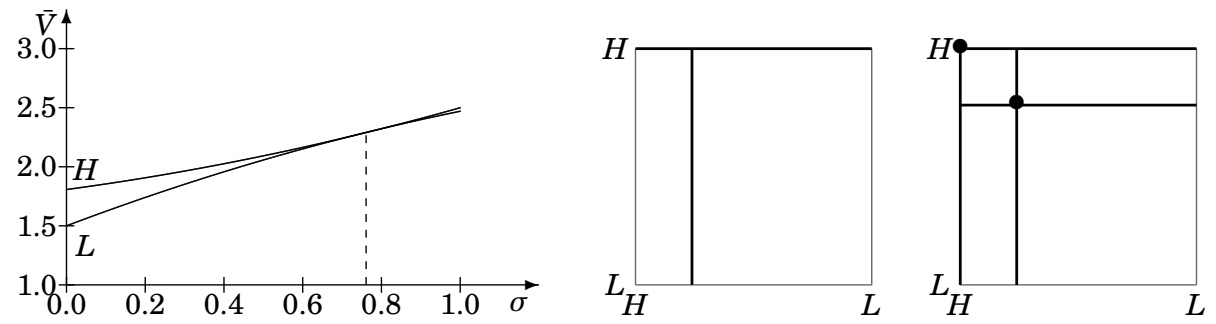

Figure 4.10: $\delta=0.6052=\delta_{1} ; \sigma_{-}=\sigma_{+}=0.7609$.
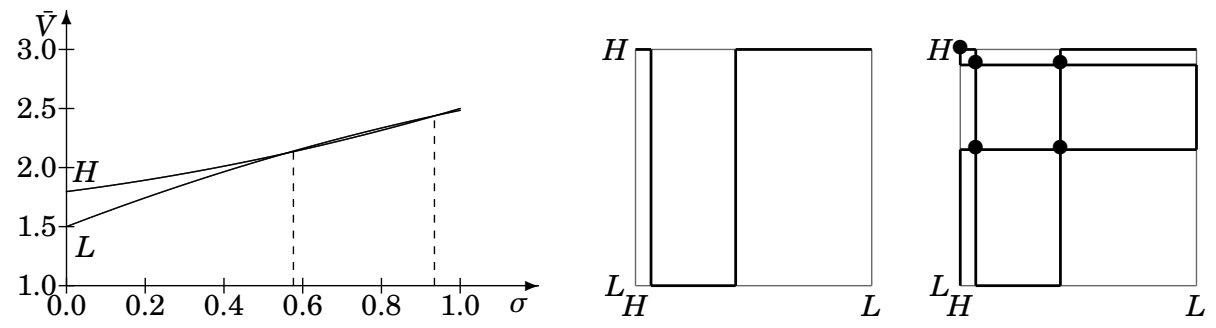

Figure 4.11: $\delta=0.6103 \in\left(\delta_{1}, \delta_{2}\right) ; \sigma_{-}=0.5763, \sigma_{+}=0.9345$.
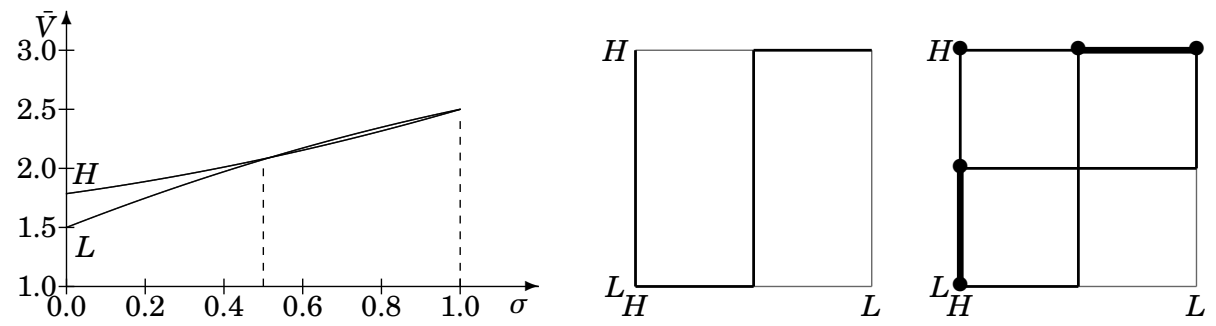

Figure 4.12: $\delta=0.6154=\delta_{2} ; \sigma_{-}=0.5000, \sigma_{+}=1.0000$. 

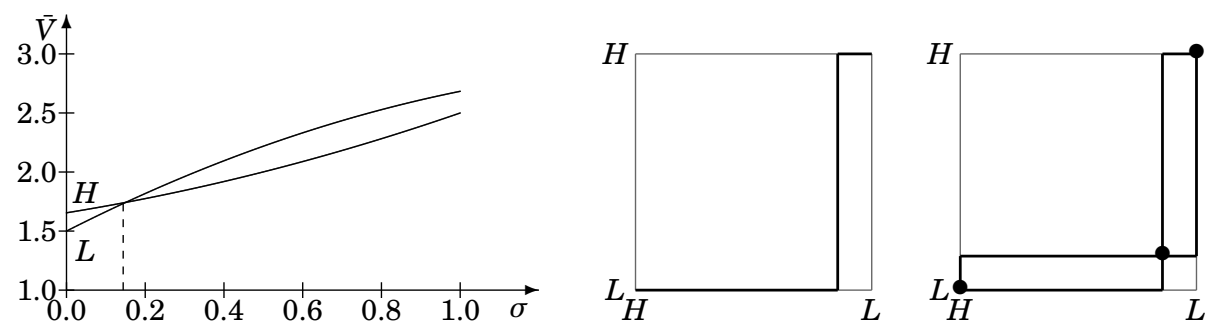

Figure 4.13: $\delta=0.6713 \in\left(\delta_{2}, \delta_{3}\right) ; \sigma_{-}=0.1439$.
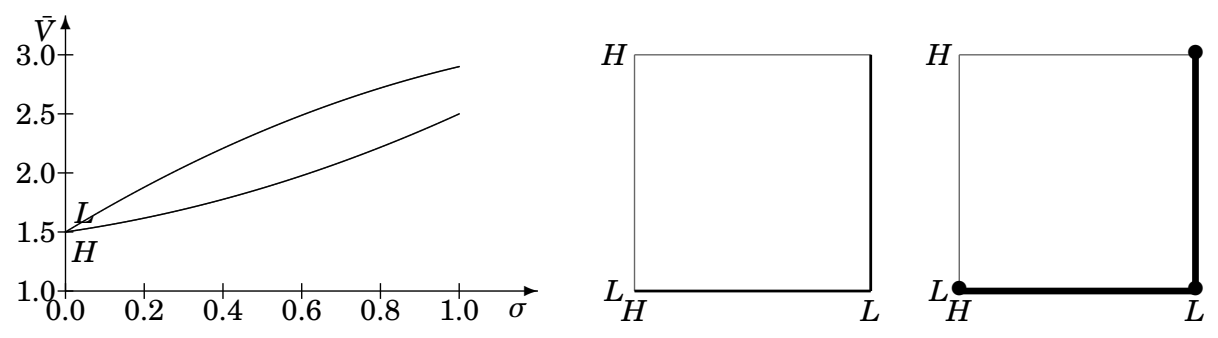

Figure 4.14: $\delta=0.7273=\delta_{3} ; \sigma_{-}=0.0000$.
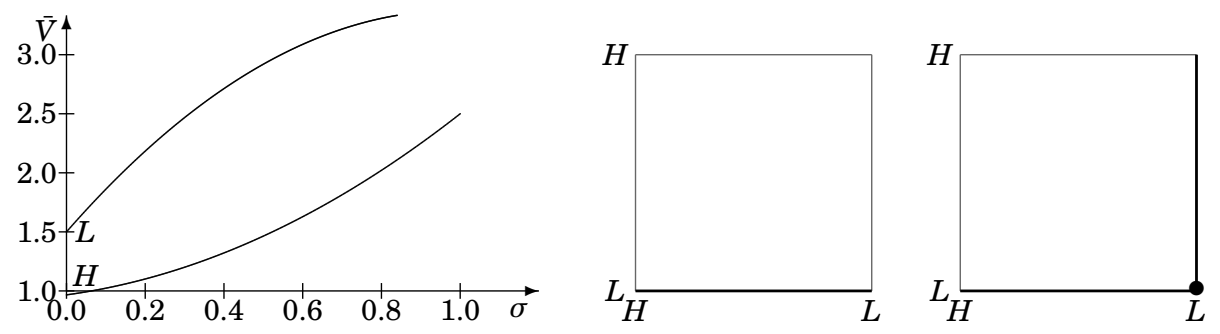

Figure 4.15: $\delta=0.8636>\delta_{3}$. 


\section{Chapter 5}

\section{Competition versus Collusion: The Impact of Consumer Inertia}

\subsection{Introduction}

Standard theory of industrial collusion assumes that firms essentially face a prisoner's dilemma when attempting to fix prices above competitive levels. ${ }^{1}$ Slightly undercutting the collusive price presumably leads to an immediate and substantial increase in sales and thereby profits. Following modern economic theory, firms can sustain high prices by ensuring that cheating does not go unpunished. Firms will then have an incentive to abide by the collusive agreement when short-run gains of cheating fall short of future losses, which typically requires a credible punishment strategy as well as a sufficiently high discount factor. ${ }^{2}$ The notion that colluding oligopolists are confronted with an intertemporal trade-off between short-term gains and future losses lies at the heart of most contributions to the theory of industrial collusion.

A critical assumption in these studies is that a seller can indeed increase its sales instantly and significantly by setting its price slightly below the agreed level. While clearly there are instances in which consumers respond

\footnotetext{
${ }^{1}$ This chapter is based on Bos, Peeters and Pot (2010a).

${ }^{2}$ Friedman (1971) was among the first to show that collusion is sustainable in the context of an infinitely repeated game when firms are sufficiently patient.
} 
Chapter 5. Competition versus Collusion: The Impact of Consumer Inertia

quickly to price changes, it is often more realistic to assume that they will not switch suppliers instantaneously. For example, in many industries, customers exhibit brand loyalty, switching costs or a lack of information on the price and quality of competing products. Also, buyers may have established long-term contracts with their suppliers. ${ }^{3}$ These types of consumer inertia directly affect the intertemporal trade-off that oligopolists face. Given that demand is viscous, undercutting the collusive price does not lead to a short-term gain but a loss. This holds because individual demand is not immediately affected by the change in price and existing customers spend less on the product or service. At the same time, however, cutting price might lead to additional future profits as buyers may switch over time to a lower priced firm. ${ }^{4}$

The basic observation that buyers may not respond instantly to a price cut generates a number of interesting questions. How does (the degree of) consumer inertia affect the ability of firms to sustain collusion? Under what industry conditions can we expect firms to set high prices? In this chapter, we explore these and related issues. We consider a model of dynamic price competition in which two sellers interact for an infinite number of periods. ${ }^{5}$ In any given period, customers are loyal to their seller independent of the price it charges. ${ }^{6}$ Hence, firms have some market power over their existing customers. However, buyers might switch suppliers in future periods if they observe a price difference. Consequently, in deciding whether or not to cut price, firms are given the following options. On the one hand, a seller may charge a high price and thereby exploit its current customer base ('harvesting incentive'). Yet, by doing so, it faces the risk of losing customers in the future when its rival chooses to price low. Alternatively, a seller may charge a low price, thereby foregoing short-run profits, but with some probability it increases its market share in the future ('investment incentive').

In deciding whether or not to deviate from the collusive price, there are

\footnotetext{
${ }^{3}$ Klemperer (1995) provides many arguments for why buyers may not instantly respond to a price cut.

${ }^{4}$ Strategic pricing behavior in the presence of demand viscosity is also studied in Chen and Rosenthal (1996) and Radner (2003). However, these papers do not consider the impact of consumer inertia on (tacit) collusion.

${ }^{5} \mathrm{~A}$ similar setting is studied in Pot, Flesch, Peeters and Vermeulen (2009) (and chapter 4 of this thesis), which fully characterizes the set of stationary equilibria. However, that paper does not consider more sophisticated behavioral strategies and collusion.

${ }^{6}$ An alternative interpretation is that consumers face substantial switching costs. See, for example, Farrell and Shapiro (1988) and Beggs and Klemperer (1992).
} 
at least three factors that play an important role. First, this decision will be driven by the amount of additional sales that can potentially be obtained by cutting price. This depends on the relation between consumer tastes and preferences and product attributes. For instance, if products are significantly differentiated, then a price cut will only attract a limited number of additional buyers. Second, the decision depends on the likelihood that customers will indeed switch suppliers. This is a dynamic factor, which includes loyalty and informational effects. For example, a customer who purchased from a particular seller may, ceteris paribus, be more inclined to buy from this seller in the future. That is, consumers might not always opt for the cheapest product even when the products are functionally identical. ${ }^{7}$ Third, sustainability of high prices depends on the value of expected additional sales. Indeed, like in the standard model of collusion, the rate that is used to discount future profits is an important determinant of strategic pricing behavior. These three factors are all taken into account in our analysis.

Summarizing our main results, sustainability of high prices does not require punishment strategies when firms are sufficiently myopic. This result holds for all customer preferences and any degree of consumer inertia. Moreover, high prices can be sustained for all discount factors when demand is sufficiently viscous. ${ }^{8}$ Finally, we find that the ability to maintain high prices might depend non-monotonically on the level of the discount factor. That is, collusion may be sustainable for extreme values of the discount factor, but not when firms are moderately patient. For this to occur, it is required that the industry exhibits network externalities and that buyers are sufficiently inert.

All these results contrast with predictions of the standard model of collusion and therefore provide a number of interesting insights with regard to strategic pricing behavior. For example, our analysis sheds some light on when we may expect competition and collusion to lead to similar market outcomes. ${ }^{9}$ This is valuable information in light of antitrust enforcement, particularly because economic methods of cartel detection typically aim to

\footnotetext{
${ }^{7}$ One way to think about this is that there is an informational advantage about the quality of the product when used before. As a consequence, a customer has to put some (costly) effort in finding out whether he could better switch or not. Likewise, customers may be slow to become aware of the most attractive brand due to a lack of (or a lag in) relevant information.

${ }^{8}$ This contrasts with Padilla (1995) who finds that tacit collusion in markets with switching costs is more difficult to sustain than in markets without switching costs.

${ }^{9}$ This possibility is also suggested by Radner (2003).
} 
Chapter 5. Competition versus Collusion: The Impact of Consumer Inertia

discriminate between competitive and collusive pricing behavior. ${ }^{10}$ Moreover, for a particular degree of consumer inertia, a credible and severe punishment strategy might be insufficient to sustain high prices in some types of industries. In this case, firms may try to influence the level of inertia to create a situation in which high prices can be sustained. For instance, sellers may agree not to advertise in each other's home markets. In this chapter, we argue how such direct communication may help firms to facilitate collusion.

This chapter proceeds as follows. In the next section, the model is introduced and described. Section 5.3 solves the model and provides a full characterization of high price equilibria. In Section 5.4, we discuss implications of our main findings. A formal illustration of how direct communication about prices may facilitate collusion is provided in Section 5.5. All proofs are in Section 5.6.

\subsection{Model}

Our prime purpose is to explore the qualitative impact of consumer inertia on the ability of firms to sustain high prices. To that end, we study an infinitely repeated price game between two sellers. Akin to a prisoner's dilemma, both can choose between two actions: a high (collusive) price $H$ and a low (competitive) price $L$. As demand is viscous, customers will not respond immediately to price changes. We take account of this by assuming that, in any given period, pricing decisions can only have an effect on the amount of future sales, and not on the amount of current sales. Note that this implies that charging a high price is a dominant strategy in the one-shot version of this game. Moreover, consumers might only consider switching when they can obtain the product or service at a lower price. Consequently, cutting price leads to a decrease in immediate profits with certainty, but a potential increase in future profits.

Given a common discount factor $\delta \in[0,1)$, both firms maximize the expected present value of their profit stream. Notice that the presence of demand viscosity gives firms temporary market power, which fundamentally alters the intertemporal trade-off that oligopolists face in traditional models of industrial collusion. In a repeated prisoner's dilemma, firms compare short-term gains with future losses when deciding whether or not to cut price. If buyers are inert, then undercutting the collusive price is beneficial

\footnotetext{
${ }^{10}$ See Harrington (2008) for an overview and discussion of economic methods of cartel detection.
} 
only when expected future profits outweigh short-term losses. Hence, firms have to decide whether to exploit their current customer base by charging a high price or to increase or protect their market share by setting a low price. In principle, any future reward would be sufficient to capture this intertemporal trade-off. ${ }^{11}$ Here, we model potential future gains by two absorbing monopolistic states. The structure of the game is depicted in Figure 5.1.

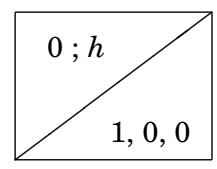

state 1

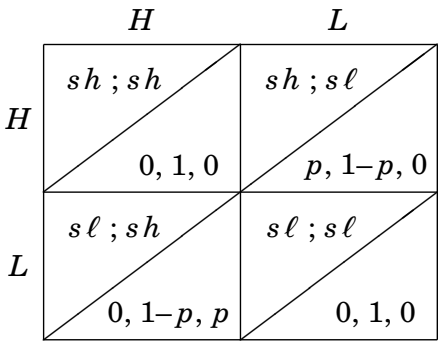

state 2

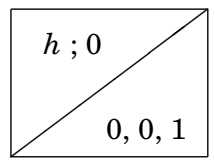

state 3

Figure 5.1: A duopolistic model of dynamic price competition with consumer inertia. In each cell, the north-west part shows respectively the profit of firm 1 (the row player) and firm 2 (the column player); the south-east part shows respectively the probability to transit to state 1 , state 2 and state 3 .

The price game contains three states; one competitive state (state 2) and two absorbing monopolistic states in which one of the firms has captured the entire market (state 1 and state 3 ). Starting in the competitive state, firms simultaneously and independently set a price. If both firms choose the same action, then play resumes with probability 1 in the competitive state. In this state, sales are assumed to equal $s \in(0,1)$ for both firms. Costs of production are normalized to 0 and fixed costs are absent. As a result, depending on whether firms opted for $H$ or $L$, profits in the competitive state are respectively given by $s h$ or $s \ell$ (with $h>\ell>0$ ). If firm $i$ chooses $L$ and its rival chooses $H$, then play resumes with probability $p \in(0,1]$ in the absorbing state in which firm $i$ is a monopolist. With probability $1-p$, play resumes in the competitive state. In the monopolistic state, the surviving firm earns a profit of $h$ every period.

In this setting, both parameters $p$ and $s$ have a broader interpretation. The parameter $p$ is the probability that a price cut is successful in attracting additional sales. It therefore captures the degree of consumer inertia. For

\footnotetext{
${ }^{11}$ Pot et al. (2009) and chapter 4 of this thesis provide analysis and evidence.
} 
Chapter 5. Competition versus Collusion: The Impact of Consumer Inertia

example, higher values of $p$ correspond to lower switching costs, more price awareness or less brand loyalty. The parameter $s$ represents the sales of a firm in competition relative to the sales it makes as a monopolist. When $s \geq \frac{1}{2}$, total sales in the competitive state (weakly) exceed the amount a monopolist can sell. This is characteristic for markets with differentiated goods or when products are complements. Thus, a larger $s$ can be interpreted as a higher level of differentiation or complementarity. By contrast, when $s<\frac{1}{2}$, total sales are higher when the market is served by one firm. This is typically the case when both firms sell incompatible network goods. A smaller $s$ then corresponds to a higher level of consumptive externalities. The parameters $p$ and $s$ thus allow us to take account of various degrees of demand viscosity and different types of markets.

\subsection{Results}

The model we study is contained in the class of finite discounted stochastic games and we will use the conventional concepts and methods. In this model, the most general type of strategy a firm can formulate is a behavior strategy in which decisions are conditioned on state, time, full history of all visited states and all actions chosen. A pair of behavior strategies constitutes a Nash equilibrium if, given the initial state, neither of the firms can improve its (expected) profits by unilaterally adopting another behavior strategy. One particular type of behavior strategy that firms can employ is a stationary strategy, in which decisions are independent of time and history and therefore conditioned on states only. A pair of stationary strategies that constitutes a Nash equilibrium is called a stationary equilibrium. If there does not exist any combination of state, time and history that allows a firm to profitably defect, then the Nash equilibrium is called subgame perfect.

The next result shows that high prices can be supported as a stationary subgame perfect equilibrium if and only if the discount factor is sufficiently low.

Proposition 5.3.1 (stationary behavior). High prices are sustainable as a stationary subgame perfect equilibrium if and only if

$$
\delta \leq \delta_{H} \equiv \frac{s(h-\ell)}{s(h-\ell)+p(1-s) h} .
$$

There exists no high price stationary subgame perfect equilibrium for high discount factors, because then the investment incentive dominates the harvesting incentive. Yet, high prices may still be sustainable as a subgame 
perfect equilibrium when firms adopt slightly more sophisticated strategies, e.g., trigger strategies. A trigger strategy basically consists of three parts: (1) a specification of the collusive strategy, (2) a specification of a punishment strategy to be adopted in the event of deviation from the collusive strategy, and (3) a specification of a strategy to be adopted when punished by the rival.

Firms choose high prices in the collusive phase. In case of defection, the most effective punishment is to price low. Note that as the punishment strategy is stationary, the deviating firm has a stationary best response. However, whether the punished firm responds by charging a high or a low price depends on the level of the discount factor. The punished firm optimally sets a low price when $\delta \geq \delta_{L} \equiv \frac{h-\ell}{h-(1-p) \ell}$ and a high price when $\delta<\delta_{L}$. The reason for this is that, when the discount factor is below the threshold $\delta_{L}$, the immediate costs of fighting for survival exceed the future benefits of being in the competitive state. ${ }^{12}$

In sum, the trigger strategy for both firms is given by

$T= \begin{cases}H & \text { if } L \text { has not been chosen in any previous period (collusion) } \\ L & \text { if the rival was the first to choose } L \text { (punishment) } \\ H & \text { if one was first to choose } L \text { and } \delta<\delta_{L} \text { (reaction to punishment) } \\ L & \text { if one was first to choose } L \text { and } \delta \geq \delta_{L} \text { (reaction to punishment). }\end{cases}$

Notice that, when both firms adopt this trigger strategy, the way the punishment affects the deviating firm's future profits differs for the two different ranges of the discount factor. For discount factors below $\delta_{L}$ there are no consequences for the future per-period profits as long as the market is in the competitive state, but in every future period there is a positive probability to be driven out of the market. For discount factors above $\delta_{L}$ there is a relative loss in all future per-period profits, while none of the firms will ever obtain a monopoly position (like in the case without deviation).

Next, we analyze when the trigger strategy profile constitutes a subgame perfect equilibrium. For this to be the case, there are two requirements. First, the strategies employed in the punishment phase should constitute a (stationary) subgame perfect equilibrium. Second, deviation from the coordinated high price strategies should not be beneficial. The first requirement is guaranteed to be satisfied according to the following proposition.

\footnotetext{
${ }^{12}$ In this model it would not be appropriate to revert to one-shot game Nash equilibrium strategies as that would imply choosing a high price as punishment. Therefore, firms revert to stationary subgame perfect equilibrium strategies.
} 
Chapter 5. Competition versus Collusion: The Impact of Consumer Inertia

Proposition 5.3.2 (punishment). Decisions in the punishment phase constitute a stationary subgame perfect equilibrium.

The conditions under which the second requirement is met depend on the value of the discount factor $\delta$ relative to the threshold $\delta_{L}$, because this determines the strategy that will be adopted in the punishment phase.

Proposition 5.3.3 (sustainability). Let $\delta \geq \delta_{L}$. High prices are sustainable in subgame perfect equilibrium if and only if

$$
\delta \leq \delta_{L L} \equiv \frac{s(h-\ell)}{p(h-s \ell)} .
$$

Let $\delta_{H}<\delta<\delta_{L}$. High prices are sustainable in subgame perfect equilibrium if and only if

$$
\delta \notin\left(\delta_{L H}^{-}, \delta_{L H}^{+}\right)
$$

with

$$
\delta_{L H}^{-} \equiv \frac{2(1-p) s(h-\ell)+p(h-s \ell)-\sqrt{[2(1-p) s(h-\ell)+p(h-s \ell)]^{2}-4(1-p) s(h-\ell)[s(h-\ell)+p h]}}{2(1-p)[s(h-\ell)+p h]}
$$

and

$$
\delta_{L H}^{+} \equiv \frac{2(1-p) s(h-\ell)+p(h-s \ell)+\sqrt{[2(1-p) s(h-\ell)+p(h-s \ell)]^{2}-4(1-p) s(h-\ell)[s(h-\ell)+p h]}}{2(1-p)[s(h-\ell)+p h]} .
$$

The first part of Proposition 5.3.3 specifies the condition for which high prices are sustainable when in the punishment phase the punishing firm sets low prices and the deviating firm responds optimally by charging a low price. The condition states that high prices are sustainable as long as the discount factor does not exceed $\delta_{L L}$. Observe that the threshold $\delta_{L L}$ can give rise to two scenarios. If $\delta_{L L}$ is less than one, then high prices cannot be sustained for high discount factors (Scenario 2 in Figure 5.2); otherwise high prices are sustainable for discount factors arbitrarily close to one (Scenario 1 in Figure 5.2).

The second part of Proposition 5.3.3 specifies the condition for which high prices are sustainable when in the punishment phase the punishing firm sets low prices and the deviator responds optimally with a high price. The condition shows that, with the exception of an interval of intermediate values of the discount factor, high prices are sustainable in equilibrium. As before, two scenarios may arise, depending on whether the interval $\left(\delta_{L H}^{-}, \delta_{L H}^{+}\right)$ has a nonempty intersection with the interval $\left(\delta_{H}, \delta_{L}\right)$ (Scenario b in Figure 5.2 ) or not (Scenario a in Figure 5.2).

Combining Propositions 5.3.1, 5.3.2 and 5.3.3, we summarize our findings in the following theorem. 
Theorem 5.3.4. The effect of the discount factor on the sustainability of high prices as a (stationary) subgame perfect equilibrium takes one of the four forms as depicted in Figure 5.2.

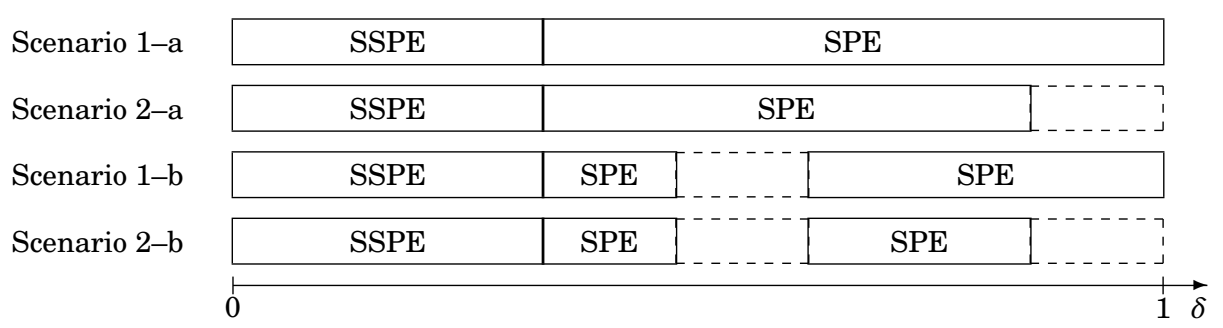

Figure 5.2: Sustainability of high prices by means of stationary strategies (SSPE) and trigger strategies (SPE) for different values of the discount factor. The values of the thresholds depend on the parameters $h, \ell, s$ and $p$ and are therefore not necessarily the same among the different scenarios.

Theorem 5.3.4 shows that the presence of consumer inertia results in three main differences as compared to an infinitely repeated prisoner's dilemma. First, while it is well-known that in standard models of collusion high prices can be sustained in a subgame perfect equilibrium when the discount factor is sufficiently high, we here find a reversed effect. In all four scenarios, high prices are an equilibrium outcome when the discount factor is sufficiently low. The explanation for this is that firms are short-term focused when the discount factor is low. If buyers are inert, then firms can maximize their profits through exploiting their current customer base by setting a high price. Moreover, for very low discount factors, any changes in future market share are considered to be of little importance and setting a high price is a strictly dominant strategy.

Remark If $\delta$ is sufficiently low, then the high price equilibrium is unique.

A second difference caused by consumer inertia is the possibility that high prices are sustainable as a subgame perfect equilibrium for every value of the discount factor (Scenario 1-a). As Theorem 5.3.4 shows, for high discount factors this requires the use of trigger strategies. If firms know that defecting will evoke a punishment phase in which low prices will be set in all future periods, then their only incentive to deviate is the possibility to obtain a monopoly position. However, if demand is viscous or when only a few 
Chapter 5. Competition versus Collusion: The Impact of Consumer Inertia

extra consumers can be gained by cutting price, then this potential "reward" may be insufficient to justify the immediate profit decrease that results from choosing a low instead of a high price. If this is the case, then high prices can be sustained in equilibrium for all values of the discount factor.

A third difference with standard models of collusion is that there may be a non-monotonicity in the sustainability of high prices (Scenario 1-b and $2-b)$. This striking result can occur for intermediate values of the discount factor. In this range, deviation from the trigger strategy is followed by a punishment phase in which the deviator responds optimally to the low price of its rival by setting a high price. In this case, the deviating firm foregoes part of its immediate profit in exchange for a chance to be a monopolist from the next period onwards. In case monopoly is not attained, per-period profits of the deviator will be at collusive levels from the next period onwards, because choosing a high price is the optimal response to the punishment. Notice, however, that as the punishing firm sets a low price, the deviator faces the risk of losing its market share in every period. These rather subtle differences in the timing of different profit streams can give rise to this apparent irregularity. Hypothetically, if we would let the discount factor increase from zero, we would find a threshold above which the expected profits of acquiring a monopoly position in period $t+1$ outweigh the immediate costs of cutting price in period $t$. At this point, high prices can no longer be supported as an equilibrium. Yet, if we would let the discount factor increase more, then the expected costs of losing market share from period $t+2$ onwards gains more weight. As a result, deviating becomes less attractive and high prices become sustainable again.

Which of the four scenarios applies depends on the value of the parameters $p$ and $s$, as the next result indicates.

Theorem 5.3.5. The relation between the parameters $p$ and $s$ and the scenarios of Theorem 5.3.4 is as depicted in Figure 5.3.

Scenarios 1-a and 1-b are characterized by high prices being sustainable for values of the discount factor arbitrarily close to one. Theorem 5.3.5 reveals that this situation arises for low values of $p$ and high values of $s$. In this case, chances of successful monopolization are low and the additional sales that can be obtained by cutting price are limited. As explained below Theorem 5.3.4, the reward of monopolization is not sufficient to justify the immediate profit decrease that results from choosing a low instead of a high price. This can be illustrated by looking at two extreme cases. If $p=0$, it 


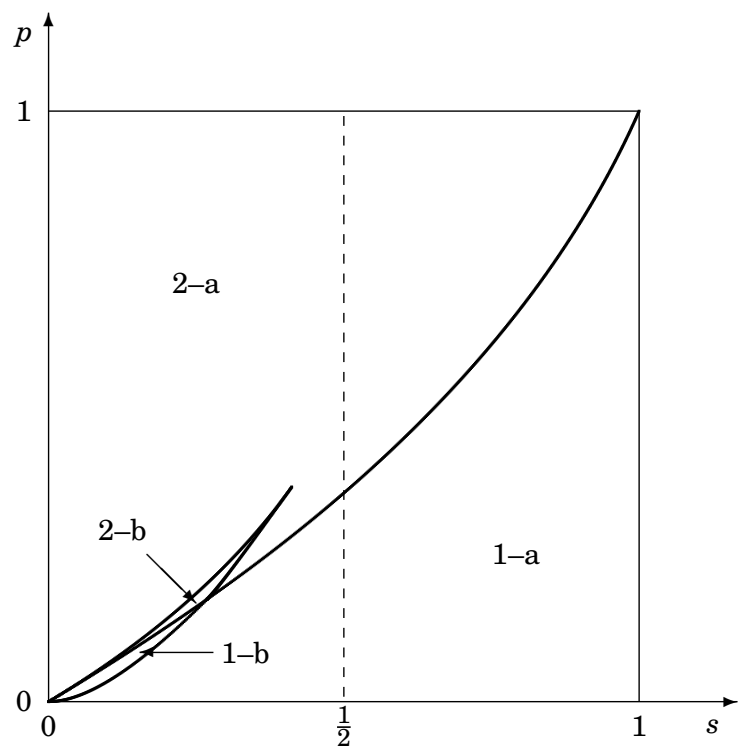

Figure 5.3: Relation between parameters and scenarios.

is impossible to acquire a monopoly position and the high price strategy is (weakly) dominant for all values of the discount factor. If $s=1$, the collusive profits are equal to the monopoly profits. Consequently, firms have no incentive to strive for a monopoly position and setting a high price is a dominant strategy for any level of the discount factor.

In Scenario 2-a and Scenario 2-b, high prices are not sustainable for discount factors sufficiently close to one. Theorem 5.3.5 reveals that this situation may arise for high values of $p$ and low values of $s$. In this case, the probability on successful monopolization is significant and firms can potentially increase their sales substantially by cutting price. Looking at the extreme case where $p=1$, undercutting the collusive price is guaranteed to be successful and firms that are sufficiently patient will surely aim to monopolize the market. In the other extreme case where $s=0$, investment costs are zero and the punishment strategy will be completely ineffective. Therefore, both firms would price aggressively to gain market share.

Finally, the banana-shaped area in Figure 5.3 reveals that the non-monotonicity in the sustainability of high prices (Scenario 1-b and 2-b) can only occur for low values of $s$ and $p$. In particular, such non-monotonicities will not be present for values of $s$ above $\frac{1}{2}$. 
Chapter 5. Competition versus Collusion: The Impact of Consumer Inertia

Corollary 5.3.6 (traditional industries). Assume $s \geq \frac{1}{2}$. If high prices can be sustained at a given discount factor, then these can also be sustained at any lower discount factor.

Hence, only when $s$ is sufficiently low (but certainly less than $\frac{1}{2}$ ), sustainability of high prices may depend non-monotonically on the level of the discount factor. Furthermore, it is required that $p$ is not too high, but not too low either.

Corollary 5.3.7 (network industries). Assume $s<\frac{1}{2}$. It may occur that high prices cannot be sustained at a given discount factor, while these can be sustained for smaller and higher values of the discount factor.

\subsection{Discussion}

A common assumption in the theory of industrial collusion is that undercutting the collusive price leads to an instant and substantial increase in sales and profits. In many industries, however, buyers are hesitant to switch suppliers in response to a price cut. This may for example be due to switching costs, contractual commitments and brand loyalty. In this chapter, we have explored the impact of such consumer inertia on the ability of firms to sustain high prices. Contrary to predictions of the standard model of collusion, high prices are always sustainable when the value of expected future profits is sufficiently low. Moreover, there is a possibility that high prices can be maintained for all values of the discount factor. Finally, whether or not collusion is feasible may depend non-monotonically on the patience level of firms. If firms are only moderately patient, then high prices might not be sustainable when the industry exhibits network effects and demand is sufficiently viscous.

These results provide a number of interesting and important insights with regard to strategic firm behavior. First, our analysis reveals that high prices can be supported as a stationary subgame perfect equilibrium. Thus, setting high prices does not necessarily require an implicit or explicit coordination of actions. In particular, no triggers or threats are needed to reach the most profitable market outcome. High prices can therefore emerge naturally in competition and do not necessarily result from collusive practices. As such, this result is not new. For example, in markets with differentiated goods, firms typically have the power to raise prices without losing too many 
5.4. Discussion

customers. Yet, a fundamental difference with our results is that the stationary high price equilibrium can occur in all four scenarios and therefore does not rely on the degree of consumer inertia and differentiation (type of market). Consequently, high prices in competition may not be driven only by a demand-side characteristic (e.g., consumer taste). In fact, we find that it is caused by a supply-side characteristic; the patience level of firms as reflected by the discount factor.

Moreover, when firms are sufficiently myopic, the stationary high price equilibrium is the unique equilibrium outcome. As the patience level of firms is typically unknown, this raises the question of how to distinguish between competitive and collusive pricing behavior. Arguably, low prices is the preferred market outcome from the perspective of consumers. Yet, in this situation, it seems difficult to effectively incentivize firms to charge lower prices. In particular, it is doubtful whether standard antitrust remedies can be effective in this case, because clearly no collusive conduct can be demonstrated when firms set high prices without coordinating their actions. There seems to be no obvious solution to this problem. Perhaps, regulating prices is currently the only available measure to improve consumer welfare in this particular situation.

A second main finding is that high price equilibria may exist for all values of the discount factor (Scenario 1-a). This occurs when buyers are sufficiently inert or when the number of customers that can be gained by cutting price is limited. Hence, the market situation and consumer characteristics might be such that firms always have a possibility to sustain high prices. This can potentially be remedied by lowering the degree of consumer inertia. Theorem 5.3.5 shows that, ceteris paribus, by increasing $p$ (the likelihood that a price reduction results in attracting more consumers), we may end up in Scenario 2-a; a state in which high prices cannot be sustained for high levels of the discount factor. Thus, our analysis indicates that it may be worthwhile to take measures that result in less demand viscosity. For instance, our findings provide some support for decisions that lead to more price transparency and short-term contracts. ${ }^{13}$ If such measures are successful and firms are sufficiently patient, then this may provide them with an incentive to charge low prices.

\footnotetext{
${ }^{13}$ Note, however, that increasing price transparency may have adverse effects when it allows firms to better observe the transaction prices of their rivals. See Albaek, Mollgaard and Overgaard (1997) in which it is suggested that the publication of firm-specific transaction prices in Danish markets for concrete led to a significant increase in prices.
} 
Chapter 5. Competition versus Collusion: The Impact of Consumer Inertia

We furthermore find that, under certain conditions, high prices cannot be sustained for moderate values of the discount factor, while these would be sustainable for more extreme values of the discount factor. This can occur only when the industry exhibits network effects or when there is a lack of a common standard. The fact that the ability of firms to maintain high prices can depend non-monotonically on the level of the discount factor may have some important implications. For example, suppose that economy-wide measures are taken in order to reduce the level of consumer inertia. Although this can have a beneficial effect in some markets for reasons described above, it potentially helps firms to escape from Scenario $b$ and bring them into Scenario a. Consequently, measures that aim to lower the degree of consumer inertia can have adverse effects and, in fact, facilitate collusion.

It is important to realize that the applicable scenarios are partly endogenous. That is to say, both the parameters $p$ and $s$ can to some extent be influenced by firms and can therefore potentially be used to facilitate collusion. ${ }^{14}$ For example, if firms are very patient and find themselves in Scenario 2-a, then they could try to enhance consumer inertia (e.g., take measures to increase switching costs). This may bring them into Scenario 1-a in which high prices can be supported as a subgame perfect equilibrium. Depending on the magnitude, measures that increase consumer inertia may even create a situation in which high prices become sustainable in stationary strategies, which means that no coordination of actions is required to get the most profitable market outcome. Similarly, if firms find themselves in the "non-monotonic area" of Scenario b, then they can try to affect the degree of consumer inertia to end up in Scenario a in which the non-monotonicity is absent. Observe that, in this case, an increase as well as a decrease in the level of consumer inertia can have the desired effect. Hence, firms may implement apparently pro-competitive measures that reduce the level of consumer inertia, with the sole purpose to create a situation in which high prices can be sustained.

These considerations imply that there are several distinct possibilities for firms to benefit from communication in markets where buyers are inert. In particular, agreeing to influence demand inertia might be equally effective, but easier to arrange and less conspicuous than a price-fixing agreement. Arguably, changing the level of consumer inertia is more effective than direct price fixing as it alters the incentives of firms to set a high or a

\footnotetext{
${ }^{14}$ See, for instance, Genesove and Mullin (2001) who describe how the Sugar Cartel in the U.S. (1927-1936) colluded on various business practices so as to facilitate price collusion.
} 
low price. This type of strategy can be especially beneficial in markets with network effects, because in those markets it is most rewarding to acquire a dominant market position by becoming the standard. At the same time, however, the presence of demand viscosity may provide an explanation for why firms sometimes choose to explicitly discuss prices, which makes them subject to antitrust enforcement. The standard model of collusion suggests that there is no real need for talking about prices as any collusive outcome can be explained as resulting from a tacit coordination of actions. However, if antitrust enforcement makes collusion costly, but not too costly, then it may effectively function as a commitment device. ${ }^{15}$ That is, the risk of a fine or even a prison sentence makes short-term profits relatively more important and if demand is viscous, then these short-term gains are maximized by setting high prices. This argument is formally illustrated in Section 5.5. In sum, our findings suggest that it might be more fruitful for society to try to affect firms' incentives by changing levels of consumer inertia rather than to punish behavior caused by adverse incentives.

\subsection{Appendix A: explicit collusion}

The difference between tacit and explicit collusion is an issue that has puzzled economists already for quite a while. ${ }^{16}$ In the standard model of collusion - the infinitely repeated prisoner's dilemma - every collusive outcome can be explained as a consequence of a tacit coordination of actions. Hence, according to the theory of industrial collusion, there is no real need for firms to explicitly discuss their pricing policies. Yet, there is an abundance of evidence from antitrust practice that a great many firms decided to talk about prices. In the following, we show how the presence of demand viscosity can explain the added value of direct communication about prices. ${ }^{17}$

Suppose that communication between firms is detected with probability $\alpha$ and, once detected, is sanctioned with a fine of size $F$ to be paid to the antitrust authority. We assume that the possibility of getting caught exists

\footnotetext{
${ }^{15} \mathrm{McCutcheon}$ (1997) also shows that antitrust enforcement may have adverse effects when it makes collusion costly, but not too costly, but for a different reason. This paper argues that the expected costs created by antitrust law enforcement may prevent renegotiations in case of defection. Hence, antitrust may help in making the punishment strategy credible, thereby facilitating collusion.

${ }^{16}$ See, for example, Whinston (2006) for a discussion on this issue.

${ }^{17}$ For a more general treatment of this issue, see Bos, Peeters and Pot (2010b).
} 
Chapter 5. Competition versus Collusion: The Impact of Consumer Inertia

after periods in which at least one firm sets the high collusive price. Moreover, we assume that after discovery of the price-fixing agreement firms are strictly monitored so that low prices are set in all future periods. We will show that the presence of this type of antitrust enforcement can make high prices sustainable, while these cannot be sustained without such measures.

First, suppose firms communicate. One can show that high prices are sustainable in trigger strategies if and only if

$$
\frac{1}{1-(1-\alpha) \delta}\left(s h+\alpha \delta\left[\frac{s \ell}{1-\delta}-F\right]\right) \geq s \ell+(1-\alpha) \delta\left[p \frac{h}{1-\delta}+(1-p) \frac{s \ell}{1-\delta}\right]+\alpha \delta\left[\frac{s \ell}{1-\delta}-F\right] .
$$

For $\alpha=0$ this inequality simplifies to $\delta \leq \frac{s(h-\ell)}{p(h-s \ell)}$, which is equivalent to the condition for high prices to be sustainable without direct communication (see Proposition 5.3.3). As we analyze when high prices become sustainable when communication is introduced, we assume this inequality to be violated. Yet, for $\alpha=1$ the inequality simplifies to $s(h-\ell) \geq 0$, which is always satisfied. From this we can conclude that there exists a lower bound on the probability of being caught above which high prices are sustainable. Hence, external monitoring may provide firms with an incentive to abide by the collusive agreement.

Second, in the presence of antitrust enforcement, communication is profitable if and only if

$$
\frac{1}{1-(1-\alpha) \delta}\left(s h+\alpha \delta\left[\frac{s \ell}{1-\delta}-F\right]\right) \geq \frac{s \ell}{1-\delta} \quad \Longleftrightarrow \quad s(h-\ell) \geq \alpha \delta F .
$$

Thus, communication is beneficial if and only if the per-period benefit of collusion exceeds the expected fine. So, if the probability of getting caught is sufficiently high and the fine $F$ is sufficiently low, explicit collusion can be an equilibrium in a model with consumer inertia, whereas tacit collusion may be infeasible.

It remains to be shown that antitrust enforcement cannot be used as a commitment device in the standard model of collusion. To that end, assume that high prices are not sustainable in equilibrium in an infinitely repeated prisoner's dilemma without communication. That is, assume that $\delta<\frac{\pi^{d}-\pi^{c}}{\pi^{d}-\pi^{n}}$, where $\pi^{c}, \pi^{d}$ and $\pi^{n}$ represent the one-shot profits associated with collusion, unilateral deviation and competition respectively (with $\pi^{d}>\pi^{c}>\pi^{n}$ ). When firms choose to communicate directly, high prices are sustainable if and only if

$$
\left.\frac{1}{1-(1-\alpha) \delta}\left(\pi^{c}+\alpha \delta\left[\frac{\pi^{n}}{1-\delta}-F\right]\right) \geq \pi^{d}+(1-\alpha) \delta \frac{\pi^{n}}{1-\delta}+\alpha \delta\left[\frac{\pi^{n}}{1-\delta}-F\right]\right) .
$$

For $\alpha=0$ this inequality simplifies to $\delta \geq \frac{\pi^{d}-\pi^{c}}{\pi^{d}-\pi^{n}}$ and for $\alpha=1$ to $\pi^{c} \geq \pi^{d}$. The condition for high prices to be sustainable is not satisfied for these two 
5.6. Appendix B: proofs

extreme values of $\alpha$ and it can be easily verified that the condition is not satisfied for any $\alpha$ in $[0,1]$. Hence, in the standard model of collusion communication cannot help to sustain high prices.

\subsection{Appendix B: proofs}

Proof of Proposition 5.3.1. For the proof we make use of the well-known property that a firm always has a stationary best response against a rival adopting a stationary strategy. Given that the rival adopts the stationary high price strategy, the present value of the profits that results from responding with the stationary strategy that prescribes to select the high respectively the low price is given by:

$$
V_{H}=s h+\delta V_{H} \quad \text { and } \quad V_{L}=s \ell+\delta\left\{p \frac{h}{1-\delta}+(1-p) V_{L}\right\} .
$$

High prices are sustainable as a stationary subgame perfect equilibrium if and only if the stationary high price strategy is a best response. This is the case when

$$
V_{H} \geq V_{L} \quad \Longleftrightarrow \quad \frac{s h}{1-\delta} \geq \frac{(1-\delta) s \ell+\delta p h}{(1-\delta)(1-\delta(1-p))} \quad \Longleftrightarrow \quad \delta \leq \frac{s(h-\ell)}{s(h-\ell)+p(1-s) h} .
$$

Proof of Proposition 5.3.2. Suppose that the rival adopts the stationary low price strategy. Responding with the stationary low price strategy is optimal if and only if

$$
\frac{s \ell}{1-\delta} \geq \frac{s h}{1-\delta(1-p)} \quad \Longleftrightarrow \quad \delta \geq \frac{h-\ell}{h-\ell+p \ell} .
$$

Consequently, the optimal response is to adopt the stationary high price strategy when $\delta<\frac{h-\ell}{h-\ell+p \ell}$.

Proof of Proposition 5.3.3. Suppose $\delta \geq \delta_{L}$ and the rival adheres to the trigger strategy. Then, the present value of adhering to the trigger strategy equals $\frac{s h}{1-\delta}$, while a deviation generates a present value of $s \ell+\delta\left\{p \frac{h}{1-\delta}+(1-\right.$ p) $\left.\frac{s \ell}{1-\delta}\right\}$. It can be easily verified that deviating is not profitable if $\delta<\delta_{L L}$.

Suppose now that $\delta_{H}<\delta<\delta_{L}$ and the rival adheres to the trigger strategy. Then, the present value of adhering to the trigger strategy equals $\frac{s h}{1-\delta}$, while deviating to the low price generates a present value of $s \ell+\delta\left\{p \frac{h}{1-\delta}+\right.$ $\left.(1-p) \frac{s h}{1-(1-p) \delta}\right\}$. It can be easily verified that deviating is not profitable if $\delta$ is such that

$$
(1-p)[s(h-\ell)+p h] \cdot \delta^{2}-[2(1-p) s(h-\ell)+p(h-s \ell)] \cdot \delta+s(h-\ell) \geq 0 .
$$


Chapter 5. Competition versus Collusion: The Impact of Consumer Inertia

This quadratic inequality is satisfied when $\delta$ is smaller than $\delta_{L H}^{-}$or larger than $\delta_{L H}^{+}$.

Proof of Theorem 5.3.4 and Theorem 5.3.5. We prove both theorems along the following lines. First, we provide the conditions that determine whether the model is in Scenario 1 or in Scenario 2. Next, the conditions that distinguish scenario a and $b$ are derived. Finally, we show - after illustrating the conditions graphically - that all combinations of conditions are compatible. More precisely, we show that, for each $h$ and $\ell$, there exist values of $p$ and $s$ such that the conditions are met.

Scenario 1 and 2. The only condition that needs to be satisfied for the model to be in Scenario 1 is $\delta_{L L}>1$; or, $p<\frac{s(h-\ell)}{h-s \ell}$. Otherwise, the model is in Scenario 2.

Scenario a and b. There are three conditions that need to be satisfied for the model to be in Scenario b: (1) $\delta_{L H}^{-}, \delta_{L H}^{+} \in \mathbb{R}$; (2) $\delta_{L H}^{-}<\delta_{L}$; and (3) $\delta_{L L}>\delta_{L}$.

Condition (1). Without the first condition the intersection of $\left(\delta_{L H}^{-}, \delta_{L H}^{+}\right)$with $\left(\delta_{H}, \delta_{L}\right)$ is guaranteed to be nonempty. This condition is satisfied if and only if $p \geq \frac{4 h s^{2}(h-\ell)}{4 h s^{2}(h-\ell)+(h-s \ell)^{2}}$.

Condition (2). It can be easily verified that, whenever the first condition is satisfied, $\delta_{L H}^{+} \geq \delta_{L H}^{-}>\delta_{H}$. The second condition guarantees that the earlier intersection is nonempty, and hence there is a range of discount factors in $\left(\delta_{H}, \delta_{L}\right)$ for which high prices are not sustainable. This condition is satisfied if and only if

$$
\begin{aligned}
& {[h-\ell+p \ell] \sqrt{[2(1-p) s(h-\ell)+p(h-s \ell)]^{2}-4(1-p) s(h-\ell)[s(h-\ell)+p h]}} \\
& >p(h-s \ell)[h-\ell+p \ell]-2 p(1-p)(h-\ell)(h-s \ell) .
\end{aligned}
$$

This inequality is certainly satisfied when the right hand side is negative, i.e., $p<\frac{h-\ell}{2 h-\ell}$. Suppose next that the right hand side is positive. Then, with some effort, the inequality can be rearranged to $p(h-2 s \ell)>s(h-\ell)$.

Condition (3). The third condition warrants that there is range of discount factors just above $\delta_{L}$ for which high prices are sustainable by means of trigger strategies. By continuity of the present values it follows that this condition implies that there is also a range of discount factors just below $\delta_{L}$ for which high prices are sustainable. Hence, this condition implies $\delta_{L H}^{+}<\delta_{L}$. This condition is satisfied if and only if $p(h-2 s \ell)<s(h-\ell)$. 
Notice that the second and third condition are incompatible when $p>\frac{h-\ell}{2 h-\ell}$. From this it can be concluded that Scenario b can only occur when $p<\frac{h-\ell}{2 h-\ell}$.

Graphical representation of conditions. Figure 5.4 plots the relevant curves. Curve $c .1$ plots precisely the parameter values separating Scenario

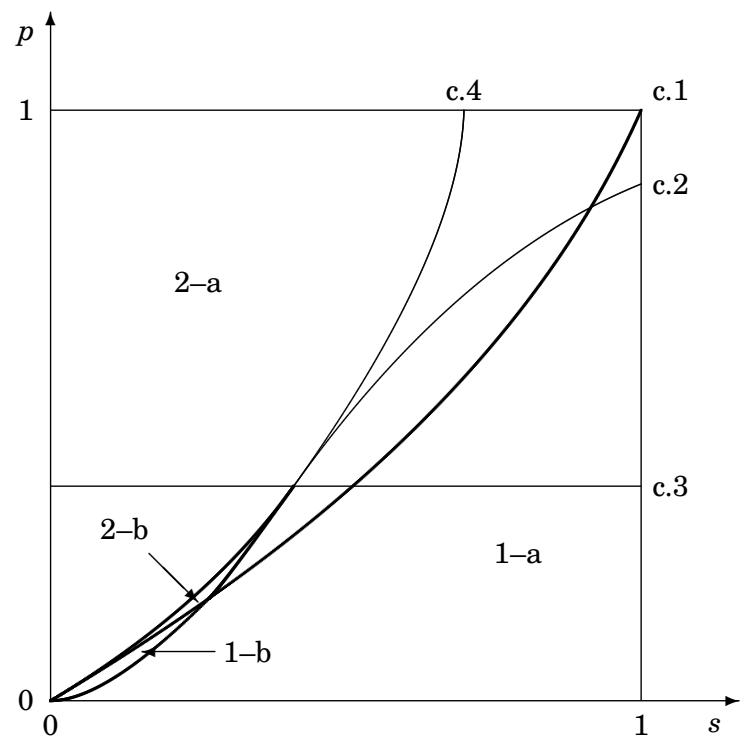

Figure 5.4: Relation between parameters and scenarios.

1 and 2: $p=\frac{s(h-\ell)}{h-s \ell}$. The other three curves $-c .2, c .3$ and $c .4-$ enclose Scenario b. First, curve $c .2$ plots the values of $p$ above which condition (1) is satisfied; that is, $p=\frac{4 h s^{2}(h-\ell)}{4 h s^{2}(h-\ell)+(h-s \ell)^{2}}$. Next, curve $c .3$ plots the values of $p$ below which condition (2) is satisfied, while enabling compatibility of condition (2) and (3): $p=\frac{h-\ell}{2 h-\ell}$. Finally, curve $c .4$ captures the condition $p(h-2 s \ell)<s(h-\ell)$. For $s \geq \frac{h}{2 \ell}$ this condition is satisfied for all values of $p$. For lower values of $s$ it requires $p<\frac{s(h-\ell)}{h-2 s \ell}$. Curve $c .4$ plots the values for which $p=\frac{s(h-\ell)}{h-2 s \ell}$. All values of $p$ and $s$ to the south-east of this curve, and only these values, are compatible with condition (3).

Non-emptiness of the areas. Suppose for the moment that $s<\frac{h}{2 \ell}$. Curve $c .2$ is below curve $c .4$ if and only if $(2 h+\ell)^{2} s^{2}-2 h(2 h+\ell) s+h^{2}>0$, which is satisfied for all $s$ except for $s=0$ and $s=\frac{h}{2 h+\ell}$. At the latter point the two curves are tangent to each other, and the corresponding value of $p$ at 
Chapter 5. Competition versus Collusion: The Impact of Consumer Inertia

this point is $\frac{h-\ell}{2 h-\ell}$. Hence, both curves intersect curve $c .3$ at precisely this point. Notice that this is at a value of $s$ below $\frac{h}{2 \ell}$, which is in agreement with our supposition. This guarantees non-emptiness of Scenario b. Next, non-emptiness of the area 2-b results from curve $c .1$ being below curve $c .4$ with exception of the origin. Finally, non-emptiness of the area 1-b follows from the slope of curve $c .2$ being less than the slope of curve $c .1$ at the origin: $0<\frac{h-\ell}{h}$. 


\section{Part III}

\section{Welfare-Enhancing Cartels}





\section{Chapter 6}

\section{Welfare-Enhancing Hard Core Cartels}

\subsection{Introduction}

Standard economic theory teaches that cartels are detrimental to social welfare. ${ }^{1}$ Firms engaging in a cartel generally limit production and raise prices, which results in allocative inefficiencies and additionally leads to a redistribution of income from consumers to producers. Compared to a competitive market, some customers refrain from purchasing (or buy less-preferred substitutes), while others have to spend a larger portion of their budget to obtain the product or service. In addition, cartels are believed to give rise to technical and X-inefficiencies. In absence of competition, firms are thought to lack incentives to organize their operations and production as efficient as possible. $^{2}$ As the conventional wisdom is that cartels have no obvious benefits for society, most capitalist societies have adopted antitrust laws declaring cartel contracts illegal. In particular, the antitrust system typically does not allow for an assessment of the costs and benefits of a cartel arrangement to determine its (il)legality and proving its existence often suffices to establish an infringement of the antitrust laws.

In this paper, we theoretically explore the extent to which cartels lead to allocative inefficiencies. We do so by deriving necessary and sufficient conditions for the existence of a welfare-enhancing hard core cartel. Our

\footnotetext{
${ }^{1}$ This chapter is based on Bos and Pot (2010).

${ }^{2}$ One could further think of inefficiencies that arise because firms may spend part of their resources to establish and maintain the cartel and to protect its market power.
} 
approach to welfare is 'neutral' in the sense that we define it as the sum of consumer and producer surplus. We restrict ourselves to horizontal cartels that have a direct impact on market prices. ${ }^{3}$ In practice, such so-called hard core cartels can take a variety of forms. ${ }^{4}$ The Organization for Economic Co-operation and Development (OECD) defines a hard core cartel as "an anticompetitive agreement, anticompetitive concerted practice, or anticompetitive arrangement by competitors to fix prices, make rigged bids (collusive tenders), establish output restrictions or quotas, or share or divide markets by allocating customers, suppliers, territories, or lines of commerce." ${ }^{5}$ In our analysis, we focus on hard core cartel contracts that lead exclusively to a decrease of industry output and higher prices. We consider two types of hard core cartel contracts; one with and one without side payments. In a simple but fairly general framework, we derive necessary and sufficient conditions for the existence of a hard core cartel that is beneficial for firms and society at large.

We find that welfare-enhancing cartels with side payments (strong cartels) and without side payments (weak cartels) both exist when price is below unit costs at competitive production levels for at least one firm, i.e., when at least one firm makes a loss on part of its sales. In this situation, there exists a hard core cartel that leads to an increase of allocative efficiency. Moreover, such a cartel allows for a substantial increase of firm profits as it reduces the amount of unprofitable sales and improves the price-cost margin on remaining sales. A welfare-enhancing strong cartel exists whenever there is a difference in unit costs at competitive production levels. In this case, individual and total profits can increase by shifting production from the inefficient firm to the efficient firm. It is shown that there always exists a cartel contract for which this profit increase dominates the loss in consumer surplus. Finally, we find that a welfare-enhancing weak cartel exists when the difference in unit costs is sufficiently large. Here, the price increase that results from the cartel is sufficient to compensate the inefficient firm for reducing its outputs. At the same time, this price effect should have a limited impact on consumer welfare in order for aggregate welfare to increase, which requires

\footnotetext{
${ }^{3}$ Some horizontal cartels only affect the price mechanism indirectly. See, for example, Genesove and Mullin (2001) which describes how the sugar cartel in the U.S. (1927-1936) colluded on business practices to facilitate tacit collusion on prices.

${ }^{4}$ Harrington (2006), for example, contains a detailed description of about twenty European cartel cases over 2000-2004. This study illustrates the remarkable variety in hard core cartels regarding both their content and their organization.

${ }^{5}$ OECD report (1998).
} 
market demand to be sufficiently inelastic.

Reviewing the existing literature, there are at least three arguments indicating how horizontal collusion may promote social welfare. One strand of work argues that "non-naked" cartels can have a potential welfare-enhancing effect, i.e., cartel contracts that are ancillary to cooperative productive activity engaged in by the cartel members. This is essentially the view of the Chicago school of economics. The key argument is that when business practices such as price-fixing or market division form an essential part of a bigger arrangement between firms, then a cartel could potentially increase productive efficiency more than it reduces allocative efficiency. ${ }^{6}$ For instance, a cartel between sellers may increase social welfare when participating firms advertise jointly using media that they cannot afford individually, even though this requires an agreement upon the prices that will be advertised. ${ }^{7}$ In fact, deterring or prosecuting efficient cartels could result in higher market prices as unit production costs will be higher in absence of the cartel. ${ }^{8}$

A second strand of literature highlights the possibility that unrestricted competition may not necessarily lead to a competitive equilibrium. Most notably, a competitive equilibrium may be absent in industries with large fixed costs and decreasing long-run average costs. That is, with increasing returns markets may have an empty core. ${ }^{9}$ This basically means that, even when firms are willing to compete, competition is not viable in certain markets. As a result, some sort of strategy coordination between firms is required to maintain an industry, thereby contributing to social welfare. One particular solution for these type of markets is to allow sellers to establish sales quotas. Such a hard core cartel would be welfare-enhancing as it saves a surplus generating business that would not exist with unrestricted compe-

\footnotetext{
${ }^{6}$ This is also the prime rationale for exempting export cartels from antitrust laws. First, the cartel allows for higher selling prices and, second, members can save costs, e.g., because they can use one and the same sales organization. Within a country, therefore, a cartel is likely to increase productive efficiency more than it reduces allocative efficiency, because costs due to a misallocation of resources are expected to be borne mainly by foreign customers. See Dick (1996) for a detailed discussion and analysis of the Webb-Pomerene Export Trade Act of 1918, which made cartel arrangements between U.S. exporters legal. However, it is doubtful if export cartels are beneficial for social welfare of trading nations together.

${ }^{7}$ See Bork (1993, p. 278).

${ }^{8}$ Sproul (1993), for example, finds that prices charged by firms indicted for price fixing gradually rose over the years following the indictment. As the author suggests, one potential explanation for this rather surprising result is that firms had established an economically efficient cartel.

${ }^{9}$ See Telser (1996).
} 
tition. ${ }^{10}$ It is noteworthy that the cost conditions under which the core may be empty sometimes seem to describe quite closely the cost structure in manufacturing industries such as cement and steel; industries that repeatedly have witnessed hard core cartel behavior. ${ }^{11}$

A third strand of work shows that naked cartels may result in higher welfare standards even in markets with constant or decreasing returns. Taking a dynamic approach, it can be argued that cartels may (temporarily) lead to an increase (or stabilization) instead of a decrease in industry output. ${ }^{12}$ For example, under the assumption that firms are risk-averse, Dewey (1979) argues that a cartel will attract additional production given that barriers to entry are limited. ${ }^{13}$ In a related vein, Rotemberg (1998) shows that with imperfect financial markets and demand uncertainty cartels may lead to higher output levels than under (perfect) competition. The reason is that the additional profits that result from the cartel either encourages entry or provides cartel members with the incentive to invest in production capacity. This is confirmed by Fershtman and Pakes (2000), which studies collusion in a structural dynamic setting. They find that collusion may yield more and higher quality products, which more than compensates consumers for collusive prices. Finally, in the context of an infinitely repeated game with quantity competition and demand shocks, Montero and Guzmán (2010) shows that, under certain conditions, a profit-maximizing incomplete cartel may find it optimal to extend production beyond competitive levels. ${ }^{14}$ It should be noted, however, that cartels leading to an increase in industry output do not necessarily result in higher welfare standards compared to the competi-

\footnotetext{
${ }^{10}$ See, for instance, Sjostrom (1989) in which it is suggested that cartel behavior in ocean shipping is an attempt to solve the problem of an empty core.

${ }^{11}$ See, for example, Bittlingmayer (1982) which argues that the empty core theory is likely to have applied to the classic Addyston Pipe antitrust case. U.S. v. Addyston Pipe and Steel Co., 85 Fed. 271 (6th Cir. 1898).

${ }^{12}$ For example, Kinghorn (1996) and Troesken (1989) find empirical support for expansion of output by cartels. See also Bittlingmayer (1995) which shows that the National Industrial Recovery Act (NIRA), which was an essential part of Franklin Roosevelt's New Deal of 1933, had no significant effects on real output. This contrasts, however, with Taylor (2002) which shows that the NIRA led the U.S. manufacturing industry to reduce outputs.

${ }^{13}$ It is noteworthy that this paper triggered quite a few comments, which perhaps also illustrates the controversy of this topic. See the American Economic Review, Vol. 72, No. 1, 1982.

${ }^{14}$ Röller and Steen (2006), for example, studies a hard core cartel arrangement in the Norwegian cement industry. They find that industry output increased during the cartel regime and that domestic customers actually benefited from the cartel. However, it is also shown that total surplus would have been higher in competition.
} 
6.2. Model and conditions

tive alternative. This is so because the increase in consumer surplus may be more than offset by a loss in producer surplus. ${ }^{15}$

In contrast to the above references, this work aims to provide a complete characterization for the existence of welfare-enhancing hard core cartels. Moreover, our paper is complementary as we focus on naked hard core cartels that lead to a reduction in total industry supply in markets in which a competitive equilibrium exists. As we are primarily interested in the welfare effects, we will abstract from issues related to the formation and sustainability of cartels. That is to say, throughout the chapter, we assume that profitable cartels are viable. ${ }^{16}$

This chapter proceeds as follows. In the next section, the model is described and we establish necessary and sufficient conditions for the existence of an individually rational naked hard core cartel contract. In Section 6.3 , these conditions are analyzed in more detail. In Section 6.4, we provide some applications and examine to what extent the conditions may hold in traditional price and quantity competition models. In Section 6.5, we summarize and discuss our main findings. A simple illustration of a possibility how consumers can benefit from a cartel is presented in Section 6.6. All proofs are in Section 6.7.

\subsection{Model and conditions}

We first define the elements of our model. Consider an industry with two firms $i=1,2$ selling a homogeneous product. Total cost for a firm $i$ of producing a quantity $q_{i}$ is given by the cost function $C_{i}\left(q_{i}\right)$, which we assume to be increasing and convex, i.e., $C_{i}^{\prime}\left(q_{i}\right)>0$ and $C_{i}^{\prime \prime}\left(q_{i}\right) \geq 0$ for all $q_{i}>0$. Total industry production is denoted by $Q=q_{1}+q_{2}$ and the inverse market demand function is $p(Q)$, which is twice continuously differentiable with $p^{\prime}(Q)<0$ and $p^{\prime \prime}(Q) \leq 0$ at all $Q>0$. We assume that markets clear, so total output is always equal to total demand. Thus, for some given price-quantity combination $\left(p(Q), q_{1}, q_{2}\right)$, firm $i$ 's profit $\pi_{i}$ and the net consumer surplus $C S$ are respectively given by

$$
\pi_{i}=p(Q) q_{i}-C_{i}\left(q_{i}\right), \text { for } i=1,2
$$

\footnotetext{
${ }^{15}$ See Matsui (1989) for a theoretical analysis of how a horizontal cartel may benefit consumers, while making firms worse off.

${ }^{16}$ We discuss the implications of this assumption in Section 6.5.
} 
and

$$
C S=\int_{0}^{Q} p(x) d x-p(Q) Q .
$$

Society's welfare $W$ is defined as the sum of firm profits and consumer surplus:

$$
W=\pi_{1}+\pi_{2}+C S=\int_{0}^{Q} p(x) d x-C_{1}\left(q_{1}\right)-C_{2}\left(q_{2}\right) .
$$

Hence, for any given $\left(p(Q), q_{1}, q_{2}\right)$, total welfare equals gross consumer surplus minus the total costs of production.

The starting point of our analysis is a competitive outcome, which is some point on the inverse demand curve and which we denote by $\left(p^{*}\left(Q^{*}\right)\right.$, $\left.q_{1}^{*}, q_{2}^{*}\right)$. Total output $Q^{*}$ is thus divided in some way between the two firms in individual outputs $q_{1}^{*}$ and $q_{2}^{*}$. The only assumption we make about this competitive point is the following:

Assumption 6.2.1. $C_{1}^{\prime}\left(q_{1}^{*}\right) \leq C_{2}^{\prime}\left(q_{2}^{*}\right)$ and $q_{1}^{*}, q_{2}^{*}>0$.

The first part of Assumption 6.2.1 states that, at competitive output levels, marginal production costs of firm 1 are weakly lower than the marginal production costs of firm 2, which is without loss of generality. The second part of Assumption 6.2.1 requires both firms to be active in competition. However, individual output levels are not necessarily equal. Furthermore, our analysis does not require any assumption on how the competitive outcome $\left(p^{*}\left(Q^{*}\right), q_{1}^{*}, q_{2}^{*}\right)$ emerges (e.g., as a result of price or quantity competition, or any other competitive process). In fact, the goal of our analysis is to identify conditions on this competitive point such that a welfare-enhancing cartel is possible. In Section 6.4, we explore to what extent our results apply in the familiar duopoly models of Bertrand and Cournot competition.

Given a competitive outcome $\left(p^{*}\left(Q^{*}\right), q_{1}^{*}, q_{2}^{*}\right)$, we want to investigate if there exists some point $\left(p^{c}\left(Q^{c}\right), q_{1}^{c}, q_{2}^{c}\right)$ on the inverse demand curve which satisfies the conditions for a welfare-enhancing hard core cartel. These conditions are (1) there should be a total industry output reduction, (2) the total welfare should be higher, and (3) the firms' profits should be higher.

First, as our focus is on hard core cartels that cause a reduction of industry output, we require $Q^{c}<Q^{*}$ and, equivalently, $p^{c}>p^{*}$. Note that we again do not make specific assumptions on how total output is divided between the two firms. In particular, the division of individual outputs might be different from the one in the competitive point (i.e., we allow redistribution of production to be part of a cartel contract). 
6.2. Model and conditions

Second, we consider a cartel contract to be welfare-enhancing whenever the agreement results in more aggregate welfare than the competitive alternative. Thus, a cartel agreement $\left(p^{c}\left(Q^{c}\right), q_{1}^{c}, q_{2}^{c}\right)$ is welfare-enhancing if $W^{c}>W^{*}$, which is equivalent to

$$
C_{1}\left(q_{1}^{*}\right)+C_{2}\left(q_{2}^{*}\right)-C_{1}\left(q_{1}^{c}\right)-C_{2}\left(q_{2}^{c}\right)>\int_{Q^{c}}^{Q^{*}} p(x) d x .
$$

A hard core cartel arrangement will therefore result in an increase of aggregate welfare only when the decrease in total production costs is strictly larger than the loss in gross consumer surplus. Condition (6.4) captures the welfare trade-off that is often present when firms cooperate. For example, in a classic discussion of mergers, Williamson (1968) emphasizes the issue of whether the increase in productive efficiency more than makes up for the loss in allocative efficiency, which typically results from higher market concentration. Similarly, by achieving a sufficiently large cost reduction, naked hard core cartels might have a positive effect on welfare, although in our model this will not result from economic integration.

Third, we require both firms to benefit from the cartel. Therefore, we only consider cartel agreements for which profits of both firms are strictly higher than in competition. We distinguish two types of cartel arrangements; one that includes the possibility of making side payments (strong cartel) and another in which such monetary transfers are absent (weak cartel). ${ }^{17}$ The following definition formalizes this participation constraint.

Definition 6.2.2. A hard core cartel agreement $\left(p^{c}\left(Q^{c}\right), q_{1}^{c}, q_{2}^{c}\right)$ is individually rational if

(i) $\pi_{i}^{c}>\pi_{i}^{*}, \forall i=1,2$ (weak cartel), or

(ii) $\sum_{i=1,2} \pi_{i}^{c}>\sum_{i=1,2} \pi_{i}^{*}$ (strong cartel).

Notice that the first part of this definition is stronger than the second as Definition 6.2.2(i) implies Definition 6.2.2(ii), but not vice versa. However, to ensure individual rationality, we implicitly assume that total cartel profit of a strong cartel will be distributed such that $\pi_{i}^{c}>\pi_{i}^{*}, \forall i=1,2$.

The main issue is now to establish whether a point $\left(p^{c}\left(Q^{c}\right), q_{1}^{c}, q_{2}^{c}\right)$ exists which satisfies the three conditions for a welfare-enhancing hardcore cartel, given a competitive outcome $\left(p^{*}\left(Q^{*}\right), q_{1}^{*}, q_{2}^{*}\right)$. Due to concavity of the

\footnotetext{
${ }^{17}$ This is a common distinction in the literature on collusion. See, for example, Pesendorfer (2000).
} 
profit and welfare functions, ${ }^{18}$ a welfare-enhancing cartel exists if and only if there exists a direction of change from the competitive point $\left(p^{*}\left(Q^{*}\right), q_{1}^{*}, q_{2}^{*}\right)$ for which price goes up (and total output goes down), welfare increases and individual (in case of a weak cartel) or total (in case of a strong cartel) profits increase. Note that even though we have not specified whether price or quantity is the strategic variable, we can represent any change from the competitive point as a change in individual output (e.g., if firms change their price, total demand goes down, which in turn causes individual output to go down for at least one of the firms). Thus, we can define a vector $\mathbf{u}=\left(u_{1}, u_{2}\right)$ which represents the direction of change from the competitive point in terms of $q_{1}$ and $q_{2}$, respectively. Because this change should result in a total output decrease we focus on vectors that satisfy $u_{1}+u_{2}<0$.

We can now identify the impact a change from the competitive point in the direction $\mathbf{u}$ has on welfare and profits. The impact on total welfare is given by the directional derivative

$$
u_{1}\left(p^{*}-C_{1}^{\prime}\left(q_{1}^{*}\right)\right)+u_{2}\left(p^{*}-C_{2}^{\prime}\left(q_{2}^{*}\right)\right) .
$$

The impact of a change in individual outputs from the competitive point in the direction $\mathbf{u}$ on individual and total profits is respectively given by

$$
u_{i}\left(p^{*}+p^{* \prime} q_{i}^{*}-C_{i}^{\prime}\left(q_{i}^{*}\right)\right)+u_{j}\left(p^{* \prime} q_{i}^{*}\right), \text { for } i=1,2 .
$$

and

$$
u_{1}\left(p^{*}-C_{1}^{\prime}\left(q_{1}^{*}\right)\right)+u_{2}\left(p^{*}-C_{2}^{\prime}\left(q_{2}^{*}\right)\right)+\left(u_{1}+u_{2}\right) p^{* \prime} Q^{*} .
$$

As mentioned above, for a welfare-enhancing cartel to exist, we must have that there exists a direction of change such that welfare and profits increase. Thus, (6.5) must be positive, which is represented by the following condition.

Condition 6.1. $u_{1}\left(p^{*}-C_{1}^{\prime}\left(q_{1}^{*}\right)\right)+u_{2}\left(p^{*}-C_{2}^{\prime}\left(q_{2}^{*}\right)\right)>0$.

Likewise, Condition 6.2(i), in case of a weak cartel, and Condition 6.2(ii), in case of a strong cartel, must hold for some direction $\mathbf{u}$ to prove that there exists a cartel agreement that is individually rational.

Condition 6.2. (i) $u_{i}\left(p^{*}+p^{* \prime} q_{i}^{*}-C_{i}^{\prime}\left(q_{i}^{*}\right)\right)+u_{j}\left(p^{* \prime} q_{i}^{*}\right)>0$, for $i=1,2($ weak cartel).

(ii) $u_{1}\left(p^{*}-C_{1}^{\prime}\left(q_{1}^{*}\right)\right)+u_{2}\left(p^{*}-C_{2}^{\prime}\left(q_{2}^{*}\right)\right)+\left(u_{1}+u_{2}\right) p^{* \prime} Q^{*}>0$ (strong cartel).

${ }^{18}$ That is, $\frac{\partial^{2} \pi_{i}}{\partial q_{i}^{2}}<0$ and $\frac{\partial^{2} W}{\partial Q^{2}}<0$ so that both have a unique maximum. 
6.3. Analysis and results

In sum, if Condition 6.1 holds, then there exists a cartel agreement $\left(p^{c}\left(Q^{c}\right), q_{1}^{c}, q_{2}^{c}\right)$ for which $W^{c}>W^{*}$ and if Condition 6.2 holds, then there exists a cartel agreement $\left(p^{c}\left(Q^{c}\right), q_{1}^{c}, q_{2}^{c}\right)$ for which $\pi_{i}^{c}>\pi_{i}^{*}$, for $i=1,2$. Thus, Condition 6.1 in conjunction with Condition 6.2 marks situations in which there exists an individually rational welfare-enhancing cartel arrangement. In the next section, we analyze these conditions in more detail.

\subsection{Analysis and results}

In this section, we identify conditions on the competitive point such that a welfare-enhancing cartel is possible. Starting from some competitive outcome $\left(p^{*}\left(Q^{*}\right), q_{1}^{*}, q_{2}^{*}\right)$, the key question is whether there exists a direction $\mathbf{u}=\left(u_{1}, u_{2}\right)$ with $u_{1}+u_{2}<0$ such that Conditions 6.1 and 6.2 hold simultaneously. If so, then there exists another point on the market demand curve $\left(p^{c}\left(Q^{c}\right), q_{1}^{c}, q_{2}^{c}\right)$ for which both profits and aggregate welfare are higher and total output is smaller than in the competitive point.

\subsubsection{Weak cartels}

In focusing on hard core cartel contracts without side payments, the question is what the conditions are for the competitive outcome $\left(p^{*}\left(Q^{*}\right), q_{1}^{*}, q_{2}^{*}\right)$ such that there exists a direction $\mathbf{u}=\left(u_{1}, u_{2}\right)$ with $u_{1}+u_{2}<0$ that simultaneously satisfies Conditions 6.1 and 6.2(i). The following result provides a necessary condition for the existence of an individually rational welfareenhancing weak cartel.

Lemma 6.3.1. If there exists an individually rational welfare-enhancing weak cartel, then $\pi_{i}^{\prime}\left(q_{i}^{*}\right)<0$ for at least one firm $i$.

Hence, if an individually rational welfare-enhancing weak cartel exists, then at least one firm would be willing to cut back production. Yet, the competitive situation may be such that an uncoordinated reduction of output is not in a firm's best interest. In other words, restricting one's own output may not be an optimal strategy given the strategy adopted by competitors.

Using this result, we can specify necessary and sufficient conditions for the existence of an individually rational welfare-enhancing weak cartel. 
Theorem 6.3.2. There exists an individually rational welfare-enhancing weak cartel if and only if:

$$
p^{*}-C_{2}^{\prime}\left(q_{2}^{*}\right)<\max \left\{0, \frac{p^{* \prime} q_{2}^{*}\left(p^{*}-C_{1}^{\prime}\left(q_{1}^{*}\right)\right)}{p^{* \prime} q_{2}^{*}-\left(p^{*}-C_{1}^{\prime}\left(q_{1}^{*}\right)\right)}\right\} .
$$

This result shows that there are two situations in which an individually rational welfare-enhancing weak cartel exists. First, such a cartel exists when at least one firm makes a loss on (part of) its sales in competition, i.e., $p^{*}-C_{2}^{\prime}\left(q_{2}^{*}\right)<0$. To provide some intuition, suppose that both firms engage in the following cartel contract. Firm 1 keeps its output constant, while firm 2 is reducing its production slightly. This agreement is individually rational as firm 1 sells the same amount of products at a higher price, while firm 2 avoids selling a loss-making item and enjoys a higher margin on its remaining sales. The cartel contract has a positive impact on total surplus as it prevents (part of) the losses from trade in competition and does not create a deadweight loss. In fact, in this case there exists a cartel that would lead to an increase of allocative efficiency.

Second, an individually rational welfare-enhancing weak cartel may exist when the price-cost margin is (weakly) positive for both firms at competitive production levels, i.e., $p^{*}-C_{2}^{\prime}\left(q_{2}^{*}\right) \geq 0$. Following Theorem 6.3.2, such a cartel does exist whenever

$$
p\left(Q^{*}\right)-C_{2}^{\prime}\left(q_{2}^{*}\right)<\alpha\left(p\left(Q^{*}\right)-C_{1}^{\prime}\left(q_{1}^{*}\right)\right), \text { with } \alpha \equiv \frac{p^{* \prime} q_{2}^{*}}{p^{* \prime} q_{2}^{*}-\left(p^{*}-C_{1}^{\prime}\left(q_{1}^{*}\right)\right)} .
$$

Observe that (6.8) in combination with Assumption 6.2.1 implies that $p^{*}-C_{1}^{\prime}\left(q_{1}^{*}\right)>0$ and therefore $\alpha \in(0,1)$. For (6.8) to apply, we then must have that $p^{*}-C_{1}^{\prime}\left(q_{1}^{*}\right)>p^{*}-C_{2}^{\prime}\left(q_{2}^{*}\right)$ or $C_{2}^{\prime}\left(q_{2}^{*}\right)>C_{1}^{\prime}\left(q_{1}^{*}\right)$, because $\alpha<1$.

Thus, given that the price-cost margin is positive for both firms, the existence of a welfare-enhancing weak cartel requires a difference in unit costs at competitive production levels. The following result shows that this difference must be sufficiently large, which depends on the price elasticity of demand $\varepsilon \equiv-\frac{\partial Q}{\partial p} \frac{p^{*}}{Q^{*}}$ and the market share of the less efficient firm $s_{2}=\frac{q_{2}^{*}}{Q^{*}}$.

Corollary 6.3.3. If $p^{*}-C_{2}^{\prime}\left(q_{2}^{*}\right) \geq 0$, then there exists an individually rational welfare-enhancing weak cartel if and only if:

$$
p^{*}-C_{2}^{\prime}\left(q_{2}^{*}\right)<\frac{s_{2}}{\varepsilon\left(\frac{p^{*}-C_{1}^{\prime}\left(q_{1}^{*}\right)}{p^{*}}\right)}\left(C_{2}^{\prime}\left(q_{2}^{*}\right)-C_{1}^{\prime}\left(q_{1}^{*}\right)\right) .
$$


6.3. Analysis and results

The intuition behind this result is as follows. Recall that, for an increase of aggregate welfare, profits must be sufficiently higher under a cartel regime. Given that total industry production is lower with a cartel, this implies that the less efficient firm has to reduce its output, while the more efficient firm has to increase its production (by a smaller amount). This has two effects. First, there is a total cost reduction resulting from a shift in production from the inefficient to the efficient firm. This positively affects both profits and welfare. Second, the output reduction (and price increase) caused by the cartel has a positive impact on profits, but a negative impact on welfare. For the cartel to be welfare-enhancing, we must have that the first effect dominates the second, which is the case when the difference in unit costs is sufficiently large. Notice that whether the difference in unit costs is sufficient in part depends on the price elasticity of demand. In particular, the required difference in productive efficiency is smaller the more inelastic is demand, all else equal. The reason is that the deadweight loss created by the cartel is positively related to the price elasticity of demand.

As to the individual rationality requirement, observe that the efficient firm always finds it in its interest to take part in this cartel, because it will sell more products at a higher price. However, the less efficient firm wants to participate only if it is sufficiently compensated for its losses due to lower output. This is the case when it experiences a sufficient increase in the pricecost margin of its remaining production. If the less efficient firm has a large market share, then the higher price-cost margin caused by the cartel has a significant impact as remaining production is still substantial. Thus, the above situation is more likely to apply, the larger the market share of the less efficient firm, all else equal. Also, the increase in the price-cost margin depends negatively on the elasticity of demand. Therefore, ceteris paribus, it is easier to sufficiently compensate the less efficient firm when demand is relatively inelastic. Finally, the increase in price-cost margin is more likely to be sufficient when unit costs of the less efficient firm are relatively large in competition. The reason for this is that under a cartel regime it gives up part of its production for which profits are limited. As before, this makes it

more likely that the higher mark-up on remaining production is sufficient to compensate for the loss in sales.

\subsubsection{Strong cartels}

We now turn our attention to strong cartels. Thus, the issue is what the conditions are for the competitive outcome $\left(p^{*}\left(Q^{*}\right), q_{1}^{*}, q_{2}^{*}\right)$ such that there 
Chapter 6. Welfare-Enhancing Hard Core Cartels

exists a direction $\mathbf{u}=\left(u_{1}, u_{2}\right)$ with $u_{1}+u_{2}<0$ that simultaneously satisfies Condition 6.1 and Condition 6.2(ii). As the following lemma indicates, it suffices to focus exclusively on Condition 6.1.

Lemma 6.3.4. If Condition 6.1 is satisfied, then Condition 6.2(ii) is satisfied.

Using the above result, the next theorem shows necessary and sufficient conditions for the existence of an individually rational welfare-enhancing strong cartel.

Theorem 6.3.5. There exists an individually rational welfare-enhancing strong cartel if and only if:

(i) $C_{1}^{\prime}\left(q_{1}^{*}\right)<C_{2}^{\prime}\left(q_{2}^{*}\right)$, or

(ii) $C_{1}^{\prime}\left(q_{1}^{*}\right)=C_{2}^{\prime}\left(q_{2}^{*}\right)>p^{*}$.

The first part of Theorem 6.3.5 reveals that an individually rational welfare-enhancing strong cartel exists whenever there is a difference in unit costs at competitive production levels. To see that this is sufficient, note that in light of Assumption 6.2.1 it is possible to shift some production from the less efficient firm to the more efficient firm. If firms would keep total output constant (a one-to-one shift), then total profits would increase. In this case, consumer welfare remains unaffected so that total surplus would increase as well. As production is a continuous variable, there exists an output level that is smaller than but sufficiently close to $Q^{*}$ such that both profits and welfare are higher compared to the competitive alternative.

The second part of Theorem 6.3.5 shows that an individually rational welfare-enhancing strong cartel also exists when marginal production costs are equal and higher than the selling price at competitive production levels. This situation satisfies the condition of Theorem 6.3.2 above. Like with weak cartels, when the unit costs of the last item(s) sold exceed price, then it is profitable to cut back production. Lowering production avoids (part of) the unprofitable sales and yields an increase of the price-cost margin on the remaining sales. If the reduction in outputs is limited, then a hard core cartel increases instead of decreases allocative efficiency and is thereby contributing to social welfare. 
6.4. Applications

\subsection{Applications}

So far, the starting point of our analysis has been some competitive point on the market demand curve $\left(p^{*}\left(Q^{*}\right), q_{1}^{*}, q_{2}^{*}\right)$. Clearly, whether or not Conditions 6.1 and 6.2 can be satisfied simultaneously directly depends on this competitive situation. Although it is not required for the derivation of our results, it is natural to think of $\left(p^{*}\left(Q^{*}\right), q_{1}^{*}, q_{2}^{*}\right)$ as a competitive equilibrium outcome of some oligopoly game. It is therefore instructive to explore the extent to which our results apply in familiar duopoly models. In this section, we analyze if and when welfare-enhancing hard core cartels exist in basic "textbook" models of price and quantity competition. Summarizing our results, both welfare-enhancing weak and strong cartels might exist when marginal costs are increasing and firms compete in price. If firms compete in quantity, then a welfare-enhancing cartel exists when firms use side payments and have different unit costs at competitive production levels.

\subsubsection{Price competition}

Consider an industry with two profit-maximizing firms producing a homogeneous product. To ensure that best responses are well-defined, we assume a discrete set of feasible prices. Firms choose their prices simultaneously from the set $\{0, \varepsilon, 2 \varepsilon, \ldots\}$, with $\varepsilon$ being positive and small. Consumers buy from the firm with the lowest price. If both charge the same price, then they share the market equally. The market demand function is given by $Q(p)$. We further assume that firms always meet demand (the market is clearing). Profits of both firms are then of the following structure

$$
\pi_{i}= \begin{cases}p_{i} \cdot Q\left(p_{i}\right)-C_{i}(Q) & \text { if } p_{i}<p_{j} \\ p_{i} \cdot \frac{1}{2} Q\left(p_{i}\right)-C_{i}\left(\frac{1}{2} Q\right) & \text { if } p_{i}=p_{j} \\ 0 & \text { if } p_{i}>p_{j}\end{cases}
$$

The outcome of this game is a Bertrand Nash equilibrium when none of the firms finds it in its interest to change its price given the price set by its rival.

Using this basic price competition model, we get the following results.

Proposition 6.4.1. (i) If $C_{i}^{\prime}(\cdot)>0$ and $C_{i}^{\prime \prime}(\cdot)=0$, for $i=1,2$, then there exists no Bertrand Nash equilibrium for which Conditions 6.1 and 6.2(i) can be satisfied simultaneously, and (ii) If $C_{i}^{\prime}(\cdot)>0$ and $C_{i}^{\prime \prime}(\cdot)>0$, for $i=1,2$, then there exists a Bertrand Nash equilibrium for which Conditions 6.1 and 6.2(i) can be satisfied simultaneously. 
Chapter 6. Welfare-Enhancing Hard Core Cartels

Hence, given the above model specifications, firms cannot form a welfareenhancing weak cartel when unit costs are constant. By contrast, a welfareenhancing weak cartel may exist when unit costs are increasing. In the latter case, there always exists a Bertrand Nash equilibrium for which at least one of the firms has marginal costs that exceed price at competitive production levels. By Theorem 6.3.2, we know that this is sufficient for the existence of an individually rational welfare-enhancing weak cartel.

As to welfare-enhancing strong cartels, we get a similar result. The main difference is that the set of competitive equilibria for which a welfareenhancing strong cartel exists is typically larger.

Proposition 6.4.2. (i) If $C_{i}^{\prime}(\cdot)>0$ and $C_{i}^{\prime \prime}(\cdot)=0$, for $i=1,2$, then there exists no Bertrand Nash equilibrium for which Conditions 6.1 and 6.2(ii) can be satisfied simultaneously, and (ii) If $C_{i}^{\prime}(\cdot)>0$ and $C_{i}^{\prime \prime}(\cdot)>0$, for $i=1,2$, then there exists a Bertrand Nash equilibrium for which Conditions 6.1 and 6.2(ii) can be satisfied simultaneously.

The following example illustrates the possibility for a welfare-enhancing cartel when firms compete in price.

Example 6.4.3. Suppose market demand is $Q=1-p$. Assume further that both firms have identical cost functions of the form $C_{i}\left(q_{i}\right)=\frac{1}{4} q_{i}^{2}$. Thus, individual profits are given by

$$
\pi_{i}=p_{i} q_{i}-\frac{1}{4} q_{i}^{2}, \text { for } i=1,2 .
$$

As the situation is symmetric, both firms will charge the same price in equilibrium. Let $p^{\circ}=p_{1}^{*}=p_{2}^{*}$ and $\pi=\pi_{1}+\pi_{2}$. In competition, total profits and social welfare are then respectively

$$
\pi=\left(p^{\circ}-\frac{1}{8}\left(1-p^{\circ}\right)\right)\left(1-p^{\circ}\right)
$$

and

$$
W=\left(p^{\circ}-\frac{1}{8}\left(1-p^{\circ}\right)\right)\left(1-p^{\circ}\right)+\frac{1}{2}\left(1-p^{\circ}\right)^{2} .
$$

Now suppose both firms set $p^{\circ}=\frac{1}{8}$, which yields profits $\pi_{i}=\frac{7}{1024}$, for $i=1,2$. Since $\pi_{i}>0$, none of the firms finds it profitable to raise its own price. Moreover, none of the firms finds it profitable to undercut the price of its rival as this would yield a profit of $\pi_{i}=\left(\frac{1}{8}-\frac{1}{4} \frac{7}{8}\right) \frac{1}{2} \frac{7}{8}=-\frac{21}{512}$, for $i=1,2$. 
6.4. Applications

Thus, $p^{\circ}=\frac{1}{8}$ is a Bertrand Nash equilibrium and the corresponding total surplus is $W^{*}=\frac{203}{512}$.

In this situation, both firms could form a welfare-enhancing weak cartel by, for example, fixing the price at $p^{c}=\frac{1}{5}$. With $p^{c}=\frac{1}{5}$, profits are equal to $\pi_{i}=\frac{1}{25}>\frac{7}{1024}$, for $i=1,2$, and total welfare is equal to $W^{c}=\frac{2}{5}>\frac{203}{512}$. Hence, this cartel would lead to an increase of individual profits and aggregate welfare.

\subsubsection{Quantity competition}

We now turn to the question whether a welfare-enhancing hard core cartel is a possibility in a basic Cournot model with homogeneous goods. In this case, both firms choose their outputs simultaneously. In competition, firms independently choose production levels to maximize profits, which implies that

$$
p^{\prime}(Q) q_{i}+p(Q)-C_{i}^{\prime}\left(q_{i}\right)=0, \text { for } i=1,2 .
$$

A solution $\left(p^{*}\left(Q^{*}\right), q_{1}^{*}, q_{2}^{*}\right)$ to (6.9) is here referred to as a Cournot Nash equilibrium.

The following result shows that there exists no individually rational welfare-enhancing weak cartel when quantity is the strategic variable.

Proposition 6.4.4. There exists no Cournot Nash equilibrium for which Conditions 6.1 and 6.2(i) can be satisfied simultaneously.

By Lemma 6.3.1, we know that a necessary condition for the existence of a welfare-enhancing weak cartel is that at least one firm would prefer to cut back production. Clearly, as firms will choose their outputs optimally none of them will produce 'too much' in competition.

In contrast, an individually rational welfare-enhancing strong cartel always exists as long as there is a difference in unit costs at competitive production levels.

Proposition 6.4.5. In Cournot competition, Conditions 6.1 and 6.2(ii) can be satisfied simultaneously if and only if $C_{1}^{\prime}\left(q_{1}^{*}\right)<C_{2}^{\prime}\left(q_{2}^{*}\right)$.

In light of Theorem 6.3.5, a difference in unit costs is sufficient for the existence of a welfare-enhancing strong cartel. The only other situation in which such a cartel exists is when unit costs are equal and exceed price. However, this cannot occur in Cournot competition. That is, (6.9) reveals 
that in a Cournot Nash equilibrium both firms have a positive price-cost margin.

The following example illustrates the possibility for a welfare-enhancing strong cartel in a standard Cournot model.

Example 6.4.6. Suppose the (inverse) market demand is $p(Q)=1-Q$. Unit costs of both firms are constant. Let $C_{1}^{\prime}(\cdot)=0$ and $C_{2}^{\prime}(\cdot)=c$ with $c \in\left(0, \frac{1}{2}\right)$. Profits of firm 1 and firm 2 are then given by

$$
\pi_{1}=\left(1-\left(q_{1}+q_{2}\right)\right) q_{1}
$$

and

$$
\pi_{2}=\left(1-\left(q_{1}+q_{2}\right)-c\right) q_{2} .
$$

Total welfare is equal to

$$
W=\left(1-\left(q_{1}+q_{2}\right)\right)\left(q_{1}+q_{2}\right)-c q_{2}+\frac{1}{2}\left(q_{1}+q_{2}\right)^{2} .
$$

In this case, the Cournot Nash equilibrium pair of quantities is $\left(q_{1}^{*}, q_{2}^{*}\right)=$ $\left(\frac{1+c}{3}, \frac{1-2 c}{3}\right)$. Total competitive profits are $\pi^{*}=\pi_{1}^{*}+\pi_{2}^{*}=\frac{2-2 c+5 c^{2}}{9}$ and social welfare in competition is $W^{*}=\frac{8(1-c)+11 c^{2}}{18}$.

Now suppose both firms form a strong cartel by agreeing that the entire competitive output will be produced by the efficient firm (firm 1). Such an agreement would lead to an increase in total profits and aggregate welfare of $\frac{c-2 c^{2}}{3}$. As both the profit and welfare functions are continuous, there exists a nondegenerate interval of values for $q_{1}^{c}\left(<Q^{*}\right)$ such that total industry production is lower, but total profits and welfare are higher.

\subsection{Discussion}

In a simple but fairly general setting, we have derived necessary and sufficient conditions for the existence of an individually rational welfare-enhancing hard core cartel. We considered both strong and weak hard core cartel contracts and found that (i) both strong and weak welfare-enhancing cartels exist when at least one firm makes a loss on part of its sales in competition, (ii) a welfare-enhancing strong cartel exists whenever there is a difference in unit costs at competitive production levels, and (iii) a welfare-enhancing weak cartel exists when this difference is sufficiently large. In thinking about these results, there are at least three issues that warrant discussion. 
6.5. Discussion

First, to what extent are our results model specific? Second, if and to what extent can we expect the identified conditions to apply in practice? And third, what are potential implications of our findings for antitrust policy?

The first issue is to what extent our results are model specific. One may, for example, wonder whether our results will hold in a dynamic setting. In our analysis, we abstracted from issues related to cartel formation and cartel sustainability. Note, however, that the requirement that both firms benefit from the cartel implies that forming the cartel is individually rational. Moreover, in the context of an infinitely repeated game, such an agreement can be enforced by standard means (e.g., trigger strategies) provided that both firms are sufficiently patient. Therefore, one should expect our analysis to mark a lower bound on the size of the set of welfare-enhancing cartel contracts. A dynamic model would, for instance, allow for an analysis of the welfare impact of so-called structural crisis cartels. During an economic crisis such cartel agreements may allow for a smooth reconstruction of the industry and an orderly withdrawal of firms from the market. In the long run, crisis cartels may be superior in terms of social welfare as excess capacity during recessions may lead to destructive competition. ${ }^{19}$ More generally, taking a dynamic approach will, in all likelihood, enlarge the set of welfareenhancing hard core cartel contracts, because there typically are more possibilities to save on total costs of production.

Moreover, our focus has been on what is arguably the "most evil" of all cartel contracts; those that exclusively lead to lower output and higher prices. In the above setting, whether or not such agreements yield an increase in total surplus solely depends on the condition as given in (6.4). This condition reveals that what is needed for a hard core cartel to be welfareenhancing is a sufficient decrease in total production costs. We have derived results for given cost functions. Clearly, one could extent our setting by taking account of potential synergies or additional costs of production. For example, Doyle and Han (2009) analyze a model in which colluding firms form so-called buyer groups. This buyer group may effectively lower marginal production costs which, depending on the magnitude, may benefit both customers and society at large. Deltas, Salvo and Vasconcelos (2009) use a spatial setting to show that collusion may promote the welfare of both cus-

\footnotetext{
${ }^{19}$ In the U.S., structural crisis cartels, like other hard core cartels, are subject to the per se rule under the Sherman Act. By contrast, in Europe these type of cartels are sometimes permitted. See, for instance, Commission Decision 4 July 1984 OJ L 207/17 (EC synthetic fibres industry).
} 
tomers and society when savings on transportation costs under the cartel regime are substantial. These contributions suggest that allowing for "a shift of the cost functions" is likely to enlarge the set of welfare-enhancing hard core cartels. In a similar vein, welfare-enhancing hard core cartels may exist when there are additional costs of production that are not incurred by firms. For example, in industries that exhibit severe negative externalities in production, a naked hard core cartel arrangement can be beneficial in terms of social welfare when the agreed upon cartel production is closer to the social optimum. ${ }^{20}$

The second question concerns the degree of realism of the results derived above. We have used a framework that is quite similar to the static textbook model of collusion that is frequently applied to illustrate the harmful effects of hard core cartels. In this setting, we have demonstrated that one can identify situations in which hard core cartels may lead to an increase of total surplus. Clearly, whether and how often such situations occur in practice is ultimately an empirical question and is likely to depend on the industry under consideration. However, it seems that the conditions under which a welfare-enhancing hard core cartel exists do not hold in rare cases only. For instance, firms having different unit costs at competitive production levels is likely to be the rule rather than the exception.

Yet, it should be emphasized that the mere fact that a welfare-enhancing hard core cartel exists does not imply that firms will actually form such an agreement. Even though Condition 6.2 guarantees that it might be individually rational to establish a welfare-enhancing cartel agreement, firms often have a whole set of sustainable collusive strategies available and it seems unlikely that every viable cartel contract will yield an increase of aggregate welfare. In the theory of collusion, it is common to assume that firms will choose the cartel contract(s) that maximize firms' profits. In the above framework, it appears difficult to draw general conclusions about whether and when the set of welfare-enhancing cartels contains the profitmaximizing cartel. However, to illustrate that this possibility is real, consider the following example.

Example 6.5.1. Suppose the inverse market demand function is given by $Q=1-10 p$ and that firms have identical cost functions $C\left(q_{i}\right)=\frac{1}{4} q_{i}^{2}$. Thus, unit costs are $\frac{1}{2} q_{i}$, for $i=1,2$. Total profits and consumer surplus are then

\footnotetext{
${ }^{20}$ See 6.6 .
} 
respectively given by

$$
\pi=\pi_{1}+\pi_{2}=(1-10 p)\left(p-\frac{1}{8}(1-10 p)\right),
$$

and

$$
C S=\frac{1}{2}(1-10 p)\left(\frac{1}{10}-p\right) .
$$

Hence, total welfare equals,

$$
W=(1-10 p)\left(p-\frac{1}{8}(1-10 p)\right)+\frac{1}{2}(1-10 p)\left(\frac{1}{10}-p\right) .
$$

Now suppose that $p=\frac{1}{18}$ (so that both firms make zero profits in competition). In this case, aggregate welfare is equal to $W=\frac{8}{810}$. A profitmaximizing cartel would charge a cartel price of $p^{c}=\frac{7}{90}$, which yields total cartel profits equal to $\pi^{c}=\frac{1}{90}$ and total welfare $W^{c}=\frac{11}{810}$. Consequently, a profit-maximizing cartel may lead to an increase of aggregate welfare.

The above illustrates that formulating policy implications on the basis of our findings is everything but trivial. As mentioned, if and how often the existence conditions for a welfare-enhancing hard core cartel hold is ultimately an empirical question and is likely to depend on the (type of) industry under consideration. An interesting and important research question is to explore what optimal antitrust enforcement looks like in a setting where the (unknown) pool of potential cartels contains both "good cartels" and "bad cartels". An improvement of the antitrust system might be within reach if one would have a means to discriminate between efficient and inefficient cartel arrangements. Clearly, determining whether or not a potential cartel harms or contributes to social welfare is not an easy task. The answer might lie in modifying the current system in such a way that potential "good cartels" have an incentive to reveal their type. When feasible, such a system would allow for the possibility to grant an exemption on the basis of the welfare effects of the potential cartel agreement. It is, however, $a$ priori unclear whether and in what way relaxing the per se rule would indeed lead to higher welfare standards. We leave this issue for future research.

\subsection{Appendix A: negative externalities}

Although it may not be their intention, firms that engage in a cartel can (partly) offset losses due to market failure. This is particularly true in industries that exhibit severe negative externalities in production. It has long 
been recognized that competitive markets may yield too much output from a social welfare perspective when firms do not take account of all costs associated with the production of the good or service. Thus, in the presence of negative externalities, a naked hard core cartel arrangement is beneficial in terms of social welfare when the agreed upon cartel production is closer to the social optimum. In this section, we present a simple graphical analysis to illustrate this point.

The potential impact of a naked hard core cartel in an industry with negative externalities in production is shown graphically in Figure 6.1, which depicts a single market with linear downward-sloping demand $D$. The corresponding marginal revenue curve is twice as steep and labelled $M R$. The supply curve is based on the marginal private costs of production incurred by firms and denoted $S^{p}$. Therefore, the competitive equilibrium price-output combination $\left(p^{*}, Q^{*}\right)$ is such that $D$ equals $S^{p}$. When there are negative externalities in production, however, there are additional costs not incurred by firms, but by third parties (or society as a whole). For simplicity, it is assumed that these 'marginal damages of production' $(M D)$ are linear in production (line not drawn). Marginal social cost of production then equals $S^{p}$ plus $M D$ and is denoted $S^{s}$ in Figure 6.1. Welfare maximization therefore requires a price-quantity combination $\left(p^{s}, Q^{s}\right)$, which is the point where $D$ intersects with $S^{s}$.

In competition, total welfare (consumer plus producer surplus) is given by the area $a d p^{*}+p^{*} d c-c d e=a d c-c d e=a b c-b d e .^{21}$ With the optimal price-quantity combination $\left(p^{s}, Q^{s}\right)$, total welfare is given by de area $a b p^{s}+$ $p^{s} b f c-b c f=a b f c-b c f=a b c$. As $a b c>a b c-b d e$, total welfare is higher for $\left(p^{s}, Q^{s}\right)$ than for $\left(p^{*}, Q^{*}\right)$. Hence, in competition too much is produced from a social welfare point of view and a reduction of industry output (and an increase in prices) will potentially lead to higher welfare standards.

Now suppose that firms establish a hard core cartel contract. In Figure 6.1, a profit-maximizing cartel would reduce total market output to $Q^{c}$ and charge a cartel price $p^{c}$. Under such a cartel regime, total welfare is given by the area $a h p^{c}+p^{c} h g c-c g i=a c g h-c g i=a b c-b h i$. Observe that in this particular example a profit-maximizing cartel would lead to a less than optimal welfare standard. However, as $a b c-b h i>a b c-b d e$, total welfare is higher with this cartel contract than with competition. In fact, it is easy to see that $b h i<b d e$ as long as $Q^{*}>Q^{c}>Q^{s}$. Consequently, if there are

\footnotetext{
${ }^{21}$ Note that the marginal damages of production in this particular example are significant as total welfare would be higher with zero industry output.
} 
6.6. Appendix A: negative externalities

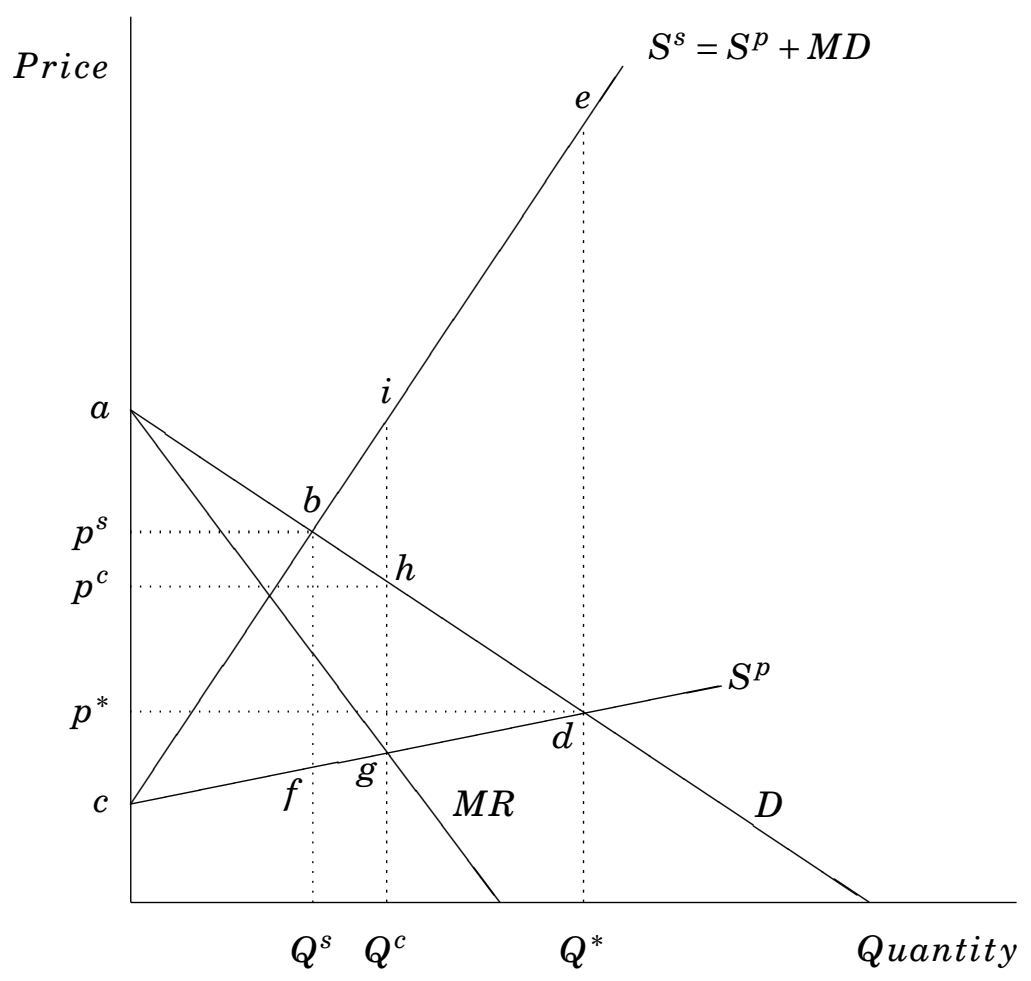

Figure 6.1: Welfare-Enhancing Cartel with $Q^{*}>Q^{c}>Q^{s}$.

negative externalities in production, a hard core cartel is welfare-enhancing when total cartel production is lower than in competition, but exceeds socially optimal output levels.

Yet, a hard core cartel can be welfare-enhancing even when it reduces industry output below the socially optimal production level. This possibility is depicted in Figure 6.2.

As with the situation sketched in Figure 6.1, total welfare in competition is marked by the area $a b c-b d e$ and total surplus corresponding to the socially optimal price-quantity combination is given by the triangle $a b c$. In Figure 6.2, a profit-maximizing cartel will reduce industry output to $Q^{c}$, which is less than $Q^{s}$. Welfare under a cartel regime is then given by $a h p^{c}+p^{c} c g h-c g i=a c g h-c g i=a h i c$. Observe that the area ahic equals $a b c-h i b$. Thus, total surplus with a cartel regime is higher than in com- 


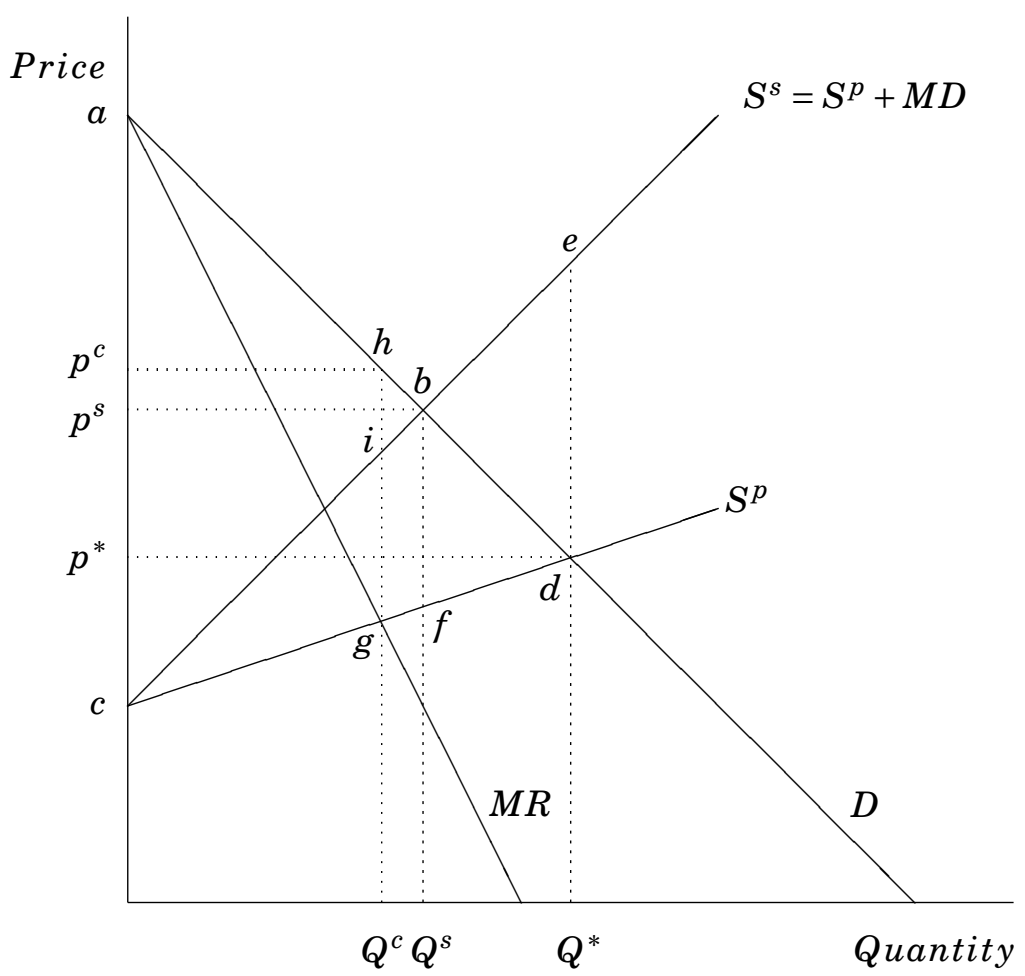

Figure 6.2: Welfare-Enhancing Cartel with $Q^{*}>Q^{s}>Q^{c}$.

petition as long as $a b c-h i b>a b c-b d e$ or $b d e>h i b$, which is the case in Figure 6.2. Hence, in markets that exhibit negative externalities, a hard core cartel can be welfare-enhancing when total cartel production is below the welfare-maximizing output level.

In sum, a naked hard core cartel can be welfare-enhancing in industries with severe negative externalities in production as long as industry output is not restricted 'too much'. Clearly, whether or not a cartel will actually lead to an increase in total surplus ultimately depends on the elasticity of supply and demand as well as on the magnitude of the negative externalities. 
6.7. Appendix B: proofs

\subsection{Appendix B: proofs}

Proof of Lemma 6.3.1. Take competitive outcome $\left(p^{*}\left(Q^{*}\right), q_{1}^{*}, q_{2}^{*}\right)$ and suppose $\pi_{i}^{\prime}\left(q_{i}^{*}\right) \geq 0$ for $i=1,2$. Suppose further that there exists a direction $\mathbf{u}=\left(u_{1}, u_{2}\right)$ for which Condition 6.1 and Condition 6.2(i) are satisfied. We will show that this yields a contradiction. We can distinguish two cases: $u_{1}>0$ and $u_{1} \leq 0$.

1. If $u_{1}>0$, then it must be the case that $u_{2}>0$, because otherwise Condition 6.2(i) is violated for firm 2. However, $u_{1}>0$ and $u_{2}>0$ is not allowed as $u_{1}+u_{2}<0$ by assumption.

2. If $u_{1} \leq 0$, then it must be the case that $u_{2}<0$, because otherwise Condition 6.2(i) is violated for firm 1 . This implies $u_{1}<0$, because otherwise Condition 6.2(i) is violated for firm 2. For Condition 6.1 to hold with $u_{1}<0$ and $u_{2}<0$, we then need that $p^{*}-C_{2}^{\prime}\left(q_{2}^{*}\right)<0$ as $C_{1}^{\prime}\left(q_{1}^{*}\right) \leq C_{2}^{\prime}\left(q_{2}^{*}\right)$ by Assumption 6.2.1. However, if $p^{*}-C_{2}^{\prime}\left(q_{2}^{*}\right)<0$, then $p^{*}-C_{2}^{\prime}\left(q_{2}^{*}\right)+p^{* \prime} q_{2}^{*}<0$, because $p^{* \prime} q_{2}^{*}<0$. Thus, $\pi_{2}^{\prime}\left(q_{2}^{*}\right)<0$, which yields a contradiction.

Proof of Theorem 6.3.2. By Lemma 6.3.1, we know that a necessary condition for the existence of an individually rational welfare-enhancing weak cartel is that $\pi_{i}^{\prime}\left(q_{i}^{*}\right)<0$ for at least one firm $i$. What remains is to derive sufficient conditions for the existence of such a cartel. We can distinguish two cases: (1) $p^{*}-C_{i}^{\prime}\left(q_{i}^{*}\right)<0$, for at least one firm $i$, and (2) $p^{*}-C_{i}^{\prime}\left(q_{i}^{*}\right) \geq 0$, for $i=1,2$. We show for both cases if and when a direction $\mathbf{u}=\left(u_{1}, u_{2}\right)$ with $u_{1}+u_{2}<0$ exists for which Condition 6.1 and Condition 6.2(i) are satisfied.

1. Suppose that $p^{*}-C_{i}^{\prime}\left(q_{i}^{*}\right)<0$, for at least one firm $i$. By Assumption 6.2.1, we know that $C_{1}^{\prime}\left(q_{1}^{*}\right) \leq C_{2}^{\prime}\left(q_{2}^{*}\right)$, which implies $p^{*}-C_{2}^{\prime}\left(q_{2}^{*}\right)<0$. In this case, Conditions 6.1 and 6.2 (i) can be satisfied simultaneously with, for instance, $u_{1}=0$ and $u_{2}<0$.

2. Suppose that $p^{*}-C_{i}^{\prime}\left(q_{i}^{*}\right) \geq 0$, for $i=1,2$. By Assumption 6.2.1, it follows that $p^{*}-C_{1}^{\prime}\left(q_{1}^{*}\right) \geq p^{*}-C_{2}^{\prime}\left(q_{2}^{*}\right) \geq 0$. In order for Condition 6.1 to hold, we thus need that $u_{1}>0$ and $u_{2}<0$ with $\left|u_{2}\right|>u_{1}$. More specifically, for the cartel to be welfare-enhancing, it is required that

$$
u_{2}>-u_{1} \frac{p^{*}-C_{1}^{\prime}\left(q_{1}^{*}\right)}{p^{*}-C_{2}^{\prime}\left(q_{2}^{*}\right)}
$$


Chapter 6. Welfare-Enhancing Hard Core Cartels

with $u_{1}>0$ and $u_{2}<0$. Following Condition 6.2(i), firm 1 find it in its interest to take part in the cartel when

$$
u_{1}\left(p^{*}-C_{1}^{\prime}\left(q_{1}^{*}\right)\right)+\left(u_{1}+u_{2}\right) p^{* \prime} q_{1}^{*}>0 \text { with } u_{1}+u_{2}<0 .
$$

Hence, Condition 6.2(i) is satisfied for firm 1, because $p^{* \prime} q_{1}^{*}<0, u_{1}>0$ and $p^{*}-C_{1}^{\prime}\left(q_{1}^{*}\right)>0$. Notice that, for Condition 6.2(i) to hold for firm 2, it is required that $\pi_{2}^{\prime}\left(q_{2}^{*}\right)<0$ and

$$
u_{2}<-u_{1} \frac{p^{* \prime} q_{2}^{*}}{p^{*}-C_{2}^{\prime}\left(q_{2}^{*}\right)+p^{* \prime} q_{2}^{*}} .
$$

Combining (6.10) with (6.11) then defines an interval of values for $u_{2}$ for which the cartel is individually rational and welfare-enhancing:

$$
-u_{1} \frac{p^{*}-C_{1}^{\prime}\left(q_{1}^{*}\right)}{p^{*}-C_{2}^{\prime}\left(q_{2}^{*}\right)}<u_{2}<-u_{1} \frac{p^{* \prime} q_{2}^{*}}{p^{*}-C_{2}^{\prime}\left(q_{2}^{*}\right)+p^{* \prime} q_{2}^{*}} .
$$

Thus, there exists a value $u_{2}$ for which (6.10) and (6.11) hold simultaneously when

$$
\frac{p^{*}-C_{1}^{\prime}\left(q_{1}^{*}\right)}{p^{*}-C_{2}^{\prime}\left(q_{2}^{*}\right)}>\frac{p^{* \prime} q_{2}^{*}}{p^{*}-C_{2}^{\prime}\left(q_{2}^{*}\right)+p^{* \prime} q_{2}^{*}}
$$

Rearranging yields,

$$
p^{*}-C_{2}^{\prime}\left(q_{2}^{*}\right)<\frac{p^{* \prime} q_{2}^{*}\left(p^{*}-C_{1}^{\prime}\left(q_{1}^{*}\right)\right)}{p^{* \prime} q_{2}^{*}-\left(p^{*}-C_{1}^{\prime}\left(q_{1}^{*}\right)\right)} .
$$

Notice that, in light of case 1 above, (6.12) is effective only when the right hand side of (6.12) is positive. If this is the case, then $\pi_{2}^{\prime}\left(q_{2}^{*}\right)<0$. To see this, add $p^{* \prime} q_{2}^{*}$ to both sides of (6.12), which yields

$$
p^{*}-C_{2}^{\prime}\left(q_{2}^{*}\right)+p^{* \prime} q_{2}^{*}<\frac{p^{* \prime} q_{2}^{*}\left(p^{*}-C_{1}^{\prime}\left(q_{1}^{*}\right)\right)}{p^{* \prime} q_{2}^{*}-\left(p^{*}-C_{1}^{\prime}\left(q_{1}^{*}\right)\right)}+p^{* \prime} q_{2}^{*},
$$

which is equivalent to

$$
\pi_{2}^{\prime}\left(q_{2}^{*}\right)<p^{* \prime} q_{2}^{*}\left(\frac{p^{* \prime} q_{2}^{*}}{p^{* \prime} q_{2}^{*}-\left(p^{*}-C_{1}^{\prime}\left(q_{1}^{*}\right)\right)}\right) .
$$

The right hand side of (6.13) is negative. Hence, $\pi_{2}^{\prime}\left(q_{2}^{*}\right)<0$ and the requirement of Lemma 6.3.1 is met. 
Proof of Corollary 6.3.3. Suppose that $p^{*}-C_{2}^{\prime}\left(q_{2}^{*}\right) \geq 0$. Following Theorem 6.3.2, an individually rational welfare-enhancing weak cartel exists if and only if

$$
p^{*}-C_{2}^{\prime}\left(q_{2}^{*}\right)<\frac{p^{* \prime} q_{2}^{*}\left(p^{*}-C_{1}^{\prime}\left(q_{1}^{*}\right)\right)}{p^{* \prime} q_{2}^{*}-\left(p^{*}-C_{1}^{\prime}\left(q_{1}^{*}\right)\right)} .
$$

We are going to rewrite this condition to find the condition from the corollary. Multiplying the numerator and denominator at the right hand side of (6.14) with $-\frac{Q^{*}}{Q^{*} p^{*}}$ yields

$$
p^{*}-C_{2}^{\prime}\left(q_{2}^{*}\right)<\frac{s_{2}}{s_{2}+\varepsilon\left(\frac{p^{*}-C_{1}^{\prime}\left(q_{1}^{*}\right)}{p^{*}}\right)}\left(p^{*}-C_{1}^{\prime}\left(q_{1}^{*}\right)\right)
$$

where $\varepsilon \equiv-\frac{\partial Q}{\partial p} \frac{p^{*}}{Q^{*}}$ and $s_{2}=\frac{q_{2}^{*}}{Q^{*}}$. Rearranging this term yields

$$
s_{2}\left(p^{*}-C_{2}^{\prime}\left(q_{2}^{*}\right)\right)+\varepsilon\left(\frac{p^{*}-C_{1}^{\prime}\left(q_{1}^{*}\right)}{p^{*}}\right)\left(p^{*}-C_{2}^{\prime}\left(q_{2}^{*}\right)\right)<s_{2}\left(p^{*}-C_{1}^{\prime}\left(q_{1}^{*}\right)\right),
$$

which is equivalent to

$$
p^{*}-C_{2}^{\prime}\left(q_{2}^{*}\right)<\frac{s_{2}}{\varepsilon\left(\frac{p^{*}-C_{1}^{\prime}\left(q_{1}^{*}\right)}{p^{*}}\right)}\left(C_{2}^{\prime}\left(q_{2}^{*}\right)-C_{1}^{\prime}\left(q_{1}^{*}\right)\right) .
$$

Proof of Lemma 6.3.4. Consider Condition 6.2(ii):

$$
u_{1}\left(p^{*}-C_{1}^{\prime}\left(q_{1}^{*}\right)\right)+u_{2}\left(p^{*}-C_{2}^{\prime}\left(q_{2}^{*}\right)\right)+\left(u_{1}+u_{2}\right) p^{* \prime} Q^{*}>0 \text { with } u_{1}+u_{2}<0 .
$$

As $u_{1}+u_{2}<0$, we know that $\left(u_{1}+u_{2}\right) p^{* \prime} Q^{*}>0$ at all $Q^{*}>0$. Hence, Condition 6.2(ii) holds whenever

$$
u_{1}\left(p^{*}-C_{1}^{\prime}\left(q_{1}^{*}\right)\right)+u_{2}\left(p^{*}-C_{2}^{\prime}\left(q_{2}^{*}\right)\right)>0,
$$

which is Condition 6.1. Therefore, whenever Condition 6.1 is satisfied, Condition 6.2(ii) is satisfied as well.

Proof of Theorem 6.3.5. First notice that by Lemma 6.3.4 it is sufficient to focus exclusively on Condition 6.1. We first divide the proof in two parts: one which analyzes the case with unequal marginal costs the competitive outcome and one which analyzes the case with equal marginal costs in the competitive outcome. 
- Part (i): Suppose $C_{1}^{\prime}\left(q_{1}^{*}\right)<C_{2}^{\prime}\left(q_{2}^{*}\right)$ and therefore $p^{*}-C_{1}^{\prime}\left(q_{1}^{*}\right)>p^{*}-$ $C_{2}^{\prime}\left(q_{2}^{*}\right)$. Now consider the direction $\mathbf{u}=\left(u_{1}, u_{2}\right)$ with $u_{1}>0$ and $u_{2}<$ $-u_{1}$ (so that $u_{1}+u_{2}<0$ ). We can distinguish three cases: (1) price is equal to marginal costs of firm 1, (2) price is higher than marginal costs for firm 1 and (3) price is lower than marginal costs for firm 1 . We show for each case that a direction $\mathbf{u}=\left(u_{1}, u_{2}\right)$ with $u_{1}+u_{2}<0$ exists such that Condition 6.1 can be satisfied.

1. $p^{*}-C_{1}^{\prime}\left(q_{1}^{*}\right)=0$ or $p^{*}-C_{2}^{\prime}\left(q_{2}^{*}\right)=0$. It follows immediately that Condition 6.1 is satisfied.

2. $p^{*}-C_{1}^{\prime}\left(q_{1}^{*}\right)>0$. In this case, Condition 6.1 holds whenever there exists a direction $\mathbf{u}$ such that

$$
\frac{u_{1}}{-u_{2}}>\frac{p^{*}-C_{2}^{\prime}\left(q_{2}^{*}\right)}{p^{*}-C_{1}^{\prime}\left(q_{1}^{*}\right)} .
$$

As $\frac{u_{1}}{-u_{2}} \in(0,1),(6.15)$ always holds for $p^{*}-C_{2}^{\prime}\left(q_{2}^{*}\right) \leq 0$. If $p^{*}-$ $C_{2}^{\prime}\left(q_{2}^{*}\right)>0$, then

$$
0<\frac{p^{*}-C_{2}^{\prime}\left(q_{2}^{*}\right)}{p^{*}-C_{1}^{\prime}\left(q_{1}^{*}\right)}<1 .
$$

Notice that, as $\frac{u_{1}}{-u_{2}} \in(0,1)$, there always exist values for $u_{1}$ and $u_{2}$ such that

$$
1>\frac{u_{1}}{-u_{2}}>\frac{p^{*}-C_{2}^{\prime}\left(q_{2}^{*}\right)}{p^{*}-C_{1}^{\prime}\left(q_{1}^{*}\right)}>0 .
$$

3. $p^{*}-C_{1}^{\prime}\left(q_{1}^{*}\right)<0$. In this case, Condition 6.1 holds whenever there exists a direction $\mathbf{u}$ such that

$$
\frac{u_{1}}{-u_{2}}<\frac{p^{*}-C_{2}^{\prime}\left(q_{2}^{*}\right)}{p^{*}-C_{1}^{\prime}\left(q_{1}^{*}\right)} .
$$

As $\frac{p^{*}-C_{2}^{\prime}\left(q_{2}^{*}\right)}{p^{*}-C_{1}^{\prime}\left(q_{1}^{*}\right)}>1$ and $\frac{u_{1}}{-u_{2}} \in(0,1),(6.16)$ always holds.

- Part (ii): Suppose $C_{1}^{\prime}\left(q_{1}^{*}\right)=C_{2}^{\prime}\left(q_{2}^{*}\right)=C$. In this case, Condition 6.1 simplifies to $\left(u_{1}+u_{2}\right)\left(p^{*}-C\right)>0$. As $u_{1}+u_{2}<0$, Condition 6.1 can only be satisfied when $p^{*}<C$. 
6.7. Appendix B: proofs

\section{Proof of Proposition 6.4.1.}

- Part $(i)$ : Suppose that $C_{i}^{\prime}(\cdot)>0$ and $C_{i}^{\prime \prime}(\cdot)=0$, for $i=1,2$ (i.e., constant marginal costs). We show that the resulting competitive equilibrium is such that no welfare-enhancing weak cartel can be formed.

Following Assumption 6.2.1, we need that $C_{1}^{\prime}(\cdot)=C_{2}^{\prime}(\cdot)$, because otherwise $q_{2}^{*}=0$ (as firm 1 would optimally set a price slightly below the marginal production costs of firm 2). With $C_{1}^{\prime}(\cdot)=C_{2}^{\prime}(\cdot)$, there are two (symmetric) Nash equilibria: $p^{*}=C_{i}^{\prime}\left(\frac{1}{2} Q^{*}\right)$ and $p^{*}=C_{i}^{\prime}\left(\frac{1}{2} Q^{*}\right)+\varepsilon$, which coincide as $\varepsilon \downarrow 0$.

By Theorem 6.3.2, we know that Conditions 6.1 and 6.2(i) can be satisfied simultaneously if and only if

$$
p^{*}-C_{2}^{\prime}\left(q_{2}^{*}\right)<\max \left\{0, \frac{p^{* \prime} q_{2}^{*}\left(p^{*}-C_{1}^{\prime}\left(q_{1}^{*}\right)\right)}{p^{* \prime} q_{2}^{*}-\left(p^{*}-C_{1}^{\prime}\left(q_{1}^{*}\right)\right)}\right\} .
$$

As $p^{*}-C_{2}^{\prime}\left(q_{2}^{*}\right)=0$, we must have that

$$
\frac{p^{* \prime} q_{2}^{*}\left(p^{*}-C_{1}^{\prime}\left(q_{1}^{*}\right)\right)}{p^{* \prime} q_{2}^{*}-\left(p^{*}-C_{1}^{\prime}\left(q_{1}^{*}\right)\right)}>0
$$

which implies $p^{*}-C_{1}^{\prime}\left(q_{1}^{*}\right) \neq 0$. Consequently, $C_{1}^{\prime}\left(q_{1}^{*}\right) \neq C_{2}^{\prime}\left(q_{2}^{*}\right)$, which yields a contradiction. Thus, if both firms have constant unit production costs, then there exists no welfare-enhancing weak cartel.

- Part ( $i i)$ : Suppose that $C_{i}^{\prime}(\cdot)>0$ and $C_{i}^{\prime \prime}(\cdot)>0$, for $i=1,2$ (i.e., increasing marginal costs). We will show that there exists a $p^{*}$ such that $p^{*}<C_{i}^{\prime}\left(q_{i}^{*}\right)$ for at least one firm $i$, which in light of Theorem 6.3.2 is sufficient for the existence of a welfare-enhancing weak cartel.

First note that Assumption 6.2.1 implies that both firms set the same price in equilibrium. Furthermore, a firm can always guarantee itself zero profits by raising its price above the price set by its rival. Hence, any $p^{*}$ must satisfy

$$
p^{*} q_{i}^{*}-C_{i}\left(q_{i}^{*}\right) \geq 0, \text { for } i=1,2 .
$$

As $q_{i}^{*}=\frac{1}{2} Q\left(p^{*}\right)$, for $i=1,2$, this is equivalent to

$$
p^{*} \frac{1}{2} Q\left(p^{*}\right)-C_{i}\left(\frac{1}{2} Q\left(p^{*}\right)\right) \geq 0, \text { for } i=1,2 .
$$


Rearranging yields

$$
p^{*} \geq \frac{C_{i}\left(\frac{1}{2} Q\left(p^{*}\right)\right)}{\frac{1}{2} Q\left(p^{*}\right)}, \text { for } i=1,2 .
$$

Thus, in equilibrium, prices (weakly) exceed the average production costs for both firms.

In addition, at an equilibrium price $p^{*}$ none of the firms finds it profitable to undercut this price. Therefore, the following condition must be satisfied as well.

$$
p^{*} \frac{1}{2} Q\left(p^{*}\right)-C_{i}\left(\frac{1}{2} Q\left(p^{*}\right)\right) \geq p^{*} Q\left(p^{*}\right)-C_{i}\left(Q\left(p^{*}\right)\right), \text { for } i=1,2,
$$

where the right-hand side of (6.18) is (approximately) the profit that can be obtained by slightly undercutting $p^{*}$. Rearranging (6.18) gives

$$
p^{*} \leq \frac{C_{i}\left(Q\left(p^{*}\right)\right)-C_{i}\left(\frac{1}{2} Q\left(p^{*}\right)\right)}{\frac{1}{2} Q\left(p^{*}\right)}, \text { for } i=1,2 .
$$

Thus, in equilibrium, prices are weakly lower than the average costs of the additional production that can be obtained by undercutting $p^{*}$.

Combining (6.17) with (6.19) then defines a set of equilibrium prices, which is denoted by $\mathscr{P}$. Formally,

$$
p^{*} \in \mathscr{P} \mid \frac{C_{i}\left(\frac{1}{2} Q\left(p^{*}\right)\right)}{\frac{1}{2} Q\left(p^{*}\right)} \leq p^{*} \leq \frac{C_{i}\left(Q\left(p^{*}\right)\right)-C_{i}\left(\frac{1}{2} Q\left(p^{*}\right)\right)}{\frac{1}{2} Q\left(p^{*}\right)}, \text { for } i=1,2 .
$$

Notice that for such a $p^{*}$ to exist it is necessary that $C_{i}\left(Q\left(p^{*}\right)\right) \geq$ $2 C_{i}\left(\frac{1}{2} Q\left(p^{*}\right)\right)$, for $i=1,2$, which is the case as $C_{i}^{\prime}(\cdot)>0$ and $C_{i}^{\prime \prime}(\cdot)>0$, for $i=1,2$, by assumption. Furthermore, note that Assumption 6.2.1 implies that $\mathscr{P}$ is non-empty. Finally, as $C_{i}^{\prime}(\cdot)>0$ and $C_{i}^{\prime \prime}(\cdot)>0$, for $i=1,2$, we also know that at any $p^{*}$,

$$
\frac{C_{i}\left(\frac{1}{2} Q\left(p^{*}\right)\right)}{\frac{1}{2} Q\left(p^{*}\right)}<C_{i}^{\prime}\left(\frac{1}{2} Q\left(p^{*}\right)\right)<\frac{C_{i}\left(Q\left(p^{*}\right)\right)-C_{i}\left(\frac{1}{2} Q\left(p^{*}\right)\right)}{\frac{1}{2} Q\left(p^{*}\right)}, \text { for } i=1,2 .
$$

In the following, we show that there is an element of $\mathscr{P}$ that is below unit costs of at least one firm. To that end, let $p_{i}^{\circ} \equiv \frac{C_{i}\left(\frac{1}{2} Q\left(p_{i}^{\circ}\right)\right)}{\frac{1}{2} Q\left(p_{i}^{\circ}\right)}$ 
and $p^{\circ} \equiv \max \left\{p_{1}^{\circ}, p_{2}^{\circ}\right\}$. If $p^{\circ} \in \mathscr{P}$, then it follows from (6.21) that $p^{\circ}=$ $\frac{C_{i}\left(\frac{1}{2} Q\left(p^{\circ}\right)\right)}{\frac{1}{2} Q\left(p^{\circ}\right)}<C_{i}^{\prime}\left(\frac{1}{2} Q\left(p^{\circ}\right)\right)$, which by Theorem 6.3 .2 completes the proof.

Suppose $p^{\circ} \notin \mathscr{P}$. We will show that this yields a contradiction. Let $p^{\circ}=\frac{C_{i}\left(\frac{1}{2} Q\left(p^{\circ}\right)\right)}{\frac{1}{2} Q\left(p^{\circ}\right)}$ for firm $i$ and $p^{\circ} \geq \frac{C_{j}\left(\frac{1}{2} Q\left(p^{\circ}\right)\right)}{\frac{1}{2} Q\left(p^{\circ}\right)}$ for firm $j$. By (6.21), we know that for firm $i, p^{\circ}=\frac{C_{i}\left(\frac{1}{2} Q\left(p^{\circ}\right)\right)}{\frac{1}{2} Q\left(p^{\circ}\right)}<C_{i}^{\prime}\left(\frac{1}{2} Q\left(p^{\circ}\right)\right)$. Hence, firm $i$ cannot increase profits by undercutting $p^{\circ}$, because the price-cost margin on any additional production would be negative. Moreover, it cannot increase profits by raising its price above $p^{\circ}$, because its current profits are 0 . At $p^{\circ}$, firm $j$ has a nonnegative profit and therefore it cannot increase profits by raising its price above $p^{\circ}$. The fact that $p^{\circ} \notin \mathscr{P}$ then implies that firm $j$ can profitably undercut $p^{\circ}$, i.e.,

$$
p^{\circ}>\frac{C_{j}\left(Q\left(p^{\circ}\right)\right)-C_{j}\left(\frac{1}{2} Q\left(p^{\circ}\right)\right)}{\frac{1}{2} Q\left(p^{\circ}\right)} .
$$

Recall that $\mathscr{P}$ is non-empty, which implies that there exist a price $p \in$ $\mathscr{P}$ and $p \neq p^{\circ}$. This leaves two possibilities. (1) $\exists p \in \mathscr{P}$ such that $p<p^{\circ}$, which is impossible as this would give firm $i$ a negative profit. (2) $\exists p \in \mathscr{P}$ such that $p>p^{\circ}$, which implies

$$
\frac{C_{j}(Q(p))-C_{j}\left(\frac{1}{2} Q(p)\right)}{\frac{1}{2} Q(p)}<\frac{C_{j}\left(Q\left(p^{\circ}\right)\right)-C_{j}\left(\frac{1}{2} Q\left(p^{\circ}\right)\right)}{\frac{1}{2} Q\left(p^{\circ}\right)},
$$

because $C_{i}^{\prime}(\cdot)>0$ and $C_{i}^{\prime \prime}(\cdot)>0$, for $i=1,2$. As $p^{\circ}>\frac{C_{j}\left(Q\left(p^{\circ}\right)\right)-C_{j}\left(\frac{1}{2} Q\left(p^{\circ}\right)\right)}{\frac{1}{2} Q\left(p^{\circ}\right)}$, it follows that $p>\frac{C_{j}(Q(p))-C_{j}\left(\frac{1}{2} Q(p)\right)}{\frac{1}{2} Q(p)}$ for any $p>p^{\circ}$. Thus, there is always a possibility for firm $j$ to profitably undercut and therefore $p \notin \mathscr{P}$, which yields a contradiction. Hence, $p^{\circ} \in \mathscr{P}$.

\section{Proof of Proposition 6.4.2.}

- Part (i): Suppose that $C_{i}^{\prime}(\cdot)>0$ and $C_{i}^{\prime \prime}(\cdot)=0$, for $i=1,2$. Following Assumption 6.2.1, we need that $C_{1}^{\prime}(\cdot)=C_{2}^{\prime}(\cdot)$, because otherwise $q_{2}^{*}=0$ (as firm 1 would optimally set a price slightly below the marginal production costs of firm 2). With $C_{1}^{\prime}(\cdot)=C_{2}^{\prime}(\cdot)$, there are two (symmetric) Nash equilibria: $p^{*}=C_{i}^{\prime}\left(\frac{1}{2} Q^{*}\right)$ and $p^{*}=C_{i}^{\prime}\left(\frac{1}{2} Q^{*}\right)+\varepsilon$, which coincide 
Chapter 6. Welfare-Enhancing Hard Core Cartels

as $\varepsilon \downarrow 0$. By Theorem 6.3.5, however, we know that for an individually rational welfare-enhancing strong cartel to exist it must be the case that $C_{1}^{\prime}\left(q_{1}^{*}\right)=C_{2}^{\prime}\left(q_{2}^{*}\right)>p^{*}$.

- Part (ii): See proof Proposition 6.4.1(ii).

Proof of Proposition 6.4.4. By Lemma 6.3.1, we know that a necessary condition for the existence of an individually rational welfare-enhancing weak cartel is that $\pi_{i}^{\prime}\left(q_{i}^{*}\right)<0$ for at least one firm $i$. In a Cournot Nash equilibrium, however, firms set their outputs such that $\pi_{i}^{\prime}\left(q_{i}^{*}\right)=0$, for $i=1,2$.

Proof of Proposition 6.4.5. In a Cournot Nash equilibrium, we either have that (1) $C_{1}^{\prime}\left(q_{1}^{*}\right)<C_{2}^{\prime}\left(q_{2}^{*}\right)$, or (2) $C_{1}^{\prime}\left(q_{1}^{*}\right)=C_{2}^{\prime}\left(q_{2}^{*}\right)$.

1. By Theorem 6.3.5(i), we know that Conditions 6.1 and 6.2(ii) can be satisfied simultaneously.

2. By Theorem 6.3.5(ii), we know that Conditions 6.1 and 6.2(ii) can be satisfied simultaneously only if $C_{1}^{\prime}\left(q_{1}^{*}\right)=C_{2}^{\prime}\left(q_{2}^{*}\right)>p^{*}$. In a Cournot Nash equilibrium it holds that $\pi_{i}^{\prime}\left(q_{i}\right)=p^{\prime}(Q) q_{i}+p(Q)-C_{i}^{\prime}\left(q_{i}\right)=0$, for $i=1,2$. Note that $p^{\prime}(Q) q_{i}<0$, which implies that $p^{*}>C_{i}^{\prime}\left(q_{i}^{*}\right)$, for $i=1,2$. Hence, Conditions 6.1 and 6.2(ii) cannot be satisfied simultaneously when $C_{1}^{\prime}\left(q_{1}^{*}\right)=C_{2}^{\prime}\left(q_{2}^{*}\right)$. 


\section{References}

[1] Albaek S, P Mollgaard and PB Overgaard (1997). Government-Assisted Oligopoly Coordination? A Concrete Case. Journal of Industrial Economics 45: 429-443.

[2] Athey S, K Bagwell and C Sanchirico (2004). Collusion and price rigidity. The Review of Economic Studies 71:317-349.

[3] Bagwell K and RW Staiger (1997). Collusion over the business cycle. The RAND Journal of Economics 28:82-106.

[4] Beggs A and P Klemperer (1992). Multi-period competition with switching costs. Econometrica 60: 651-666.

[5] Bertrand J (1883). Théorie des Richesses: revue de Théories mathématiques de la richesse sociale par Léon Walras et Recherches sur les principes mathématiques de la théorie des richesses par Augustin Cournot. Journal des Savants 67: 499-508.

[6] Bittlingmayer G (1982). Decreasing Average Cost and Competition: A New Look at the Addyston Pipe Case. Journal of Law and Economics 25: 201-229.

[7] Bittlingmayer G (1995). Output and Stock Prices when Antitrust is Suspended: The Effects of the NIRA. In: McChesney FS and WF Shughart II (eds.). The Causes and Consequences of Antitrust: The Public Choice Perspective. (The University of Chicago Press, Chicago, IL) 287-318.

[8] Blackwell D (1962). Discrete dynamic programming. Annals of Mathematical Statistics 33: 719-726. 
Bibliography

[9] Bork RH (1993). The Antitrust Paradox: A Policy at War with Itself. New York, NY: The Free Press.

[10] Bos I, R Peeters and E Pot (2010a). Competition versus Collusion: The Impact of Consumer Inertia. METEOR Research Memorandum 10/024 Maastricht University.

[11] Bos I, R Peeters and E Pot (2010b). Do Antitrust Agencies Facilitate Meetings in Smoke-Filled Rooms? METEOR Research Memorandum 10/030 Maastricht University.

[12] Bos I and E Pot (2010). Welfare-Enhancing Hard Core Cartels. METEOR Research Memorandum 10/004 Maastricht University.

[13] Burdett K and MG Coles (1997). Steady state price distributions in a noisy search equilibrium. Journal of Economic Theory 72: 1-32.

[14] Busse M (2002). Firm Financial Condition and Airline Price Wars. RAND Journal of Economics 33: 298-318.

[15] Cabral L (2009). Dynamic price competition with network effects. Mimeo.

[16] Chen Y and RW Rosenthal (1996). Dynamic duopoly with slowly changing consumer loyalties. International Journal of Industrial Organization 14: 269-296.

[17] Davidson J (1994). Stochastic Limit Theory. Advanced Texts in Econometrics series, Oxford University Press.

[18] Deltas G, A Salvo and H Vasconcelos (2009). Welfare-Enhancing Collusion and Trade. Mimeo.

[19] Dewey D (1979). Information, Entry and Welfare: The Case for Collusion. American Economic Review 69:: 587-594.

[20] Dick AR (1996). When are Cartels Stable Contracts? Journal of Law and Economics 39: 241-283

[21] Doyle C and MA Han (2009). Efficient Cartelization through Buyer Groups. ACLE Working Paper 2009-03.

[22] Ellison G (1994). Theories of cartel stability and the Joint Executive Committee. The RAND Journal of Economics 25:37-57.

[23] Farrell J and P Klemperer (2007). Coordination and lock-in: Competition with switching costs and network effects. In: M Armstrong and 
Bibliography

R Porter (eds). Handbook of Industrial Organization (Elsevier), Vol. 3, Ch. 31, pp. 1967-2072.

[24] Farrell J and C Shapiro (1988). Dynamic competition with switching costs. Rand Journal of Economics 19: 123-137.

[25] Fershtman C and A Pakes (2000). A Dynamic Oligopoly with Collusion and Price Wars. RAND Journal of Economics 31: 207-236.

[26] Fink AM (1964). Equilibrium in a stochastic $n$-person game. Journal of Science of the Hiroshima University. Series A-I 28: 89-93.

[27] Fishman A and R Rob (2003). Consumer inertia, firm growth and industry dynamics. Journal of Economic Theory 109: 24-38.

[28] Friedman JW (1971). A non-cooperative equilibrium for supergames. Review of Economic Studies 38:1-12.

[29] Genesove D and WP Mullin (2001). Rules, Communication and Collusion: Narrative Evidence from the Sugar Institute Case. American Economic Review 91: 379-398.

[30] Green EJ and RH Porter (1984). Noncooperative collusion under imperfect price competition. Econometrica 52:87-100.

[31] Guiltinan JP and GT Gundlach (1996). Aggressive and predatory pricing: a framework for analysis. The Journal of Marketing 60:87-102.

[32] Haltiwanger J and JE Harrington Jr. (1991). The impact of cyclical demand movements on collusive behavior. The RAND Journal of Economics 22:89-106.

[33] Harrington JE Jr. (2006). How do Cartels Operate? Foundations and Trends in Microeconomics 2: 1-105.

[34] Harrington JE Jr. (2008). Detecting Cartels. In: P Buccirossi (ed). Handbook in Antitrust Economics (MIT Press, Cambridge, MA).

[35] Heil OP and K Helsen (2001). Toward an understanding of price wars: their nature and how they erupt. International Journal of Research in Marketing 18:83-98.

[36] Hendon E, HJ Jacobsen and B Sloth (1996). The one-shot deviation principle for sequential rationality. Games and Economic Behavior 12:274-282.

[37] Herings PJJ and R Peeters (2004). Stationary equilibria in stochastic games: Structure, selection and computation. Journal of Economic Theory 118: 32-60. 
Bibliography

[38] Kandori M (1991). Correlated demand shocks and price wars during booms. The Review of Economic Studies 58:171-180.

[39] Kinghorn JR (1996). Kartells and Cartel Theory: Evidence from Early Twentieth Century German Coal, Iron and Steel Industries. Essays in Economic and Business History 14: 339-363.

[40] Klemperer P (1989). Price wars caused by switching costs. Review of Economic Studies 56: 405-420.

[41] Klemperer P (1995). Competition when Consumers have Switching Costs: An Overview with Applications to Industrial Organization, Macroeconomics and International Trade. Review of Economic Studies 62: $515-539$.

[42] Maskin E and J Tirole (2001). Markov perfect equilibrium, I: Observable actions. Journal of Economic Theory 100: 191-219.

[43] Matsui A (1989). Consumer-benefited Cartels under Strategic Capital Investment Competition. International Journal of Industrial Organization 7: 451-470.

[44] Montero J-P and JI Guzmán (2005). Welfare-Enhancing Collusion in the Presence of a Competitive Fringe. MIT CEEPR Working Paper Series 0511.

[45] McCutcheon B (1997). Do Meetings in Smoke-Filled Rooms Facilitate Collusion? Journal of Political Economy 105: 330-350.

[46] OECD report (1998), Recommendation of the Council concerning Effective Action against Hard Core Cartels. OECD Recommendations \& Best Practices.

[47] Padilla AJ (1995). Revisiting Dynamic Duopoly with Consumer Switching Costs. Journal of Economic Theory 67: 520-530.

[48] Pesendorfer M (2000). A Study of Collusion in First-Price Auctions. Review of Economic Studies 67: 381-411.

[49] Poitevin M (1989). Financial signalling and the "deep pocket argument”. RAND Journal of Economics 20:26-40.

[50] Porter RH and JD Zona (1999). Ohio school milk markets: An analysis of bidding. Rand Journal of Economics 30: 263-288.

[51] Posner RA (1975). The Social Costs of Monopoly and Regulation. Journal of Political Economy 83: 807-828. 
Bibliography

[52] Pot E, J Flesch, R Peeters and D Vermeulen (2009). Dynamic competition with consumer inertia. METEOR Research Memorandum 09/037 Maastricht University.

[53] Pot E, R Peeters, H Peters, and D Vermeulen (2008). Noncooperative collusion and price wars with individual demand fluctuations. METEOR Research Memorandum 08/017 Maastricht University.

[54] Pot E, R Peeters R, H Peters and D Vermeulen (2009). The determinants of collusion under exogenous demand fluctuations. Mimeo Maastricht University 2009.

[55] Radner R (2003). Viscous Demand. Journal of Economic Theory 112: 189-231.

[56] Rao AR, ME Bergen and S Davis (2000). How to fight a price war. Harvard Business Review 78 (March-April):107-116.

[57] Röller L-H and F Steen (2006). On the Workings of a Cartel: Evidence from the Norwegian Cement Industry. American Economic Review 96: 321-338.

[58] Rotemberg JJ (1998). Government-enforced Cartels, Output and Welfare. Harvard Business School Working Paper 98-116.

[59] Rotemberg JJ and G Saloner (1986). A supergame-theoretic model of price wars during booms. American Economic Review 76:390-407.

[60] Sjostrom W (1989). Collusion in Ocean Shipping: A Test of Monopoly and Empty Core Models. Journal of Political Economy 97: 1160-1179.

[61] Sobel MJ (1971). Non-cooperative stochastic games. Annals of Mathematical Statistics 42: 1930-1935.

[62] Sproul MF (1993). Antitrust and Prices. Journal of Political Economy 101: 741-754.

[63] Staiger RW and FA Wolak (1992). Collusive pricing with capacity constraints in the presence of demand uncertainty. The RAND Journal of Economics 23:203-220.

[64] Stigler GJ (1964). A theory of oligopoly. The Journal of Political Economy $72: 44-61$.

[65] Takahashi M (1964). Equilibrium points of stochastic, noncooperative $n$-person games. Journal of Science of the Hiroshima University. Series A-I 28: 95-99. 
Bibliography

[66] Taylor JE (2002). The Output Effects of Government Sponsored Cartels During the New Deal. Journal of Industrial Economics 50: 1-10.

[67] Telser LG (1996). Competition and the Core. Journal of Political Economy 104: 85-107.

[68] Troesken W (1989). A Note on the Efficacy of the German Steel and Coal Syndicates. Explorations in Economic History 18: 595-600.

[69] Whinston MD (2006). Lectures on Antitrust Economics. MIT Press Cambridge, MA.

[70] Williamson OE (1968). Economies as an Antitrust Defense: The Welfare Tradeoffs. American Economic Review 58: 18-36. 


\section{Nederlandse Samenvatting}

Dit proefschrift bestudeert één van de meest fundamentele vraagstukken van de (industriële) economie: wat is de verwachte uitkomst van strategische competitie tussen oligopolistische bedrijven? Een oligopolie is een marktsituatie waarin slechts een aantal bedrijven een dominante positie innemen. Deze bedrijven zullen daarom individueel veel invloed hebben op de marktuitkomst. Ze zullen zich dus strategisch gedragen terwijl ze met elkaar concurreren op producteigenschappen als prijs, kwaliteit, hoeveelheid enzovoort. Voorbeelden van oligopolies zijn gemakkelijk te vinden. Zo kan men denken aan de wereldwijde vliegtuigindustrie (Boeing en Airbus) of de mobiele telefoniemarkt in Nederland (KPN, Vodafone en T-Mobile).

De belangrijkste focus van dit proefschrift is op oligopolistische prijscompetitie. We onderzoeken wat we zouden kunnen verstaan onder een 'normale' marktuitkomst, en in het bijzonder analyseren we wanneer we extreme uitkomsten zouden moeten verwachten. Deze extreme uitkomsten zijn ofwel (i) zeer aggressieve competitie in de vorm van een prijzenoorlog of (ii) juist op samenwerking gericht gedrag in de vorm van stilzwijgende of expliciete collusie (kartelformatie).

Het is nuttig om een beter idee te krijgen wanneer deze fenomenen zich waarschijnlijk voordoen omdat beiden beschouwd worden als mogelijk slecht voor de welvaart in algemene zin. In een prijzenoorlog verlagen bedrijven hun prijzen snel achter elkaar met als doel hun marktaandeel te vergroten of te beschermen. Dit kan leiden tot situaties waarin producten onder kostprijs verkocht worden; iets wat op korte termijn gunstig is voor consumenten maar op de langere termijn kan leiden tot ontslagen, lagere productkwaliteit en minder innovatie. Kartels aan de andere kant zijn er juist op gericht 
onderlinge competitie te verminderen en prijzen hoog te houden. Dit kan overduidelijk leiden tot ongunstige situaties voor consumenten en daarom besteden competitie-authoriteiten zoals de Nederlandse NMa veel tijd en geld aan het ontdekken van dit soort afspraken tussen bedrijven.

Dit proefschrift bestaat uit drie delen, die ieder een ander aspect van (prijs)competitie belichten. Het eerste deel bouwt rechtstreeks voort op de bestaande literatuur en probeert sommige tegenstrijdigheden in die literatuur te verenigen. Het tweede deel neemt een heel ander uitgangspunt en laat zien dat voorspellingen met betrekking tot prijzenoorlogen en collusie drastisch kunnen veranderen als we sommige aannames over het gedrag van consumenten heroverwegen. Het derde deel analyseert tenslotte de vraag of kartels per definitie slecht zijn voor maatschappelijke welvaart en leidt condities af wanneer dit niet het geval is. Een kort overzicht van de belangrijkste resultaten wordt hieronder gegeven.

Het eerste deel van dit proefschrift is met name gerelateerd aan het werk van Stigler (1964), Green and Porter (1984) en Rotember and Saloner (1986). We breiden een standaard model van prijscompetitie uit zodat bedrijven niet noodzakelijkerwijs symmetrisch zijn maar dat hun individuele situatie kan fluctueren. Aan de hand van dit model laten we in hoofdstuk 2 zien dat een stabiele marktsituatie en volledige observeerbaarheid van individuele situaties cruciale elementen zijn in de verklaring voor kartelgedrag gegeven in Rotemberg and Saloner. Als er geen volledige observeerbaarheid is kan de samenwerking onstabiel worden zoals in Green and Porter. Als de marktverdeling onstabiel is kan collusie ook minder stabiel worden, in lijn met de inzichten van Stigler dat een hoge consumentenloyaliteit (wat vertaald kan worden naar een stabiele marktverdeling) collusie in de hand werkt. In hoofdstuk 3 breiden we de analyse nog wat verder uit om een verklaring te kunnen geven voor intentionele prijzenoorlogen. We laten zien dat het inderdaad een rationele strategie kan zijn om bewust een prijzenoorlog te beginnen als een bedrijf in een slechte individuele situatie terecht gekomen is. De reden hierachter is dat de samenwerking relatief te weinig oplevert en het bedrijf dus liever aggressief probeert zijn marktaandeel te vergroten. De resultaten tonen een duidelijke link aan tussen kartelgedrag en prijzenoorlogen. Intentionele prijzenoorlogen kunnen namelijk alleen plaatsvinden als omstandigheden eerst dusdanig zijn dat bedrijven bereid zijn om samen te werken.

In het tweede deel van het proefschrift veranderen we een aantal van de basale aannames over hoe consumenten hun keuze maken. In traditionele 
Nederlandse Samenvatting

modellen kiezen consumenten altijd voor de producent met de laagste prijs, als de producten zelf niet van elkaar verschillen. Ook zijn deze consumenten altijd volledig geïnformeerd en zullen ze meteen overstappen naar de goedkopere aanbieder op het moment dat prijsverschillen ontstaan. Deze aanname zorgt ervoor dat bedrijven in dit soort modellen altijd een sterke neiging hebben een lage(re) prijs te zetten, in de hoop alle consumenten van de tegenstanders af te kunnen pakken. Wij bestuderen de situatie als consumenten inert zijn, als ze niet onmiddellijk en massaal overstappen naar de aanbieder met de laagste prijs maar dat zo een switch onzeker is vanwege redenen als loyaliteit, ongeïnformeerdheid, overstapkosten enz. Deze andere aanname zorgt ervoor dat bedrijven een fundamenteel ander beslisprobleem hebben. In plaats van dat een prijsverlaging een onmiddellijke winstverhoging tot gevolg heeft, zorgt het nu voor een onmiddellijke winstverlaging maar een mogelijke lange-termijn winstverhoging als het bedrijf er toch in slaagt zijn marktaandeel te vergroten. Een prijsverlaging moet in dit geval dus meer gezien worden als een investering in de toekomst. In hoofdstuk 4 analyseren we wat normale competitieve uitkomsten zijn in een model als deze. Een aantal resultaten die essentieel verschillen van die in traditionele modellen van prijscompetitie zijn dat bedrijven hoge prijzen kunnen zetten zonder gezamenlijke coordinatie, dat geduldige bedrijven altijd lage prijzen zullen zetten in een gevecht om hogere marktaandelen en dat marktaandeelfluctuaties en zelfs monopolisatie gevolgen kunnen zijn van rationeel prijsgedrag. In hoofdstuk 5 kijken we specifiek naar de mogelijkheden tot collusie in dit model. We vinden ondermeer dat als consumenten zeer inert zijn, het altijd mogelijk is om hoge prijzen te handhaven. De resultaten in dit hoofdstuk wekken de vraag op hoe een effectief onderscheid gemaakt kan worden tussen hoge prijzen als gevolg van competitief gedrag en hoge prijzen als gevolg van samenwerkingsgedrag. Ook tonen de resultaten aan dat het soms lastig kan zijn bedrijven de juiste prikkel te geven om lage prijzen te zetten. Tot slot laten we zien dat als consumenten inert zijn, directe communicatie een toegevoegde waarde kan hebben voor bedrijven om tot hoge prijzen te komen, zelfs als het de pakkans door een competitie-authoriteit verhoogt.

In het laatste deel en hoofdstuk van dit proefschrift kijken we naar de welvaartseffecten van kartels. We kijken exclusief naar kartels die prijsverhogend werken en tonen aan dat het uitgangspunt dat deze kartels altijd slecht zijn voor de welvaart niet algemeen geldend is. We vinden dat kartels welvaartverhogend kunnen zijn als in competitie minimaal één van de 
bedrijven verlies maakt op een deel van zijn productie of wanneer er kostenverschillen bestaan tussen de bedrijven in de markt. We laten zien dat deze uitkomsten passen in tekstboek modellen van oligopolistische competitie. De analyse kan daarom functioneren als startpunt voor een nieuwe discussie over de optimale manier om 'slechte' kartels te bestrijden, in de wetenschap dat een deel van de kartels ook positieve welvaartseigenschappen kan bevatten. 


\section{Curriculum Vitae}

Erik Alexander Pot was born in Amsterdam on December 3, 1982. He attended Jacob Roelandslyceum in Boxtel, where he obtained his VWO degree in 2000. He then started studying medicine at Maastricht University. In 2002, Erik decided this had not been the right choice for him and he switched to University College Maastricht (UCM). In 2005, he obtained his Bachelor of Arts degree cum laude. During his studies at UCM, he co-founded and chaired the study association Universalis. In 2007 he graduated from the MPhil programme in Economic and Financial Research at Maastricht University. From 2006, Erik was employed by the Department of Quantitative Economics of Maastricht University School of Business and Economics (SBE), first as a student assistant and from 2007 as a $\mathrm{PhD}$ candidate. In 2008 he spent six months at the University of Warwick (United Kingdom) as a visiting scholar. During his period as a $\mathrm{PhD}$ candidate in Maastricht, Erik was actively involved in the PhD committee of the SBE and he was chairman of the university-wide $\mathrm{PhD}$ organisation $\mathrm{PhD}$ Academy. 